UNIVERSIDADE DE SÃO PAULO

ESCOLA DE ENGENHARIA DE SÃO CARLOS

Henrique Machado Kroetz

Otimização Estrutural sob Incertezas: Métodos e Aplicações 

Henrique Machado Kroetz

\title{
Otimização Estrutural sob Incertezas: Métodos e Aplicações
}

\author{
Versão corrigida
}

A Versão original encontra-se na Escola de Engenharia de São Carlos

\begin{abstract}
Tese apresentada à Escola de Engenharia de São Carlos da Universidade de São Paulo, para obtenção do título de Doutor em Ciências

- Programa de Pós-Graduação em Engenharia Civil (Engenharia de Estruturas).

Área de concentração: Estruturas

Orientador: André Teófilo Beck, Professor Associado
\end{abstract}


AUTORIZO A REPRODUÇÃO TOTAL OU PARCIAL DESTE TRABALHO, POR QUALQUER MEIO CONVENCIONAL OU ELETRÔNICO, PARA FINS DE ESTUDO E PESQUISA, DESDE QUE CITADA A FONTE.

Ficha catalográfica elaborada pela Biblioteca Prof. Dr. Sérgio Rodrigues Fontes da EESC/USP com os dados inseridos pelo(a) autor(a).

Eduardo Graziosi Silva - CRB - 8/8907 


\section{FOLHA DE JULGAMENTO}

Candidato: Engenheiro HENRIQUE MACHADO KROETZ.

Título da tese: "Otimização estrutural sob incertezas: métodos e aplicações".

Data da defesa: 18/02/2019.

\section{Comissäo Julgadora:}

Prof. Associado André Teófilo Beck

(Orlentador)

(Escola de Engenharia de São Carlos/EESC)

Prof. Associado Edson Denner Leonel

(Escola de Engenharia de São Carlos/EESC)

Prof. Dr. Wellison José de Santana Gomes

(Universidade Federal de Santa Catarina/UFSC)

Prof. Dr. André Jacomel Torli

(Universidade Federal da Paraíba/UFPB

Prof. Dr. Herbert Martins Gomes

(Universidade Federal do Rio Grande do SUI/UFRGS)

Coordenador do Programa de Pós-Graduação em Engenharia Civil (Engenharia de Estruturas):

Prof. Titular Humberto Breves Coda

Presidente da Comissão de Pós-Graduação:

Prof. Titular Luis Fernando Costa Alberto
Resultado:

APROVADO

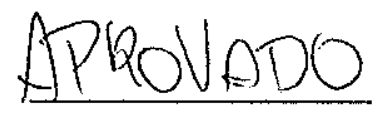

APROVAPR

APRov10O

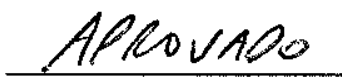



Em memória do meu amado avô. 



\section{AGRADECIMENTOS}

Agradeço aos meus pais, ao Fer, à Day, aos meus avós, ao meu orientador, aos amigos do SET, aos amigos da ETH, e aos outros amigos que continuam por aí.

Agradeço à CAPES pelo apoio financeiro. 

"Well I was in fact, I was moving backwards in time. Hmmm. Well I think we've sorted all that out now. If you'd like to know, I can tell you that in your universe you move freely in three dimensions that you call space. You move in a straight line in a fourth, which you call time, and stay rooted to one place in a fifth, which is the first fundamental of probability. After that it gets a bit complicated, and there's all sorts of stuff going on in dimensions 13 to 22 that you really wouldn't want to know about. All you really need to know for the moment is that the universe is a lot more complicated than you might think, even if you start from a position of thinking it's pretty damn complicated in the first place. I can easily not say words like «damn» if it offends you."

Douglas Adams - Mostly Harmless 



\section{RESUMO}

KROETZ, H.M. Otimização Estrutural sob Incertezas: Métodos e Aplicações. 2019. 141p. Tese (Doutorado) - Escola de Engenharia de São Carlos, Universidade de São Paulo, São Carlos, 2019.

A tarefa mais importante do projetista de estruturas é garantir a segurança em seus projetos. Obras cujas vidas úteis são medidas em décadas devem ser mantidas funcionais, garantindo níveis aceitáveis de segurança e conforto a seus usuários. Deve-se ainda levar em conta os impactos da estrutura, de maneira que o consumo de materiais, o preço, e mesmo os danos ambientais relacionados a ela não inviabilizem sua execução. A otimização estrutural permite a concepção de estruturas que atendem a requisitos desejáveis, e aliada à confiabilidade estrutural, fornece o corpo de conhecimentos necessário para a obtenção de estruturas seguras e viáveis. Apesar disso, a formulação de problemas de otimização estrutural envolvendo quantificação de incertezas envolve grande complexidade, e não foi ainda plenamente absorvida pela prática da engenharia. Nesta tese, diferentes abordagens de otimização considerando incertezas são exploradas e três métodos para a solução de problemas deste tipo são propostos. É apresentada também uma aplicação de otimização baseada em confiabilidade na calibração de coeficientes parciais de segurança. Além disso, aplicações de otimização de risco são estudadas, incluindo problemas que envolvem estruturas que sofrem degradação, e um problema envolvendo confiabilidade de sistema, cuja falha depende da trajetória dos carregamentos no tempo. A tese inclui ainda uma breve revisão e um estudo sobre técnicas de metamodelagem, que são aplicadas nos métodos propostos para a redução dos custos computacionais envolvidos na solução dos problemas de otimização. Os métodos propostos, bem como as aplicações exploradas, são estudados em vários exemplos, demonstrando-se assim a eficiência de cada um deles.

Palavras-chave: Confiabilidade Estrutural. Otimização Estrutural. Otimização sob Incertezas. Quantificação de Incertezas. Metamodelagem. Krigagem. Calibração de Normas Técnicas. Segurança das Estruturas. 



\section{ABSTRACT}

KROETZ, H.M. Structural Optimization Under Uncertainties: Methods and Applications. 2019. 141p. Tese (Doutorado) - Escola de Engenharia de São Carlos, Universidade de São Paulo, São Carlos, 2019.

The structural designer's utmost important task is to guarantee the safety of the structures designed. Buildings whose lifespan is referred to in decades must be kept functional, with acceptable levels of safety and comfort to its users. The impact caused by the structure must be taken into account as well, so that material consumption, costs and environmental damage do not make its execution unfeasible. Structural optimization allows the design of structures that attend to specific requirements, and together with structural reliability, provides the knowledge required to the achievement of safe and viable structural design. However, the formulation of structural optimization problems including uncertainty quantification involves great complexity, and has not yet been fully absorbed by engineering practice. In this thesis, different approaches to optimization under uncertainties are explored, and three methods are proposed to the solution of this kind of problem. A reliability-based design optimization application to the calibration of partial safety factors is also presented. Moreover risk optimization applications to degrading structures and a system reliability problem, whose failure depends on the trajectory followed by the loads in time are studied. This thesis also includes a study about surrogate modelling techniques, which are applied to reduce the computational burden of the methods proposed herein. The methods and applications studied in this thesis are explored in several examples, thus demonstrating their efficiency.

Keywords: Structural Reliability. Structural Optimization. Optimization under Uncertainties. Uncertainty Quantification. Metamodeling. Kriging. Standard Code Calibration. Structural Safety. 



\section{LISTA DE FIGURAS}

Figura 1 - Esquema geral de um problema de quantificação de incertezas em engenharia de estruturas. . . . . . . . . . . . . . . 36

Figura 2 - Equação de estado limite, domínio de falha e domínio de segurança (Fonte:(BECK, 2014)) . . . . . . . . . . . . . . . . . . . . 39

Figura 3 - Exemplo de sistema estrutural com elementos associados em série. . . . 41

Figura 4 - Exemplo de sistema estrutural com elementos associados em paralelo e redundância ativa. . . . . . . . . . . . . . . . . . . . . 42

Figura 5 - Exemplo de sistema estrutural com elementos associados em paralelo e redundância passiva. . . . . . . . . . . . . . . . . . . 43

Figura 6 - Amostragem e avaliação das amostras para Monte Carlo bruto. . . . . 50

Figura 7 - Amostragem e avaliação das amostras para Monte Carlo com médias ponderadas. . . . . . . . . . . . . . . . . 5 50

Figura 8 - Convergência de $P_{f}$ com o tamanho da amostra. . . . . . . . . . . . 51

Figura 9 - Arquitetura de uma rede neural, adaptada de (KROETZ; TESSARI; BECK, 2017) . . . . . . . . . . . . . . . . 70

Figura 10 - Treliça plana de 23 barras. . . . . . . . . . . . . . . . . . . . 74

Figura 11 - Índices de confiabilidade para vários projetos de experimento (Fonte:(KROETZ; TESSARI; BECK, 2017)). . . . . . . . . . . . . . . 76

Figura 12 - Representação plana e tridimensional da torre treliçada. . . . . . . . . 77

Figura 13 - Índices de confiabilidade para vários projetos de experimento (Fonte:(KROETZ; TESSARI; BECK, 2017)) . . . . . . . . . . . . . . 79

Figura 14 - Variação do parâmetro $\theta$ e sua influência na precisão do metamodelo de Krigagem (Fonte:(KROETZ; TESSARI; BECK, 2017)). . . . . . . . 80

Figura 15 - Comparação entre os índices de confiabilidade com e sem calibração, variando-se o carregamento acidental (Fonte:(SANTIAGO; KROETZ; BECK, 2018)). . . . . . . . . . . . . . . . 88

Figura 16 - Comparação entre os índices de confiabilidade com e sem calibração, variando-se o carregamento proveniente do vento (Fonte:(SANTIAGO; KROETZ; BECK, 2018)). . . . . . . . . . . . . . . . . . . 89

Figura 17 - Coluna tubular (Fonte:(ENEVOLDSEN; SORENSEN, 1994)) . . . . . . 106

Figura 18 - Viga submetida a corrosão, adaptado de Sudret (2008) . . . . . . . . . . 115

Figura 19 - Resultados para $\kappa$ fixo. . . . . . . . . . . . . . . . . . . . 117

Figura 20 - Resultados para $\kappa$ sendo uma VA. . . . . . . . . . . . . . . . . 117

Figura 21 - Resultados para $\kappa$ sendo um PE. . . . . . . . . . . . . . . . . . 118

Figura 22 - Box-plot para os custos totais considerando os três cenários de taxa de corrosão . . . . . . . . . . . . . . . . . . . . 118 
Figura 23 - Treliça plana com três tipos de barra. . . . . . . . . . . . . . . . . 119

Figura 24 - Perda de raio devido a corrosão . . . . . . . . . . . . . . . . . 119

Figura 25 - Valores ótimos dos raios para o caso \#1. . . . . . . . . . . . . . . . 120

Figura 26 - Valores ótimos dos raios para o caso \#2. . . . . . . . . . . . . . . 121

Figura 27 - Valores ótimos dos raios para o caso \#3. . . . . . . . . . . . . . . . 121

Figura 28 - Custos totais ótimos obtidos. . . . . . . . . . . . . . . . 121

Figura 29 - Treliça sujeita a cargas dependentes do tempo. . . . . . . . . . . . . 122

Figura 30 - Caminhos de carregamento. . . . . . . . . . . . . . . 123 


\section{LISTA DE TABELAS}

Tabela 1 - Dados das variáveis aleatórias no exemplo da função chapéu. . . . . . . 49

Tabela 2 - Variáveis aleatórias do problema da treliça plana . . . . . . . . . . 75

Tabela 3 - Tempo de computação para diferentes técnicas com diferentes projetos de experimento para o problema da treliça plana . . . . . . . . . . 76

Tabela 4 - Variáveis aleatórias do problema da torre tridimensional . . . . . . . 78

Tabela 5 - Tempo de computação para diferentes técnicas com diferentes projetos de experimento para o problema da torre tridimensional . . . . . . . . 80

Tabela 6 - Variáveis aleatórias construídas para o problema de calibração de norma 86

Tabela 7 - Comparação entre valores normativos e calibrados dos coeficientes parciais de segurança . . . . . . . . . . . . . . . . . . . 88

Tabela 8 - Resultados obtidos por Aoues e Chateauneuf (2010) . . . . . . . . 96

Tabela 9 - Resultados obtidos com a SLA . . . . . . . . . . . . . 97

Tabela 10 - Resultados obtidos com a utilização do método híbrido . . . . . . . . . 97

Tabela 11 - Variáveis aleatórias do problema de otimização de risco . . . . . . . . . 104

Tabela 12 - Resultados do problema de otimização de risco . . . . . . . . . . . . . 105

Tabela 13 - Variáveis aleatórias do problema da coluna tubular . . . . . . . . . . . 106

Tabela 14 - Comparação entre a abordagem proposta e a referência . . . . . . . . . 107

Tabela 15 - Parâmetros aleatórios da viga sob corrosão . . . . . . . . . . . . . 116

Tabela 16 - Treliça sujeita a corrosão - variáveis aleatórias . . . . . . . . . . . . . . 120

Tabela 17 - Média e COV dos resultados obtidos . . . . . . . . . . . . . . . . . 124 



\title{
LISTA DE ABREVIATURAS E SIGLAS
}

\author{
ABCP Associação Brasileira de Cimento Portland \\ CV Coeficiente de Variação \\ CDF Função de distribuição acumulada de probabilidade (Cumulative Distri- \\ bution Function) \\ DOE $\quad$ Projeto de experimento (Design Of Experiment) \\ DDO Otimização Determinística (Deterministic Design Optimization) \\ DP Desvio Padrão \\ EFF Função de viabilidade esperada (Expected Feasibility Function) \\ EIF Função de melhoria esperada (Expected Improvement Function) \\ EGRA Análise de confiabilidade global eficiente (Efficient Global Reliability \\ Analysis) \\ EGO Otimização global eficiente (Efficient Global Optimization) \\ EOLE Expansão da estimativa linear ótima (Expansion Optimal Linear Esti- \\ mation)
}

FORM Método de confiabilidade de primeira ordem (First-Order Reliability Method)

GA Algoritmo genético (Genetic Algorithm)

JCSS Joint Committee on Structural Safety

LHS Amostragem por hipercubo latino (Latin Hypercube Sampling)

OLE Expansão da estimativa linear ótima (Optimal Linear Estimation)

PCE Expansões em polinômios de caos (Polynomial Chaos Expansions)

PDF $\quad$ Função densidade de probabilidade (Probability Density Function)

PE Processo Estocástico

PMA Abordagem da medida de desempenho (Performance Measure Aprroach)

PSO Otimização por Enxame de Partículas (Particle Swarm Optimization) 
RBDO Otimização baseada em confiabilidade (Reliability Based Design Optimization)

RIA Abordagem do índice de confiabilidade (Reliability Index Approach)

RNA Rede Neural Artificial

RO Otimização de risco (Risk Optimization)

RSM Método de superfície de resposta (Response Surface Method)

RWAMC Simulação de Monte Carlo com médias ponderadas ranqueadas (Ranked Weighted Average Monte Carlo)

SA Recozimento simulado (Simulated Annealing)

SET Departamento de Engenharia de Estruturas

SFEM Método dos elementos finitos estocásticos (Stochastic Finite Elements Method)

SLA Abordagem do laço único (Single Loop Approach)

SQP Programação quadrática sequencial (Sequential Quadratic Programming)

StRAnD Structural Reliability Analysis and Design

SMC Simulação de Monte Carlo

USP Universidade de São Paulo

VA Variável Aleatória

WAMC Simulação de Monte Carlo com médias ponderadas (Weighted Average Monte Carlo) 


\section{SUMÁRIO}

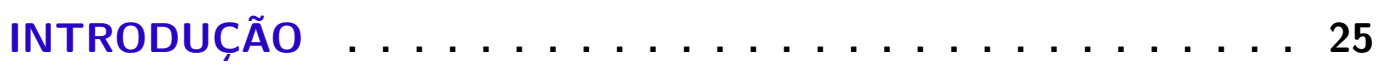

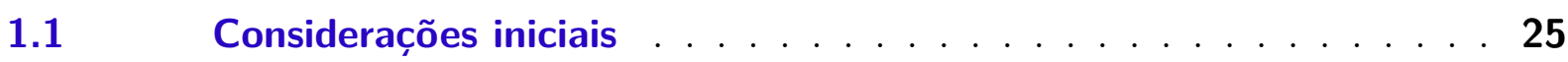

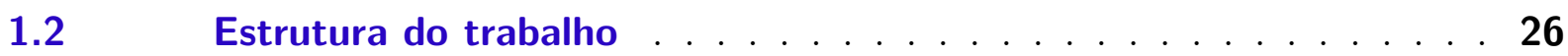

1.3 Objetivos ..................... 27

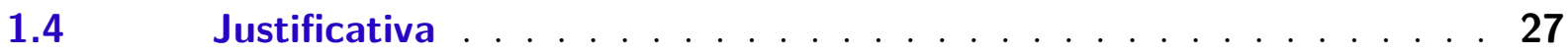

1.5 Breve ensaio sobre segurança das estruturas . . . . . . . . . 28

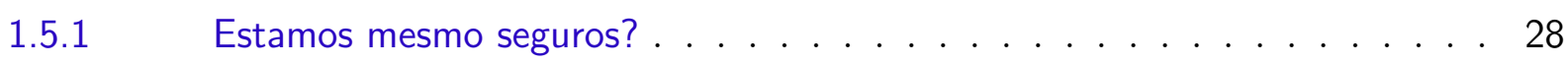

1.5.2 Como o tema foi abordado no passado? . . . . . . . . . . . . . . . . 29

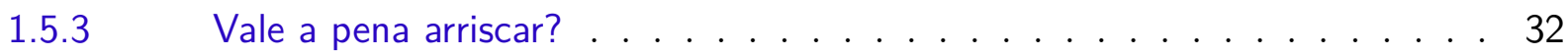

2 INCERTEZAS E CONFIABILIDADE NA ENGENHARIA DE ES-

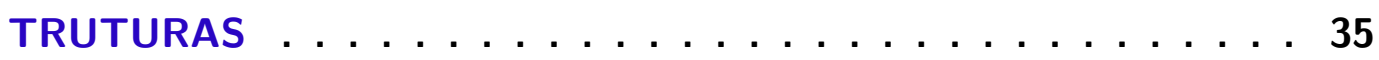

2.1 Quantificação de incertezas e confiabilidade estrutural . . . . . . 35

2.1.1 Fontes de incerteza . . . . . . . . . . . . . . . . . . . . 35

$2.1 .2 \quad$ Estados limites . . . . . . . . . . . . . . . . . . . 38

2.1.3 Propagação das incertezas - definição da probabilidade de falha . . . . . . . 39

$2.2 \quad$ Confiabilidade de sistemas . . . . . . . . . . . . . . 40

$2.3 \quad$ Confiabilidade dependente do tempo . . . . . . . . . . . 42

2.3.1 Expansão da estimativa linear ótima . . . . . . . . . . . . . . . . . 44

2.3.2 Probabilidade de falha acumulada . . . . . . . . . . . . . 45

2.4 Técnicas de solução do problema de confiabilidade . . . . . . . . 45

2.4.1 Método de confiabilidade de primeira ordem . . . . . . . . . . . 46

2.4.2 Simulações de Monte Carlo . . . . . . . . . . . . . . . . . . . 47

3 OTIMIZAÇÃO DE ESTRUTURAS SOB INCERTEZAS . . . . . 53

$3.1 \quad$ Revisão da literatura . . . . . . . . . . . . . . . . . . 54

3.1.1 Primeiras abordagens . . . . . . . . . . . . . . . . . . . . 54

3.1.2 Trabalhos recentes . . . . . . . . . . . . . . . . . 55

3.2 Otimização baseada em confiabilidade - RBDO . . . . . . . . 59

3.2.1 Abordagens de laço duplo . . . . . . . . . . . . . . . 60

3.2.2 Abordagem do laço único . . . . . . . . . . . . . . . . 61

$3.3 \quad$ Otimização de Risco - RO . . . . . . . . . . . . . . 62

4 COMPARAÇÃO DE TÉCNICAS DE METAMODELAGEM NO CONTEXTO DA CONFIABILIDADE ESTRUTURAL . . . . . . . 65

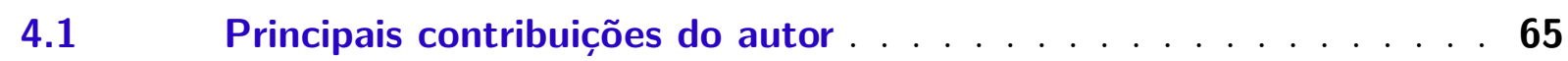




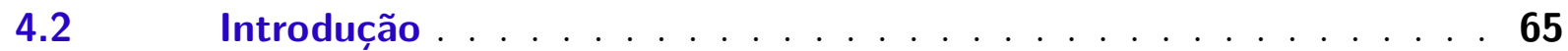

$4.3 \quad$ Revisão da literatura . . . . . . . . . . . . . . . 66

4.4 Técnicas de metamodelagem . . . . . . . . . . . . . . . . . 68

$4.4 .1 \quad$ Redes Neurais Artificiais . . . . . . . . . . . . . . . . 68

4.4.2 Expansões em polinômios de caos . . . . . . . . . . . . . . 70

$4.4 .3 \quad$ Krigagem . . . . . . . . . . . . . . . . . . 72

$4.5 \quad$ Aplicações . . . . . . . . . . . . . . . . . . . 73

$4.5 .1 \quad$ Treliça plana . . . . . . . . . . . . . . . 74

4.5.2 Torre tridimensional envolvendo confiabilidade de sistema . . . . . . . . 76

4.6 Conclusões . . . . . . . . . . . . . . . . . . . . . . 81

5 CALIBRAÇÃO DE NORMAS TÉCNICAS BASEADA EM RBDO . 83

5.1 Principais contribuições do autor . . . . . . . . . 83

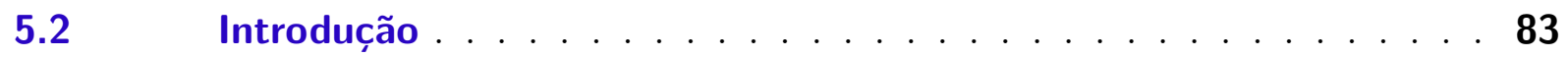

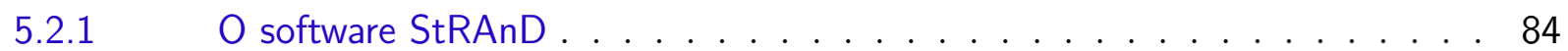

5.3 Dados sobre variáveis de resistência e solicitação . . . . . . . . . 84

5.4 Procedimento de calibração . . . . . . . . . . . . . . 86

$5.5 \quad$ Resultados . . . . . . . . . . . . . . 87

$5.6 \quad$ Conclusões . . . . . . . . . . . . . . . . . . 89

6 MÉTODO HÍBRIDO PARA A SOLUÇÃO DE PROBLEMAS DE RBDO . . . . . . . . . . . . . . . . . . 91

$6.1 \quad$ Principais contribuições do autor . . . . . . . . . . . . . 91

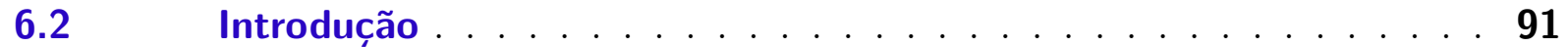

6.3 Programação quadrática sequencial . . . . . . . . . . . . . . 92

6.4 Procedimento proposto . . . . . . . . . . . . . 93

6.4.1 Otimização para variáveis do tipo Z . . . . . . . . . . . . 93

6.4.2 Otimização para variáveis do tipo D . . . . . . . . . . . . . . 95

6.4.3 Exemplo - Múltiplas equações de estado limite . . . . . . . . . . . . . . 96

$6.5 \quad$ Acoplamento com metamodelagem . . . . . . . . . . . . . 97

6.5.1 Exemplo - Método híbrido acoplado a Krigagem . . . . . . . . . . . . . 97

$6.6 \quad$ Conclusão . . . . . . . . . . . . . . . . . . . . . . . . . . 99

7 OTIMIZAÇÃO DE RISCO BASEADA EM KRIGAGEM E SIMULA-

ÇÃO DE MONTE CARLO COM MÉdIAS PONDERADAS . . . . . 101

$7.1 \quad$ Principais contribuições do autor . . . . . . . . . . . . . 101

$7.2 \quad$ Introdução . . . . . . . . . . . . . . . . . . . 101

$7.3 \quad$ Método dos Vagalumes . . . . . . . . . . . . . . . . . . . 102

7.4 Procedimento proposto . . . . . . . . . . . . . 103

$7.5 \quad$ Exemplos . . . . . . . . . . . . . . . . 104 
7.5.1 Função objetivo e equação de estado limite não lineares . . . . . . . . . . . 104

7.5.2 Confiabilidade de sistemas . . . . . . . . . . . . . . . . . 105

7.6 Conclusão . . . . . . . . . . . . . . . . 107

8 KRIGAGEM COM APRENDIZADO ATIVO PARA OTIMIZAÇÃO DE RISCO DEPENDENTE DO TEMPO . . . . . . . . . . . . 109

8.1 Principais contribuições do autor . . . . . . . . . . . . 109

8.2 Introdução . . . . . . . . . . . . . . . . . . 109

8.3 Estimativa baseada em Monte Carlo da probabilidade de falha acumulada . . . . . . . . . . . . . . . . . . . . . . . . 110

$8.4 \quad$ Otimização global eficiente . . . . . . . . . . . . . 111

$8.5 \quad$ Análise de confiabilidade global eficiente . . . . . . . . . . . . 113

8.6 Abordagem proposta . . . . . . . . . . . . . . . 114

8.7 Estruturas sob processo de degradação . . . . . . . . . . . . . . 115

8.7.1 Exemplo - Viga sujeita a corrosão . . . . . . . . . . . . . . . 115

8.7.2 Exemplo - Treliça com três tipos de barra . . . . . . . . . . . . . . . 118

8.8 Dependência do caminho dos carregamentos . . . . . . . . . . . . 121

8.8.1 Exemplo - Treliça com três modos de falha . . . . . . . . . . . . . . 124

8.9 Conclusão . . . . . . . . . . . . . . . . . . . . . 124

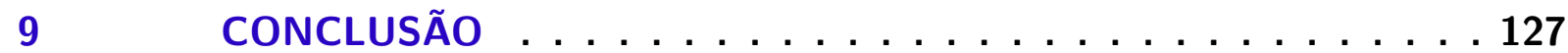

9.1 Comentários gerais . . . . . . . . . . . . . . . 127

9.2 Sugestões para trabalhos futuros . . . . . . . . . . . . . 128

REFERÊNCIAS . . . . . . . . . . . . . . . . 131 



\section{INTRODUÇÃO}

\subsection{Considerações iniciais}

A engenharia é uma ponte entre o conhecimento científico e a vida cotidiana das pessoas. Em evolução através de toda a História, vem se desenvolvendo de modo acelerado nos últimos anos. Avanços tecnológicos recentes têm propiciado condições para formas cada vez mais eficientes de concepção, modelagem e construção das mais diferentes estruturas. Neste contexto, a segurança é o primeiro requisito a ser cumprido por um projeto estrutural, se sobrepondo a especificações de outra natureza, que perdem o sentido caso a segurança não esteja garantida. Este conceito está relacionado à determinação do grau de confiabilidade de um sistema estrutural, um problema que pode envolver grande complexidade. Por consequência, sua adequada utilização na orientação de projetos é um desafio. Uma solução trivial para este problema é a adoção de estruturas exageradamente superdimensionadas, que são inviáveis por diversos motivos, como custos proibitivos e elevado impacto ambiental. Sendo assim, um bom projeto estrutural precisa atender ao mesmo tempo a, no mínimo, alguma medida de segurança e viabilidade. Configura-se assim um dilema, uma vez que, em geral, a utilização de peças estruturais com seções transversais maiores tende a aumentar o nível de segurança estrutural. Uma tentativa de se abordar este conflito de maneira a se obter a melhor configuração estrutural possível é por meio da utilização de ferramentas de otimização, que ao aumentar o escopo do problema do dimensionamento estrutural, acabam por dificultar ainda mais sua solução. Naturalmente, a otimização estrutural incluindo abordagens precisas de consideração do nível de segurança da estrutura é um problema bastante complexo, e por isso vem sendo tratado nas últimas décadas de forma simplificada.

A ciência avança de forma multidisciplinar e os últimos séculos foram palco de avanços muito proeminentes. A área da computação surgiu e se desenvolveu com grande velocidade, sendo hoje peça fundamental da engenharia de estruturas. As últimas décadas, particularmente, viram o desenvolvimento de técnicas de reconhecimento de padrões que se mostraram extremamente eficientes para a solução de problemas nas mais diversas áreas do conhecimento. Esta tese de doutorado aborda algumas delas, aplicando-as para propor metodologias eficazes para se tratar problemas de otimização estrutural considerando o nível de segurança das estruturas. 


\subsection{Estrutura do trabalho}

Capítulo 1 - Introdução

O capítulo de introdução deste trabalho foi escrito para cumprir duas funções. A primeira é a apresentação formal da tese, explicitando suas justificativas e objetivos. A segunda é apresentar um breve ensaio, escrito em uma linguagem mais adaptada à divulgação científica, tornando o tema geral da tese acessível também para aqueles menos versados nos fundamentos teóricos relevantes para a compreensão do trabalho. Desse modo, objetiva-se não apenas uma contextualização, mas também um diálogo com a comunidade leiga, numa tentativa de despertar interesse sobre o tema.

Capítulo 2 - Incertezas e confiabilidade na engenharia

Este capítulo apresenta a ideia geral da quantificação de incertezas e expõe uma fundamentação teórica sobre tópicos selecionados de confiabilidade estrutural. Algumas técnicas de solução dos problemas de confiabilidade são apresentadas.

Capítulo 3 - Otimização estrutural na presença de incertezas

Neste capítulo, as principais abordagens de otimização considerando incertezas são apresentadas, e é feita uma revisão da literatura sobre o tema.

Capítulo 4 - Comparação de técnicas de metamodelagem no contexto da confiabilidade estrutural

A solução computacional dos problemas tratados neste trabalho demanda, em geral, bastante esforço computacional. Este capítulo apresenta o conceito de metamodelo e algumas técnicas de metamodelagem que podem contornar esta dificuldade. Três técnicas de metamodelagem são apresentadas neste capítulo, e comparadas em dois problemas de confiabilidade estrutural envolvendo modelos numéricos.

Capítulo 5 - Calibração de normas técnicas baseada em RBDO

Este capítulo apresenta a calibração dos coeficientes parciais de segurança de uma norma técnica brasileira considerando-se explicitamente os níveis desejados de segurança. O problema é formulado com RBDO, e resolvido com o auxílio do método de confiabilidade de primeira ordem acoplado a um algoritmo heurístico.

Capítulo 6 - Método híbrido para solução de problemas de RBDO

Neste capítulo é proposta uma técnica de solução para problemas de otimização baseada em confiabilidade. A técnica se divide em duas etapas, uma para variáveis de projeto que definem momentos de variáveis aleatórias, e outra para variáveis de projeto simples. Dois exemplos de benchmark são apresentados para testar a eficácia da técnica. 
Capítulo 7 - Otimização de risco baseada em Krigagem e simulação de Monte Carlo com médias ponderadas

Neste capítulo é proposta uma técnica de solução para problemas de otimização de risco. A técnica, baseada em metamodelagem e simulação de Monte Carlo com médias ponderadas é testada através de dois exemplos de benchmark.

Capítulo 8 - Krigagem com aprendizado ativo para otimização de risco dependente do tempo

Este capítulo apresenta uma abordagem para a solução de problemas de otimização de risco dependentes do tempo. Duas estratégias de aprendizado ativo são utilizadas para construir metamodelos para a função objetivo e para as funções de estado limite dos problemas. Três exemplos são estudados para demonstrar a eficácia da proposta.

Capítulo 9 - Considerações Finais

Este capítulo revisita as principais contribuições do trabalho e apresenta suas conclusões, bem como sugestões para trabalhos futuros.

\subsection{Objetivos}

- Estudar e comparar técnicas de meta-modelagem, de modo a identificar seu potencial para a utilização em problemas de otimização.

- Desenvolver uma metodologia computacionalmente viável que permita a solução de problemas de otimização na presença de incertezas.

- Resolver problemas pertinentes ao tema que envolvem particularidades que dificultam suas soluções, explorando diferentes aplicações da otimização sob incertezas.

\subsection{Justificativa}

A consideração de incertezas em problemas de otimização é de extrema importância, sobretudo para a engenharia de estruturas. Muito se pesquisa sobre otimização estrutural sem uma abordagem adequada para tratar as incertezas associadas ao problema, ignorandose o fato de que o processo de otimização determinística, muitas vezes, diminui o nível de segurança da estrutura. Uma revisão da literatura revela que o interesse de pesquisadores em otimização estocástica é um advento relativamente recente, com apenas alguns poucos artigos esparsos anteriores à década de 90. As primeiras aplicações de meta-modelagem a este problema datam dos anos 2000. Apesar dos recentes avanços no campo, ainda hoje as formulações apresentam algumas limitações. O desenvolvimento de um método com maior generalidade se faz necessário para que a otimização estocástica passe a ser utilizada de forma mais ampla. O número não muito expressivo de trabalhos sobre o 
tema, quando comparado ao caso determinístico, implica em uma menor exploração das potenciais aplicações da otimização na presença de incertezas. Desse modo, há ainda bastante espaço para contribuições nessa área, como os três métodos de solução para problemas de otimização na presença de incertezas apresentados neste trabalho.

\subsection{Breve ensaio sobre segurança das estruturas}

A engenharia de estruturas é uma área do conhecimento que exige, antes de qualquer outra coisa, grande dedicação e responsabilidade. Como é usual nas engenharias, fundamentos teóricos da matemática, física e química precisam ser considerados, mas também questões sociais e econômicas. Sendo assim, é comum que as pessoas tenham dúvidas, curiosidades sobre segurança das estruturas, que dificilmente são esclarecidas em uma breve entrevista de televisão ou no "manual do proprietário" de um apartamento. Esta seção abordará três destas perguntas, fazendo uma breve explanação sobre aspectos não tão comumente comentados, mas que podem se tornar mais acessíveis.

\subsubsection{Estamos mesmo seguros?}

Duas semanas antes do início da redação deste texto, em Agosto de 2018, colapsava em Gênova, na Itália, um grande trecho da ponte Morandi, em um trágico acidente que resultou na morte de 43 pessoas. Operacional desde 1967, a grande obra de engenharia suportava uma importante rodovia para a conexão entre o norte da Itália e o sul da França. Considerada uma das obras-primas da engenharia Italiana, a ponte levou 4 anos para ser construída, tendo sido uma das maiores obras a utilizar concreto protendido à época, segundo informações do jornal local Genova Today (2018). Eventos como este levam muitas pessoas a questionar: "Como é possível que, em pleno século XXI, em uma região rica como o norte da Itália, em uma área tão avançada como a engenharia de estruturas, problemas dessa magnitude ainda aconteçam?" Infelizmente, este não é o único exemplo famoso de falha de engenharia com consequências drásticas. No Brasil, fazem parte da memória recente das pessoas notícias sobre quedas de avião (como o caso daquele que levava o time de futebol Chapecoense, em 2016), rompimento de barragens (como o desastre em Mariana, em 2015), e o desabamento nas obras do metrô da capital paulista, em 2007. Seria o caso de não estarmos seguros?

A engenharia de estruturas é uma das áreas que trabalha com produtos finais de maior segurança, ou com menor chance de falharem, porém isso pode ser difícil de perceber. A partir da década de 1960, Amos Tversky e Daniel Kahneman, dois psicólogos particularmente interessados em matemática e comportamento humano, iniciaram uma parceria para estudar problemas de tomada de decisão. Os pesquisadores dedicaram bastante atenção aos erros que são frequentemente cometidos quando um problema de análise de risco é abordado de forma intuitiva. Na verdade, incorrer em conclusões 
equivocadas como a induzida no fim do parágrafo anterior é algo muito comum. Em um artigo publicado em 1971 (TVERSKY; KAHNEMAN, 1971), os pesquisadores ilustram a prevalência da formação de opiniões a partir de uma pequena amostragem aleatória, como se fosse uma boa representação dos fenômenos apresentados, ainda que, estatisticamente, sejam muito insignificantes. Por exemplo, por mais que o número de quedas de avião seja muito pequeno em comparação com o número de voos bem sucedidos que ocorrem a cada dia, o medo de voar é algo muito comum. Por outro lado, as estatísticas que mostram uma grande correlação entre embriaguez e acidentes de carro parecem não assustar a maioria dos ébrios que vão e voltam dirigindo dos bares. Ambos os fenômenos podem ser explicados por meio de uma má interpretação do fenômeno obtida a partir de uma amostra irrelevante: uma notícia sensacionalista sobre queda de avião pode impressionar; a observação "eu dirijo há dez anos e nunca aconteceu nada" pode fornecer uma falsa sensação de segurança. De fato, o trabalho dos pesquisadores foi tão influente que Daniel Kahneman venceu o prêmio Nobel de economia em 2002 por sua contribuição ao integrar ideias das pesquisas de psicologia nas ciências econômicas, especialmente em relação ao julgamento humano e à tomada de decisões sob incerteza. Infelizmente, Tversky havia morrido em 1996, porém certamente sua contribuição foi muito importante para o prêmio do colega.

A primeira observação a ser feita sobre segurança das estruturas neste trabalho deriva da ideia de vieses cognitivos: a percepção da quantidade de falhas estruturais catastróficas é muito impactante, mas de maneira alguma se compara ao número de sucessos estruturais. Entende-se hoje que sempre haverá um grau de incerteza intrínseca, bem como a possibilidade de incertezas fenomenológicas, que impedirão uma estrutura de atingir uma probabilidade de falha exatamente nula. Ainda assim, avanços nas concepções estruturais, no controle de qualidade, na produção dos elementos estruturais e nas metodologias de dimensionamento podem garantir estruturas cada vez mais seguras e viáveis. Portanto, é equivocado se supor que as estruturas civis com as quais as pessoas interagem diariamente são inseguras, pelo contrário: estão entre os produtos mais seguros que existem. Isso, é claro, de maneira alguma é motivo para frear a busca por excelência e prevenção de novos acidentes.

\subsubsection{Como o tema foi abordado no passado?}

O desenvolvimento da engenharia de estruturas cumpriu e segue cumprindo um papel fundamental no desenvolvimento da humanidade. Mesmo em povos isolados que vivem até hoje em condições próximas àquelas da pré-história, nota-se a preferência da utilização de cabanas como abrigos, em comparação a cavernas ou árvores. Pedras lascadas são escolhidas para compor lanças, em uma rudimentar compreensão de que a pressão

exercida pelo golpe da arma está associada à área da seção transversal de sua ponta. É bem conhecido o fato de que as maiores civilizações antigas puderam apenas prosperar devido à 
proximidade de seus assentamentos a grandes rios, que proporcionavam a garantia de água, e consequentemente alimento através da agricultura e pecuária (e.g. civilização egípcia próxima ao rio Nilo, mesopotâmica entre os rios Tigre e Eufrates, chinesa próxima ao rio Amarelo, etc.). Não por acaso, as civilizações mais poderosas dos séculos que se seguiram foram aquelas a dominar as estruturas conhecidas como "aquedutos", responsáveis pelo transporte de água, que permitia a prosperidade de vilas e cidades mais distantes dos rios. Muralhas e torres para a defesa, espadas mais longas e duráveis para vantagem em combate, grandes pirâmides servindo de túmulo aos faraós e torres altas nas igrejas, sustentando pesados sinos que ecoavam pela cidade toda, são algumas das obras de engenharia que desempenharam um papel central ao longo de toda a história da humanidade. Certamente, elementos de tão grande importância para a subsistência de toda a organização social de cada época não poderiam ser tratados de forma descuidada. Então, como era a abordagem dos povos antigos, suficiente para a construção de templos que ainda hoje se mantém de pé, e quanto evoluímos até chegar ao estado da arte do início do Século XXI?

A preocupação com falhas estruturais é bastante antiga. No código de Hamurabi, atribuído ao rei mesopotâmico de aproximadamente quatro milênios atrás, constavam cláusulas como

"Se um arquiteto constrói para alguém e não o faz solidamente e a casa que ele construiu cai e fere de morte o proprietário, esse arquiteto deverá ser morto." (RIBEIRO, 2011)

$\mathrm{e}$

"Se um bateleiro constrói para alguém um barco e não o faz solidamente, se no mesmo ano o barco é expedido e sofre avaria, o bateleiro deverá desfazer o barco e refazê-lo solidamente à sua custa; o barco sólido ele deverá dá-lo ao proprietário." (RIBEIRO, 2011)

As construções mais antigas eram bastante simples (e.g. ocas, mastabas, iglus), muito provavelmente construídas com base na intuição e na experiência dos seus construtores. Não deve ser coincidência que foi por volta da invenção da escrita, há aproximadamente 6000 anos, que as construções começaram a se tornar maiores e mais complexas. A sistematização do conhecimento e a possibilidade de registrá-lo para que as próximas gerações possam aplicá-lo sem a necessidade de redescobertas é uma das grandes vantagens dos humanos na competição com as outras espécies. O estudo da matemática, possível apenas nas civilizações desenvolvidas o suficiente para pagar pelo ócio criativo de seus pensadores, viria a mudar para sempre o modo de se pensar em estruturas. A partir do momento em que as grandezas foram quantificadas, tornou-se possível uma reprodução mais detalhada de projetos bem sucedidos, que por sua vez poderiam inspirar modificações rumo a concepções 
estruturais cada vez mais eficientes. Este processo foi se revelando cada vez mais uma necessidade. Fosse a pressão do crescimento populacional, fossem os constantes conflitos entre povos, as tecnologias precisavam resolver mais que apenas problemas pontuais do dia a dia. Era necessário haver avanço suficiente para que novos problemas como guerras, secas, inundações, tornados, entre outros, não abreviassem a história de cada um dos povos que lutava por sobrevivência. Além disso, as épocas de abundância costumavam suscitar desejos de grandeza, conforto e melhoria estética. O aperfeiçoamento das técnicas de projeto e construção seguiu acompanhando a história da humanidade, e se por um lado as estruturas foram ficando cada vez maiores e mais versáteis, o potencial de que uma falha implicasse em uma catástrofe também foi aumentando.

Os métodos utilizados para se garantir a segurança avançaram bastante desde a antiguidade. Para um engenheiro do século XXI pode ser difícil imaginar o estudo da mecânica sem a utilização de integrais e equações diferenciais. De fato, apesar dos grandes feitos do passado, as abordagens utilizadas hoje são solidamente baseadas em invenções historicamente recentes. A noção fundamental de que alguns fenômenos da natureza podem ser aleatórios começou a se popularizar apenas no século XVII a partir de grandes nomes como Cardano, Galileu, Pascal e Fermat (MLODINOV, 2008). Assim, o tratamento das possíveis falhas estruturais em termos de probabilidades é também bastante recente. $\mathrm{O}$ famoso matemático Karl Pearson, fundador do primeiro departamento de estatística do mundo em uma universidade, discutia ainda no século XX os conflitos existentes entre a mentalidade ocidental e os avanços que se reforçavam frente a mais e mais observações da natureza. Um mundo compreendido como determinístico, criado cuidadosamente por um Deus onisciente parecia incompatível com a ideia de que alguns eventos poderiam ser simplesmente imprevisíveis (interpretação que teria inspirado a célebre frase "Deus não joga dados", do físico Albert Einstein). Este aparente conflito certamente atrasou o desenvolvimento de uma teoria robusta sobre segurança das estruturas, uma vez que o domínio de conceitos de probabilidade se faz essencial para tal. Atualmente, pesquisadores dos mais diversos sistemas de pensamento conseguem acomodar a percepção da probabilidade sem prejuízo para suas crenças, mas discussões sobre a natureza fundamental da aleatoriedade seguem populares nas conversas entre cientistas.

Apesar da demora, a forma de se quantificar incertezas e traduzir tal quantificação para a prática evoluiu significativamente na história recente. As revoluções industriais permitiram um grande avanço nos processos de manufatura, possibilitando a utilização de novos materiais de construção, agora produzidos em escala industrial. A introdução do ferro, do aço e do concreto armado às estruturas eram escolhas óbvias do ponto de vista da resistência e eficiência desses materiais. Por outro lado, sua utilização impedia a adoção de modelos empíricos para as construções: simplesmente não havia muita experiência na construção de estruturas metálicas ou de concreto para se tomar como base nos novos projetos. Logo foi desenvolvido o chamado "Método das Tensões Admissíveis" (ATAíDE; 
CORRêA, 2006), no qual um coeficiente de segurança era aplicado à resistência de cada material, gerando-se assim um valor de tensão admissível, a ser adotado no projeto da estrutura. O valor do coeficiente era determinado empiricamente, levando em conta a variabilidade observada na resistência do material, bem como a intensidade das cargas e a importância da estrutura. Este método foi um avanço, mas logo ficaram claras as limitações inerentes à tentativa de se representar todas as fontes de incerteza relevantes para o projeto da estrutura por meio de um único coeficiente. O método foi sendo adaptado conforme novas limitações eram percebidas, mas atualmente ele não é entendido como o mais adequado.

No século XXI, a maioria das normas de projeto estrutural utilizadas no Brasil adota o chamado "Método dos Estados Limites", no qual diferentes modos de falha possíveis para cada estrutura são considerados (ABNT, 2014). Coeficientes específicos são aplicados para garantir a segurança para cada maneira segundo a qual a estrutura pode vir a falhar. Além disso, é possível que as cargas atuantes na estrutura sejam tratadas separadamente, também sujeitas a coeficientes de majoração que dependem de sua natureza e frequência de ocorrência. Ainda assim, o método tem suas limitações, não permitindo uma quantificação das incertezas envolvidas em cada projeto. Certamente, decisões de dimensionamento baseadas na otimização de cada estrutura específica, utilizando métodos que consideram explicitamente as probabilidades de falha para cada situação forneceriam resultados mais representativos da realidade. Abordagens assim são recentes, e ainda não atingiram o grau de popularidade e viabilidade para que sejam adotadas como prática corrente na maioria dos tipos de projeto estrutural.

Basta uma breve revisão da história para se observar que a segurança estrutural foi um tema tratado com muita seriedade pelos engenheiros de diferentes épocas. $\mathrm{O}$ número relativamente baixo de falhas estruturais na história demonstra um princípio básico muito comum na engenharia de estruturas: se o erro for inevitável, erra-se no sentido do excesso, e não da falta de segurança. Ainda assim, mesmo que a introdução de uma nova tecnologia sempre traga incertezas, a busca por abordagens cada vez mais precisas e eficientes parece nunca cessar. Surge então a questão: se determinada metodologia já é tida como suficientemente segura, e já se acumulou muita informação sobre ela, por que não pararmos de buscar novos modelos, novos materiais, e novas formas de se construir? Não é arriscado demais que se descubram na prática novas formas de falhar, que eram impensáveis antes da construção de tais novas estruturas?

\subsubsection{Vale a pena arriscar?}

A história da engenharia demonstra grandeza na condição humana. Em todas as épocas, superação frente aos incontáveis desafios que a natureza propõe, realizada através da capacidade da espécie de interpretar e transformar o mundo ao seu redor. Por outro 
lado, a sede por inovação e por alçar voos cada vez maiores pode também sugerir uma importante irresponsabilidade: seriam as vidas ceifadas quando das primeiras experiências com novas tecnologias um preço justo a se pagar pela inovação? A primeira observação a se fazer é que leva tempo até que uma nova tecnologia se torne de uso comum. Adotar algo inovador na engenharia de estruturas é sempre um processo criterioso. Ainda assim, sistemas estruturais tidos como confiáveis há séculos não poderiam ser mantidos como prática corrente, de modo a garantir ainda mais segurança aos usuários?

Um dos trabalhos mais controversos da história da ciência, que pode ser acessado gratuitamente na íntegra através da internet, foi escrito pelo economista político Thomas Robert Malthus (MALTHUS, 1872). Em seu famoso trabalho, o inglês afirmou que as populações humanas aumentam de modo geométrico, enquanto o crescimento da disponibilidade de alimentos é linear. Apesar das motivações bem intencionadas, como "investigar as causas que, até o presente momento, impedem o progresso da humanidade rumo à felicidade", seu texto inspirou políticas nefastas de eugenismo social, em tentativas desesperadas de se controlar o crescimento populacional humano frente à inevitável crise de alimentos que estaria esperando no futuro próximo. O erro fundamental do trabalho de Malthus foi desconsiderar a capacidade humana de adaptação e transformação do mundo por meio do desenvolvimento tecnológico. A história mostrou que os países mais ricos e com maiores níveis de educação tendem a apresentar menores taxas de natalidade, ao mesmo tempo que o desenvolvimento de técnicas de agricultura, pecuária e engenharia de alimentos geraram um problema de certa maneira oposto: excesso de calorias na dieta dos cidadãos das nações mais desenvolvidas. Outros argumentos e exemplos neste sentido podem ser encontrados em um recente artigo da revista Scientific American (SHERMER, 2016).

Uma lição parecida se aplica à questão dos avanços tecnológicos da engenharia de estruturas. Recursos naturais são muitas vezes não-renováveis, e mesmo os renováveis podem ser bastante limitados. A construção de estruturas vai além do consumo de matérias primas: envolve sua extração, transporte e, eventualmente, seu posterior descarte. Cada uma das etapas do ciclo de vida de uma estrutura está associada a questões que transcendem a estrutura em si, como trabalho humano, questões políticas e impactos ambientais. Seja a queima de combustíveis fósseis durante o transporte e a extração de toneladas de aço, seja a segurança de operários submetidos a condições cada vez mais seguras e menos insalubres, não se pode prescindir de avanços e ganhos de eficiência. Desse modo, a otimização de sistemas estruturais é, muito além de um desejo por lucro ou por excelência, uma necessidade humana frente a um mundo com recursos escassos e pronunciado crescimento populacional. É inquestionável que a segurança é o primeiro requisito a ser cumprido, antes de qualquer ganho econômico. A questão, porém, é ainda mais ampla: os benefícios gerados pelo desenvolvimento de novos materiais, técnicas de dimensionamento e processos construtivos são inegáveis, e interagem sinergicamente com 
a possibilidade do desenvolvimento de ainda novos avanços, guiando a humanidade rumo à organização em sociedades cada vez mais eficientes e seguras. Canoas foram substituídas por caravelas, por sua vez obsoletas frente aos transatlânticos modernos. A segurança e a tecnologia embarcada presentes em um automóvel popular fabricado em 2018 seriam inimagináveis cinquenta anos antes, e certamente salvam muitas vidas a cada ano. Os exemplos de aplicações tecnológicas da engenharia estrutural contemporânea são inúmeros: de materiais compósitos mais leves usados nos aviões a peças estruturais adequadas para uma pessoa levar parafusada aos seus ossos pelo resto da vida após um acidente; de grandes plataformas de petróleo sujeitas a cargas de tempestades às proteções sísmicas dos arranha-céus. As inovações tecnológicas que tornam a engenharia cada vez mais viável, segura e proveitosa ajudam talvez em todos os aspectos da vida humana, indubitavelmente auxiliando e possibilitando a existência de bilhões de pessoas neste momento. Mesmo caso se optasse por não mudar as técnicas utilizadas nas soluções dos problemas, as condições nas quais um mesmo problema precisa ser resolvido seguiriam mudando. Ainda assim, as inovações na engenharia têm sido capazes de não apenas continuar resolvendo os problemas, mas de obter soluções cada vez melhores. 


\section{INCERTEZAS E CONFIABILIDADE NA ENGENHARIA DE ESTRUTURAS}

\subsection{Quantificação de incertezas e confiabilidade estrutural}

O vocabulário de teoria das estruturas da Associação Brasileira de Cimento Portland define uma estrutura como sendo todo corpo ou conjunto de corpos adequado a resistir a solicitações (ABCP, 1967). Forças e momentos são aplicados em sistemas estruturais, gerando deformações e esforços internos nos corpos solicitados. Estes sistemas podem ser associados a modelos físicos e matemáticos que auxiliam os engenheiros a compreender e prever o comportamento das mais diferentes estruturas. Quando as características das solicitações são consideradas como perfeitamente previsíveis, de extensão, magnitude, direção, sentido e duração conhecidos, e quando as características da estrutura, como sua geometria e propriedades dos materiais são também perfeitamente conhecidas, tem-se um problema determinístico de engenharia de estruturas. A solução destes problemas busca, em geral, a determinação do comportamento da estrutura solicitada durante e após as solicitações. A abordagem da quantificação de incertezas expande o escopo do problema ao considerar que as características mencionadas não são perfeitamente conhecidas, podendo ser modeladas de forma mais representativa com o auxílio de distribuições de probabilidade. Desse modo, os modelos estruturais apresentam também um comportamento aleatório, e as incertezas são propagadas ao longo do sistema estudado. A problemática de quantificação de incertezas em engenharia pode ser dividida em três partes distintas, conforme mostrado em Sudret (2007). Neste trabalho, tais etapas serão apresentadas de forma adaptada para o problema específico da confiabilidade estrutural. São elas: tratamento e quantificação das fontes de incerteza (1); modelagem do comportamento de interesse do sistema estrutural estudado, aqui endereçada por meio da definição de estados limites (2); e a propagação das incertezas através do sistema, que usualmente resulta na determinação de uma probabilidade de falha (3). A Figura 1 indica estas etapas de forma esquemática.

\subsubsection{Fontes de incerteza}

A primeira etapa consiste na definição das características dos parâmetros aleatórios do problema. Para tal, introduz-se o conceito de variável aleatória (VA). Seja $\Omega$ o espaço amostral de um um experimento aleatório, contendo todos os resultados $\omega$ possíveis. Uma variável aleatória $X(\omega)$ é uma função que associa números reais a eventos elementares $X: \Omega \mapsto \mathcal{D}_{X} \subset \mathbb{R}$. Costuma-se representar uma variável aleatória por uma letra maiúscula, e uma realização dela pela letra minúscula correspondente. Neste trabalho, esta notação será adotada, e o $\omega$ será omitido a partir daqui para não sobrecarregar a notação todas as vezes que uma VA for representada, exceto quando sua representação for particularmente relevante. Seja $x$ um número real qualquer. Os subconjuntos $X \leq x$ são eventos que 


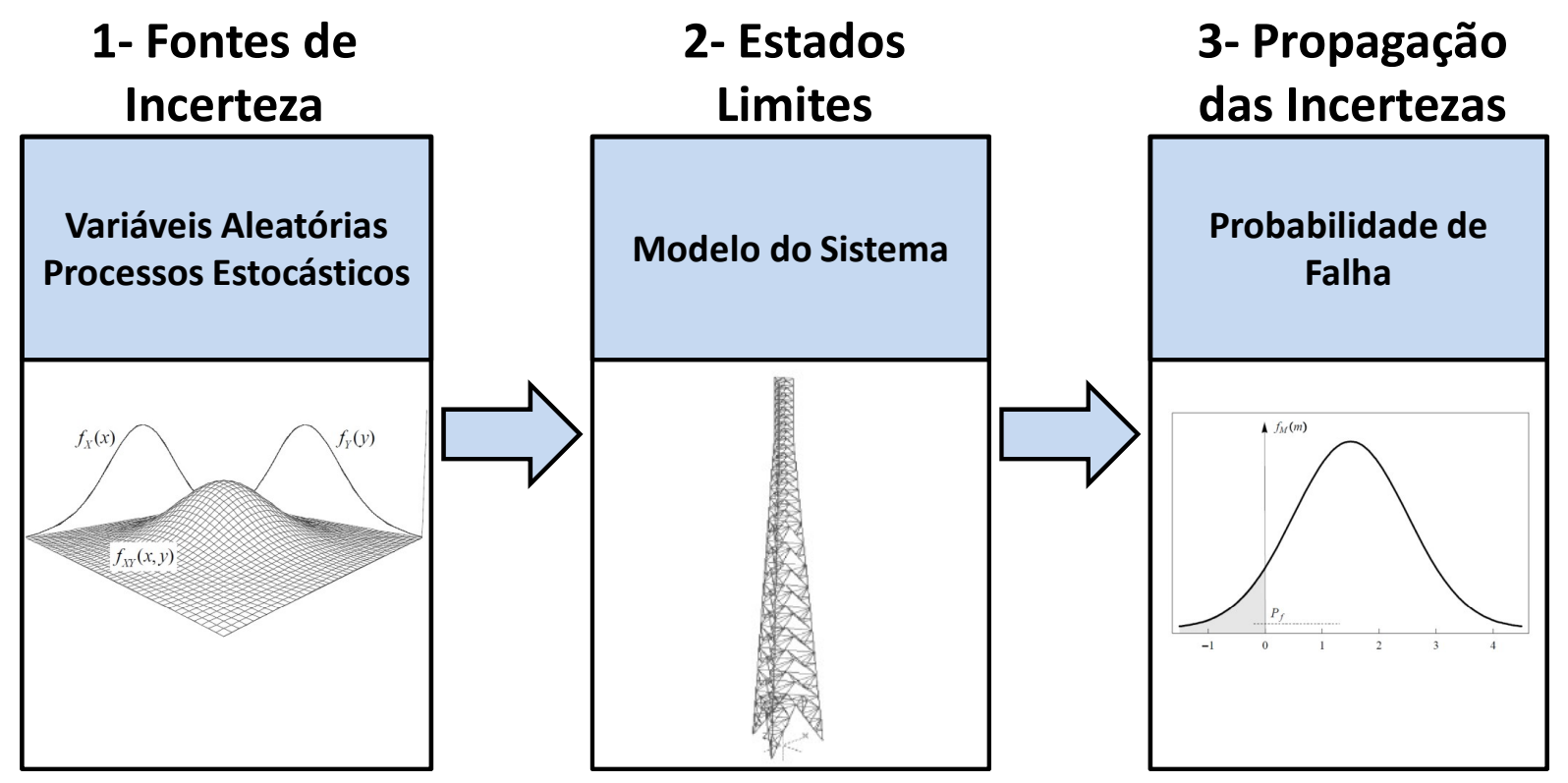

Figura 1: Esquema geral de um problema de quantificação de incertezas em engenharia de estruturas.

caracterizam as variáveis aleatórias, que podem ser definidas por meio da função de distribuição acumulada de probabilidade (CDF) $F_{X}(x)$ :

$$
F_{X}(x)=\mathbb{P}[X \leq x]
$$

em que $\mathbb{P}[$.$] denota probabilidade. Ou seja, a CDF de uma variável aleatória X$ avaliada em um número real $x$ é a probabilidade de a variável assumir um valor igual ou inferior a $x$. Para se endereçar o conteúdo de probabilidade em um dado ponto, é definida a função densidade de probabilidade $(\mathrm{PDF}) f_{X}(x)$ :

$$
f_{X}(x)=\lim _{h \rightarrow 0, h>0} \frac{\mathbb{P}[x \leq X \leq x+h]}{h} .
$$

Sendo assim, a PDF é a derivada da CDF:

$$
f_{X}(x)=\frac{d F_{X}(x)}{d x}
$$

O valor esperado ou média de uma VA é definido como

$$
\mu_{X}=E[X]=\int_{\mathcal{D}_{X}} x f_{X}(x) d x .
$$

em que $\mathcal{D}_{X}$ é o domínio de $f_{X}(x)$. Note que $E[$.] é um operador, podendo ser aplicado a outras funções. Os momentos de ordem $k$ de uma variável aleatória (Equação 2.5), bem como seus momentos centrais de ordem $k$ (Equação 2.6) também fornecem informações úteis sobre seu comportamento:

$$
E\left[X^{k}\right]=\int_{\mathcal{D}_{X}} x^{k} f_{X}(x) d x
$$




$$
E\left[\left(X-\mu_{X}\right)^{k}\right]=\int_{\mathcal{D}_{X}}\left(x-\mu_{X}\right)^{k} f_{X}(x) d x .
$$

Um caso de importância particular é o momento central de segunda ordem, bastante usado como medida de dispersão dos dados, sendo chamado de variância, que é o quadrado do desvio padrão (DP):

$$
\operatorname{Var}(X)=E\left[\left(X-\mu_{X}\right)^{2}\right]=\int_{\mathcal{D}_{X}}\left(x-\mu_{X}\right)^{2} f_{X}(x) d x=\sigma_{X}^{2} .
$$

A dispersão pode ser representada de forma adimensional, por meio do coeficiente de variação $(\mathrm{CV})$ :

$$
\mathrm{CV}=\frac{\sigma_{X}}{\mu_{X}}
$$

Relações de PDFs clássicas de probabilidades usualmente adotadas para modelar fenômenos aleatórios, bem como os parâmetros relevantes para suas determinações, podem ser amplamente encontradas na literatura, como em (BECK, 2014).

É comum em problemas de engenharia de estruturas que os carregamentos atuantes no sistema estudado não possam ser definidos com precisão absoluta. É possível também que a geometria de peças estruturais e as características dos materiais empregados também apresentem certo grau de incerteza. Quando isso acontece e modelos para os parâmetros aleatórios não estão disponíveis, é necessário caracterizar tais incertezas a partir da coleta da informação que se tem disponível. Os dados são então tratados, de modo a se associar o comportamento desconhecido a uma variável aleatória. Para tal, é possível utilizar o conhecimento de pessoas com experiência na área e observações do fenômeno a ser estudado: cada observação pode ser considerada uma realização da variável aleatória procurada. A partir dos dados obtidos, várias técnicas podem ser utilizadas para se fazer o ajuste dos dados a modelos estatísticos (BENJAMIN; CORNELL, 2014). Outra abordagem é a utilização do princípio da máxima entropia (KAPUR; KESAVAN, 1992) para aproveitar a informação disponível da melhor forma possível. Em todo caso, as metodologias para a caracterização dos parâmetros aleatórios estão além do escopo desta tese.

Quando mais variáveis aleatórias são consideradas no mesmo problema, é possível que o valor assumido por uma delas não tenha influência alguma sobre o valor assumido pela outra. Essa condição é denominada independência, e é caracterizada, para duas VAs $X_{1}$ e $X_{2}$, por:

$$
\mathbb{P}\left[X_{1} \leq x_{1}, X_{2} \leq x_{2}\right]=\mathbb{P}\left[X_{1} \leq x_{1}\right] \mathbb{P}\left[X_{2} \leq x_{2}\right]
$$

Uma vez que todas as $M$ variáveis aleatórias relevantes ao problema estudado estejam definidas, obtém-se o vetor de variáveis aleatórias $\boldsymbol{X}$, com função de distribuição 
de probabilidade conjunta dada por

$$
F_{\boldsymbol{X}}(\boldsymbol{x})=\mathbb{P}\left[X_{1} \leq x_{1}, X_{2} \leq x_{2}, \ldots, X_{M} \leq x_{M}\right]
$$

e função densidade de probabilidade conjunta

$$
f_{\boldsymbol{X}}(\boldsymbol{x})=\frac{\partial^{M} F_{\boldsymbol{X}}(\boldsymbol{x})}{\partial x_{1}, \partial x_{2}, \ldots, \partial x_{M}} .
$$

Estas funções são análogas às suas versões unidimensionais, representando a probabilidade de as variáveis assumirem conjuntamente valores menores do que limites e o conteúdo de probabilidade em um determinado subdomínio do espaço das variáveis aleatórias. Nem sempre a determinação exata das funções conjuntas é possível, portanto é comum que modelos sejam construídos a partir de alguns indicadores do comportamento conjunto das variáveis, como a covariância:

$$
\operatorname{Covar}\left(X_{1}, X_{2}\right)=E\left[\left(X_{1}-\mu_{X_{1}}\right)\left(X_{2}-\mu_{X_{2}}\right)\right]=\int_{\mathcal{D}_{X}}\left(x_{1}-\mu_{X_{1}}\right)\left(x_{2}-\mu_{X_{2}}\right) f_{X_{1} X_{2}}\left(x_{1}, x_{2}\right) d x
$$

O coeficiente de correlação entre duas VAs fornece uma medida adimensional de dependência linear:

$$
\gamma_{c}=\frac{\operatorname{Covar}\left(X_{1}, X_{2}\right)}{\sigma_{X_{1}} \sigma_{X_{2}}}
$$

\subsubsection{Estados limites}

A segunda etapa consiste na definição de um modelo para representar a estrutura a ser estudada. Seja o modelo uma função $\mathcal{M}$. As respostas de interesse para o problema, para uma realização $\boldsymbol{x}$ do vetor $\boldsymbol{X}$, são reunidas em um vetor de respostas $\boldsymbol{y}=\mathcal{M}(\boldsymbol{x}) \in \mathbb{R}^{N}$. Os modelos podem ser analíticos ou numéricos, sendo bastante comum a utilização de modelos baseados no método dos elementos finitos para a representação de estruturas.

Para se estudar a segurança de uma estrutura é necessário considerar um ou mais critérios de falha, usualmente definidos a partir da violação ou não de estados limites, que podem ser classificados como de serviço ou últimos. Estados limites de serviço são aqueles cuja violação implica em uma perda de qualidade na utilização da estrutura, gerando desconforto aos usuários. A violação de um estado limite de serviço pode se manifestar por meio de vibrações ou deslocamentos excessivos, problemas estéticos, e em geral leva à necessidade de manutenção da estrutura afetada. Estados limites últimos são aqueles que, quando violados, levam a consequências mais drásticas, estando associados a carregamentos que excedem a capacidade de resistência da estrutura, situações de instabilidade global, entre outros problemas que podem levar ao colapso. Falhas de serviço e falhas últimas são então definidas, respectivamente. Para estudar os estados limites e considerá-los num problema de confiabilidade estrutural, são definidas funções de estado limite, que comparam 
alguma medida de capacidade resistente $R$ da estrutura com alguma medida de solicitação $S$, assumindo a forma geral:

$$
g(\boldsymbol{x})=R-S .
$$

A superfície definida pela nulidade de uma função de estado limite $g(\boldsymbol{x})=0$ é conhecida como superfície de falha ou equação de estado limite. Esta superfície representa o limiar entre dois conjuntos de grande importância: quando a função de estado limite assume valores positivos, a configuração assumida por $\boldsymbol{X}$ implica em um estado seguro da estrutura. Caso contrário, a estrutura está em uma configuração que representa uma falha, o que configura a ocorrência do evento falha estrutural, denotado por $\mathcal{F}$. Como a função de estado limite é definida no espaço das variáveis aleatórias em $\boldsymbol{X}$, pode-se dividir este espaço em dois domínios, conforme as Equações 2.15. A Figura 2 ilustra a definição destes domínios.

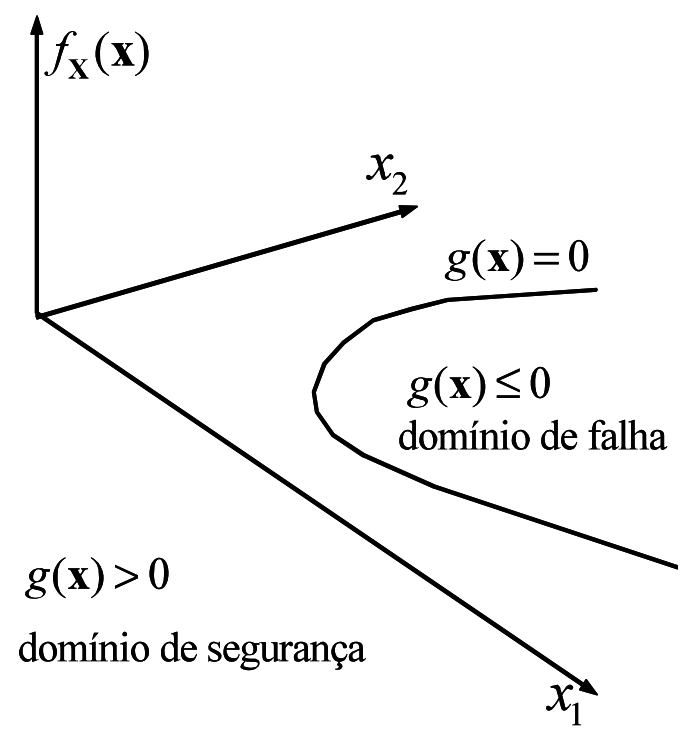

Figura 2: Equação de estado limite, domínio de falha e domínio de segurança (Fonte:(BECK, 2014)).

$$
\begin{aligned}
& D_{f}=\{\boldsymbol{x}: g(\boldsymbol{x}) \leq 0\} \quad \text { é o domínio de falha e } \\
& D_{s}=\{\boldsymbol{x}: g(\boldsymbol{x})>0\} \quad \text { é o domínio de segurança. }
\end{aligned}
$$

\subsubsection{Propagação das incertezas - definição da probabilidade de falha}

A última etapa consiste em analisar o efeito que as incertezas causam nas respostas de interesse do sistema estudado. Por exemplo, uma viga sujeita a carregamentos aleatórios apresentará também uma flecha máxima aleatória. Para se estudar a segurança de uma estrutura, interessa a probabilidade associada às configurações seguras que ela pode assumir, e complementarmente, sua probabilidade de falha. Partindo-se dos conceitos apresentados 
nas subseções 2.1.1 e 2.1.2, a definição da probabilidade de falha de uma estrutura é imediata. Uma vez definido o vetor $\boldsymbol{X}$, sua função densidade de probabilidade conjunta define o conteúdo de probabilidade em um determinado domínio. Uma vez estabelecido o domínio de falha do problema, tem-se o conjunto de todos os pontos em que realizações de $\boldsymbol{X}$ implicam em falhas estruturais. Sendo assim, a probabilidade de falha $P_{f}$ pode ser calculada como:

$$
P_{f}=\int_{D_{f}} f_{\boldsymbol{X}}(\boldsymbol{x}) \boldsymbol{d} \boldsymbol{x}
$$

É comum que a função $f_{\boldsymbol{X}}(\boldsymbol{x})$ assuma formas difíceis de se integrar, e o próprio domínio de falha $D_{f}$ pode apresentar uma geometria que desfavoreça a integração. Em problemas em que mais de um estado limite é considerado, o domínio de falha do problema pode ser definido por meio de diferentes combinações entre os domínios de falha referentes a cada estado limite, conforme será mostrado na seção 2.2. Devido a essas dificuldades, várias técnicas foram propostas para se endereçar a solução da Equação 2.16, conforme apresentado na seção 2.4. Ressalta-se que não necessariamente todas as etapas apresentadas nesta seção precisam ser cumpridas ao se resolver um problema envolvendo quantificação de

incertezas em engenharia de estruturas. É comum, por exemplo, que a mera caracterização de uma fonte de incerteza componha um problema inteiro. Em problemas de confiabilidade estrutural, é usual a adoção de modelos conhecidos para carregamentos aleatórios, bem como sua aplicação em modelos numéricos também conhecidos, concentrando-se na determinação da probabilidade de falha da estrutura.

\subsection{Confiabilidade de sistemas}

Para se aferir o grau de segurança de uma estrutura é necessário definir quais são suas configurações estruturais indesejáveis. Estados limites representam maneiras segundo as quais uma estrutura pode falhar, sendo que vários estados limites podem ser considerados concomitantemente. De fato, estruturas reais costumam estar associadas a diversos modos de falha ao mesmo tempo. A rotina de um projetista de estruturas envolve diversas verificações: uma viga de concreto armado pode estar com uma grande margem de segurança em relação a esforços de cisalhamento no instante em que é rompida à flexão, por exemplo. A consideração de modos de falha adicionais não altera a validade da Equação 2.16, mas algumas considerações precisam ser feitas para possibilitar sua solução. Diferentes modos de falha são traduzidos como diferentes regiões do espaço das variáveis aleatórias em que uma falha estrutural é considerada. Um domínio de falha composto por diferentes estados limites é frequentemente limitado por uma superfície de falha não derivável nos pontos em que os domínios de falha individuais se intersectam, o que pode dificultar algumas estratégias de solução. 
A depender da forma como se associam os modos de falha que precisam ser mobilizados para implicar em uma falha da estrutura, os modos de falha são classificados como em série ou em paralelo, configurando sistemas em série ou em paralelo, além dos mistos, compostos por associações entre eles. Seja um sistema estrutural cuja falha é representada pelo evento $\mathcal{F}$, e que conta com $n l s$ modos de falha. Seja ainda o evento $\mathcal{F}_{i}$ a violação do estado limite que define o modo de falha $i$. Um sistema em série é aquele em que $\mathcal{F}_{i} \Longrightarrow \mathcal{F} \forall i$. É o caso de uma estrutura isostática composta por vários elementos, como a retratada na Figura 3. Neste caso, poderiam ser definidos, por exemplo, um modo de falha relacionado à flambagem de cada barra. Claramente a violação de qualquer um deles levaria ao colapso da estrutura. Desse modo, o evento falha é definido como:

$$
\mathcal{F}=\bigcup_{i=1}^{n l s} \mathcal{F}_{i}
$$

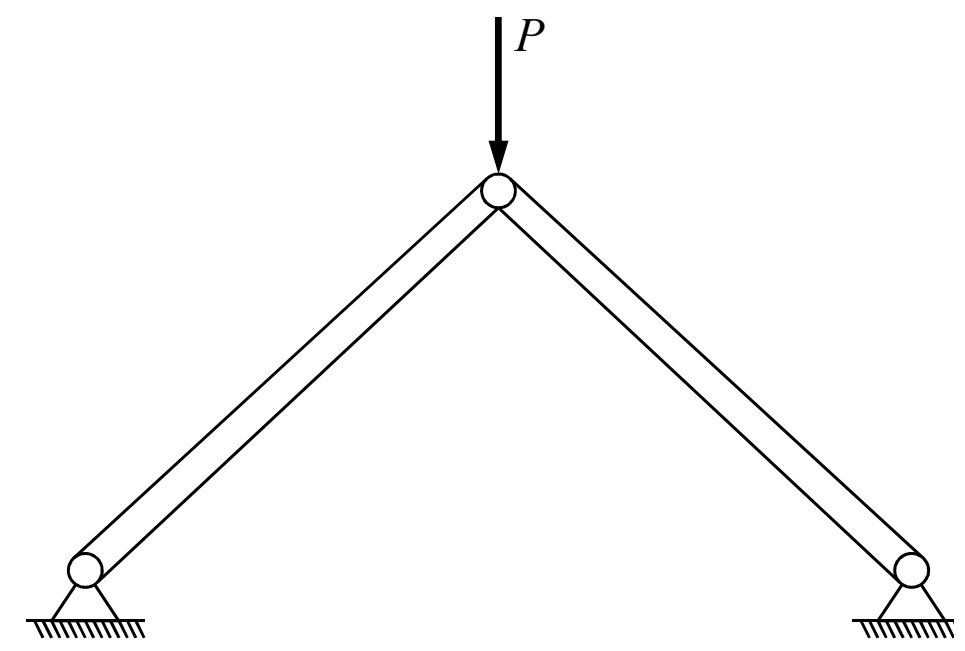

Figura 3: Exemplo de sistema estrutural com elementos associados em série.

Quando a falha de apenas um elemento estrutural não é suficiente para ocasionar a falha do sistema, mas é necessária a violação simultânea de dois ou mais estados limites, estes estão associados em paralelo. É o caso de um pórtico hiperestático em que é necessário o surgimento de várias rótulas plásticas até a formação de um mecanismo que caracteriza a falha da estrutura. Nesse caso, o evento de falha é definido como:

$$
\mathcal{F}=\bigcap_{i=1}^{n l s} \mathcal{F}_{i}
$$

Há ainda uma distinção importante nos sistemas em paralelo com relação à ordem em que os modos de falha são mobilizados. Em estruturas nas quais dois ou mais elementos são solicitados e resistem simultaneamente, mas é necessária a falha de todos para a ocorrência de $\mathcal{F}$, é dito haver redundância ativa. Considere o caso com duas barras solicitadas à tração devido à aplicação de uma força $P$, representado na Figura 4. Com a suposição de algumas 
condições ideais, espera-se que ambas as barras se rompam simultaneamente devido a uma tração que excede suas capacidades resistentes. Se por algum motivo uma barra for consideravelmente mais resistente que a outra, porém, é possível que uma delas se rompa, mas a estrutura continue íntegra. O outro caso é aquele em que um elemento estrutural não

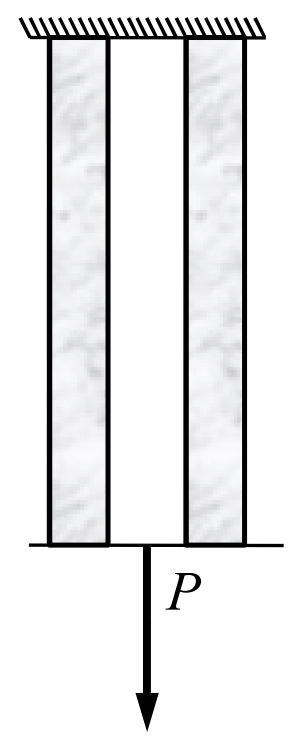

Figura 4: Exemplo de sistema estrutural com elementos associados em paralelo e redundância ativa.

é solicitado até que haja alguma falha, situação na qual ele passa a trabalhar, substituindo algum elemento que falhou. A Figura 5 ilustra essa situação. Caso a barra à esquerda falhe, o cabo à direita é mobilizado, havendo uma chance de a estrutura continuar suportando a condição de carregamento. Quando elementos falham, um a um, em tempos diferentes, configura-se uma situação de colapso progressivo. Este fenômeno não será explorado nesta tese, mas recomenda-se aqui outro trabalho com participação do autor (BECK; TESSARI; KROETZ, 2018). Os conceitos de sistemas em série e paralelo são necessários para uma formulação verossímil de problemas de confiabilidade estrutural, e podem ser aprofundados além do escopo deste trabalho. Apresentações mais exaustivas sobre o tema podem ser encontrados em Ditlevsen e Madsen (1996) e Melchers e Beck (2018).

\subsection{Confiabilidade dependente do tempo}

Quando um parâmetro de entrada de um sistema é considerado uma variável aleatória, ele assume um valor fixo, definido a partir das características da VA. Esta abordagem nem sempre é suficiente para uma boa descrição das fontes de incerteza do problema. Cargas estocásticas podem assumir diferentes valores aleatórios ao longo do tempo, bem como propriedades aleatórias de materiais podem assumir valores diferentes em diferentes pontos da mesma peça estrutural. Além disso, propriedades de materiais bem representadas por variáveis aleatórias podem simplesmente se alterar com o tempo, 


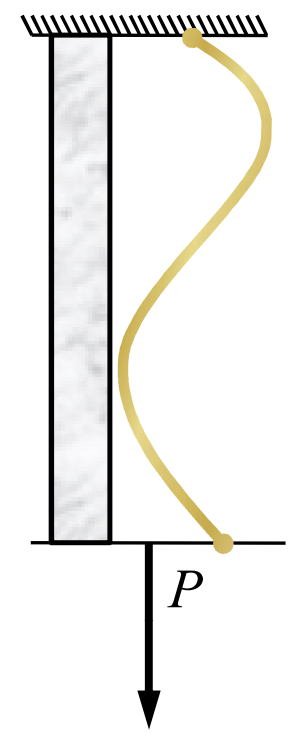

Figura 5: Exemplo de sistema estrutural com elementos associados em paralelo e redundância passiva.

como uma peça de concreto que ganha resistência conforme sua reação de hidratação avança, ou como uma estrutura metálica que vai perdendo resistência conforme sofre corrosão. Para uma melhor descrição destes fenômenos, tais variabilidades precisam ser consideradas, e para isso se introduz o conceito de campo aleatório. Um campo aleatório $X(w, t)$ é uma coleção de variáveis aleatórias indexadas por um ou mais parâmetros. Isso significa que, para um ponto fixo do espaço em que ele está indexado, um campo aleatório assume o comportamento de uma variável aleatória, e, respectivamente, para determinado resultado $w$, tem-se uma realização do campo através dos parâmetros que o indexam. Um campo aleatório pode ser discreto ou contínuo, a depender da natureza de tais parâmetros. Um caso particular de grande interesse para a engenharia de estruturas é o de campos aleatórios unidimensionais, cujo contínuo que indexa as VAs é o tempo. Para este caso, a denominação usualmente adotada é processo estocástico (PE), muito utilizado para a descrição de cargas estocásticas. Se as variáveis aleatórias que compõem o campo unidimensional apresentarem média nula e não houver correlação entre elas, obtém-se ruído branco (white noise), o que ilustra a importância da correlação para que um campo aleatório (ou processo estocástico) seja representativo de algum fenômeno físico de interesse.

As variáveis de um processo estocástico são correlacionadas por meio de uma função de autocorrelação $R_{X X}$, e sua covariância é dada pela função de autocovariância $C_{X X}$, ou função coeficiente de covariância $\rho_{X}$ :

$$
R_{X X}\left(t_{1}, t_{2}\right)=E\left[X\left(t_{1}\right) X\left(t_{2}\right)\right]
$$




$$
\begin{gathered}
C_{X X}\left(t_{1}, t_{2}\right)=E\left[\left(X\left(t_{1}\right)-\mu\left(t_{1}\right)\right)\left(X\left(t_{2}\right)-\mu\left(t_{2}\right)\right)\right]=R_{X X}\left(t_{1}, t_{2}\right)-\mu\left(t_{1}\right) \mu\left(t_{2}\right) \\
\rho_{X}\left(t_{1}, t_{2}\right)=\frac{C_{X X}\left(t_{1}, t_{2}\right)}{\sigma_{X_{1}} \sigma_{X_{2}}}
\end{gathered}
$$

Usualmente $R_{X X}$ define uma autocorrelação decrescente com a distância entre as variáveis, e o parâmetro comprimento de correlação $\lambda$ é utilizado para controlar a intensidade da diminuição. Para que uma função arbitrária possa ser função de autocorrelação de algum processo estocástico, uma matriz de autocorrelação $\boldsymbol{R}$ de ordem $n$ gerada a partir da seleção de $n$ variáveis do processo, com $R_{i j}=R_{X X}\left(X_{i}, X_{j}\right)$ deve ser positiva semi-definida e simétrica. Um processo muito utilizado para descrever fenômenos físicos é o processo estocástico gaussiano, no qual todas as variáveis aleatórias indexadas são conjuntamente gaussianas (normais). Uma função de autocorrelação bastante comum para este tipo de processo, e a adotada neste trabalho, é também denominada gaussiana:

$$
R_{X X}(\Delta t, \lambda)=\exp \left(-\frac{\Delta t}{\lambda}\right)^{2}
$$

Um processo estocástico contínuo é composto por infinitas variáveis aleatórias. No entanto, sua representação computacional é feita por meio de um número finito de variáveis aleatórias, tratadas a partir de alguma técnica que permita generalização para os demais pontos do contínuo. A maneira mais simples de se simular uma realização de um processo estocástico é a discretização do contínuo que o indexa em um número suficientemente grande de variáveis aleatórias correlacionadas. O custo computacional de tal abordagem é proibitivo, e, portanto, várias técnicas para simulação de processos estocásticos foram desenvolvidas, como as expansões de Karhunen-Loève, a expansão da estimativa linear ótima (EOLE), e as expansões de séries ortogonais (SUDRET; KIUREGHIAN, 2000). Neste trabalho, a EOLE será empregada para representar processos estocásticos.

\subsubsection{Expansão da estimativa linear ótima}

Esta expansão, baseada na estimativa linear ótima (OLE) (LI; KIUREGHIAN, 1993), consiste na representação de um processo estocástico como a combinação linear de variáveis aleatórias normais. Considere que o processo estocástico $X(t)$ é gaussiano, com média $\mu(t)$, desvio padrão $\sigma(t)$ e função coeficiente de autocorrelação $\rho_{X}\left(t_{1}, t_{2}\right)$. Um número arbitrário de pontos, $P$ é selecionado no intervalo $[0, \mathcal{T}]$, de modo que $t_{1}=0$ e $t_{P}=\mathcal{T}$. A Expansão da estimativa linear ótima é dada por:

$$
X(t, \omega) \approx \mu(t)+\sigma(t) \sum_{i=1}^{r} \frac{\xi_{i}(\omega)}{\sqrt{\lambda_{i}}} \boldsymbol{\phi}_{i}^{T} \boldsymbol{C}_{t, t_{i}}^{*}(t),
$$

sendo que $\left\{\xi_{i}(\omega), i=1, \ldots, P\right\}$ são variáveis aleatórias normais independentes entre si, $\left\{\phi_{i}, \lambda_{i}, i=1, \ldots, r\right\}$ são, respectivamente, os autovetores e autovalores da matriz índice de 
covariância $C^{*}$ organizados em ordem decrescente, com $C_{i j}^{*}=\rho_{X}\left(t_{i}, t_{j}\right), i, j=\{1, \ldots, P\}$. A ordem da expansão é definida pelo número de termos $r \leq P$ que são mantidos após o truncamento da série. Normalmente, $r$ é escolhido de maneira que uma parte significante do espectro de $\boldsymbol{C}^{*}$ seja mantido, ou seja, para um número real próximo a zero, $\varepsilon \ll 1$ :

$$
r=\min _{k \in[1, . ., P]}\left\{k, \sum_{i=1}^{k} \lambda_{i} \geq(1-\varepsilon) \operatorname{tr} \boldsymbol{C}^{*}\right\}
$$

onde $\operatorname{tr} \boldsymbol{C}^{*}=\sum_{i=1}^{P} \lambda_{i}$ é o traço da matriz $\boldsymbol{C}^{*}$. Desse modo, é possível amostrar realizações de $X(t)$ por meio da Equação 2.23 .

A utilização da EOLE se mostrou bastante eficaz para representar processos estocásticos, além de ser relativamente simples de se programar (SCHUËLLER, 1997), (STEFANOU, 2009). Ainda assim, outras formas de se representar processos estocásticos, bem como revisões teóricas mais amplas sobre confiabilidade dependente do tempo podem ser encontradas em (SUDRET; KIUREGHIAN, 2000) e (MELCHERS; BECK, 2018).

\subsubsection{Probabilidade de falha acumulada}

A Equação 2.16 define probabilidades de falha a partir do princípio que o vetor $\boldsymbol{X}$ reúne apenas variáveis aleatórias. Ela também se aplica para o caso de o vetor reunir variáveis aleatórias e processos estocásticos, mas apenas para um valor fixo do parâmetro t. Desse modo, o resultado assim obtido é também denominado probabilidade de falha instantânea. Em problemas que consideram degradação estrutural, ou em que equações de estado limite são construídas a partir de processos estocásticos, pode interessar também a probabilidade de que a estrutura falhe não apenas em um instante específico, mas em um momento qualquer durante um dado intervalo de tempo $\left[t_{1}, t_{2}\right]$. Define-se assim a probabilidade de falha acumulada, denotada por $P_{f c}\left(t_{1}, t_{2}\right)$ :

$$
P_{f_{c}}\left(t_{1}, t_{2}\right)=\mathbb{P} \exists \tau \in\left[t_{1}, t_{2}\right]: g(\tau, \boldsymbol{X}(\tau, \omega)) \leq 0
$$

Não há muitas abordagens propostas para o cálculo de $P_{f_{c}}$ em problemas práticos. Alguns métodos baseados em aproximações foram utilizados nesse contexto, como o PHI2 (ANDRIEU-RENAUD; SUDRET; LEMAIRE, 2004) e o PHI2 assintótico (SUDRET, 2008). A precisão destes métodos é bastante limitada, e eles são muito pouco utilizados atualmente. Neste trabalho, quando o cálculo de probabilidades de falha acumuladas for necessário, se optará por uma abordagem baseada em simulação de Monte Carlo, conforme será detalhado no Capítulo 8.

\subsection{Técnicas de solução do problema de confiabilidade}

Uma vez que as variáveis aleatórias e as equações de estado limite que descrevem um sistema estão definidas, tem-se um problema de confiabilidade. Por "solução do problema", 
denota-se a obtenção do comportamento estocástico da resposta, aqui considerada por meio da determinação da probabilidade de falha. Para além das dificuldades da correta construção do problema, a integral cuja solução resulta no valor de $P_{f}$ é, em geral, de difícil solução, sobretudo quando envolve um domínio de falha muito complexo ou a dimensão de $\boldsymbol{X}$ é grande. Por isso, diversas técnicas foram desenvolvidas ao longo das últimas décadas para se endereçar este problema. Algumas das técnicas mais utilizadas são apresentadas a seguir.

\subsubsection{Método de confiabilidade de primeira ordem}

A dificuldade da solução analítica do problema da confiabilidade levou a tentativas de soluções numéricas para a integral da Equação 2.16. Estas soluções eram inviáveis para os primeiros computadores, e, de certa forma, soluções de "força bruta" continuam inviáveis até hoje para muitos tipos de problemas. O método de confiabilidade de primeira ordem (FORM) foi desenvolvido para endereçar este tipo de problema por meio de algumas aproximações, sem a necessidade de simulações numéricas. A primeira etapa da solução via FORM é um mapeamento do problema estudado, no espaço das variáveis $\boldsymbol{X}$, para o espaço normal padrão das variáveis $\boldsymbol{\Xi}$, de média nula e desvio padrão unitário, através de uma transformação $T(\boldsymbol{X})=\boldsymbol{\Xi}$. Este mapeamento pode ser feito por meio da transformação de Nataf (1962) ou da transformação de Rosenblatt (1952). O resultado é um novo problema cuja PDF é conjuntamente normal, tem seu valor máximo na origem e decresce exponencialmente com a distância à origem. Como a integração da PDF tem sentido de conteúdo de probabilidade, a superfície de falha do problema indica a região do domínio de falha mais relevante na composição da $P_{f}$. Desse modo, espera-se que ao se realizar uma aproximação da equação de estado limite na região em que esta mais se aproxima da origem, erros cometidos em regiões mais distantes sejam desprezáveis. Tal aproximação tem por objetivo a simplificação da geometria do domínio de falha. Assim, a segunda etapa do FORM consiste na determinação do chamado ponto de projeto, o ponto sobre a superfície de falha que é mais próximo da origem. Seja $\|\boldsymbol{\xi}\|=\sqrt{\boldsymbol{\xi}^{T} \cdot \boldsymbol{\xi}}$ a distância entre um ponto qualquer e a origem do espaço normal padrão. As coordenadas do ponto de projeto podem ser encontradas com a solução do problema de otimização:

$$
\left.\boldsymbol{\xi}^{*}=\operatorname{argmin}\left[\|\boldsymbol{\xi}\|: g\left(T^{-1}(\boldsymbol{\xi})\right)=0\right)\right]
$$

Este problema pode, a princípio, ser resolvido por qualquer método de otimização, mas é bastante comum abordá-lo por meio do algoritmo HLRF, método desenvolvido especialmente para ele (HASOFER; LIND, 1974), (RACKWITZ; FIESSLER, 1978). A distância entre a origem e o ponto de projeto é chamada indice de confiabilidade, denotado por $\beta$. A 
probabilidade de falha é então obtida através da aproximação:

$$
P_{f_{F O R M}}=\Phi(-\beta)
$$

sendo $\Phi$ a CDF normal padrão. Este resultado consiste na aproximação do domínio de falha por um semi espaço delimitado pelo hiperplano tangente ao ponto de projeto, sendo portando uma aproximação linear. Apesar de se tratar de uma simplificação, a utilização do índice de confiabilidade se tornou tão conveniente que ele passou a ser adotado mesmo em métodos que calculam probabilidades de falha sem o sentido geométrico de $\beta$. Mesmo quando métodos de simulação são utilizados, um índice de confiabilidade pode ser calculado como:

$$
\beta=-\Phi^{-1}\left(P_{f}\right)
$$

Esta notação é utilizada em problemas de otimização na presença de incertezas para retratar restrições em probabilidade independentemente da técnica de solução do problema de confiabilidade, conforme será visto no capítulo 3.

\subsubsection{Simulações de Monte Carlo}

Apesar da conveniência da utilização do FORM, há várias limitações associadas à técnica, bem como a outros métodos aproximativos menos utilizados. É bem conhecido o fenômeno da perda de precisão da resposta fornecida pelo FORM quando a dimensão do problema aumenta significativamente. Problemas de confiabilidade de sistemas precisariam de muitas considerações adicionais, uma vez que cada estado limite é associado a um ponto de projeto. Sendo assim, a simulação de Monte Carlo (SMC) se destaca por sua capacidade de endereçar problemas de todos os níveis de complexidade, com a desvantagem de poder demandar um custo computacional bastante elevado. A SMC é uma técnica geral para solução de integrais, encontrando aplicações em muitos outros campos. Na confiabilidade estrutural, convém utilizá-la para determinar a probabilidade de falha definida na Equação 2.16 .

A primeira etapa deste técnica é a geração de $n_{s i}$ realizações do vetor $\boldsymbol{X}$ a partir de $f_{\boldsymbol{X}}(\boldsymbol{x})$. Em seguida, cada uma dessas realizações é aplicada ao modelo estudado, obtendo-se $n_{s i}$ valores para a função de estado limite do problema em questão. Isso significa que o modelo estrutural é analisado $n_{s i}$ vezes, e daí o elevado custo computacional desta técnica. Introduz-se então uma função indicadora $I$, que para cada realização assume os valores:

$$
\begin{array}{ll}
I[\boldsymbol{x}]=0 & \text { se } \boldsymbol{x} \in D_{s} \\
I[\boldsymbol{x}]=1 & \text { se } \boldsymbol{x} \in D_{f}
\end{array}
$$


Utilizando-se a função indicadora, a integração da equação 2.16 pode ser feita sobre todo o domínio:

$$
P_{f}=\int_{D_{f} \cup D_{s}} I[\boldsymbol{x}] f_{\boldsymbol{X}}(\boldsymbol{x}) \boldsymbol{d} \boldsymbol{x} .
$$

Note que a Equação 2.30 é a expressão do valor esperado da função $I$ (Equação 2.4). Sendo assim, é possível calcular uma probabilidade de falha aproximada $\tilde{P}_{f}$ por um estimador para o valor esperado de $I$ :

$$
\tilde{P}_{f}=\sum_{i=1}^{n_{s i}} \frac{I\left[\boldsymbol{x}_{i}\right]}{n_{s i}}=\frac{n_{f}}{n_{s i}}
$$

sendo $n_{f}$ o número de vezes em que uma realização correspondeu a um ponto sobre o domínio de falha. A variância deste estimador é dada por:

$$
\operatorname{Var}\left[\tilde{P}_{f}\right]=\frac{P_{f}\left(1-P_{f}\right)}{n_{s i}}
$$

o que demonstra que a variância tende a desaparecer conforme o número de realizações aumenta. O coeficiente de variação $C V$ de $\tilde{P}_{f}$ é dado por:

$$
C V\left[\tilde{P}_{f}\right]=\frac{\sqrt{\operatorname{Var}\left[\tilde{P}_{f}\right]}}{E\left[\tilde{P}_{f}\right]}=\frac{1}{\sqrt{n_{s i} P_{f}}} .
$$

Esta expressão ilustra a limitação da SMC. Suponha uma probabilidade de falha $P_{f}=10^{-5}$, magnitude comum para problemas de confiabilidade estrutural. O tamanho da amostra necessária para um $C V$ de $5 \%$ seria $n_{s i}=4 \cdot 10^{7}$. Como a avaliação de modelos estruturais pode levar desde uma fração de segundo até horas ou mesmo dias, uma aplicação direta de SMC pura é impraticável, exceto em exemplos bastante simples. Esta abordagem é usualmente conhecida como Monte Carlo Bruto. Uma forma de contornar os elevados custos computacionais é por meio da utilização de técnicas de metamodelagem, conforme será estudado no Capítulo 4. Ainda, diversas modificações foram propostas na própria simulação de Monte Carlo para melhorar sua eficiência. Santos e Beck (2015) exploram várias destas técnicas e apresentam exemplos comparando a eficiência de cada uma delas. Uma técnica de especial importância para este trabalho é a simulação de Monte Carlo com médias ponderadas (WAMC). Proposta por Rashki, Miri e Moghaddam (2012), e posteriormente aplicada a problemas de otimização em Rashki, Miri e Moghaddam (2014) e Okasha (2016), consiste na realização de uma amostragem uniforme para todas as variáveis aleatórias do problema considerado, e da posterior atribuição de um peso a cada uma delas. Os intervalos das amostragens devem ser selecionados a partir de uma estimativa da ordem de grandeza da probabilidade de falha, de modo que regiões relevantes do espaço das VAs não sejam desconsideradas. Em todo caso, na abordagem de Monte Carlo bruto, o próprio tamanho da amostra precisa ser definido com base em uma estimativa da $P_{f}$, portanto isso não configura uma desvantagem para o WAMC. Desse modo, o espaço das 
variáveis aleatórias é preenchido com amostras em todas as suas regiões de importância, e a distinção de conteúdo de probabilidade se dá não pelo número de pontos em determinada região do espaço, mas do peso atribuído a cada um deles. O peso $W$ de cada ponto é definido como a imagem da função densidade de probabilidade conjunta das variáveis aleatórias naquele ponto. Ou seja, no caso de variáveis independentes, o valor do peso $W$ de um ponto será dado pelo produto das funções densidade de probabilidade marginais de cada variável aleatória no ponto amostrado. Em seguida, a probabilidade de falha é estimada como:

$$
\bar{P}_{f_{W}}=\frac{\sum_{i=1}^{n_{s i}} I_{i} W_{i}}{\sum_{i=1}^{n_{s i}} W_{i}}
$$

sendo $I_{i}$ o valor da função indicadora para a realização de número $i$. Esta abordagem pode reduzir bastante o número necessário de simulações para a obtenção de um bom resultado. O tamanho de amostra necessário para a obtenção de um resultado aceitável pode ser ainda mais reduzido caso as amostras sejam organizadas por ordem de peso. Uma vez que o peso de todas as realizações é conhecido, é possível somar todas aquelas que correspondem aos maiores pesos, até se obter toda a parte significativa do conteúdo de probabilidade, de acordo com a precisão desejada para cada problema. Essa abordagem se baseia no fato de que a amostragem uniforme tende a considerar pontos muito insignificantes do espaço das variáveis aleatórias, que representam conteúdos de probabilidade de ordem muito menor do que a precisão requerida para o problema. A favor da segurança, considera-se então que todas as demais realizações pertencem ao domínio de falha, obtendo-se assim uma estimativa suficientemente boa da $P_{f}$ sem a necessidade da avaliação de todas as realizações. Essa abordagem foi proposta por Okasha (2016), e denominada simulação de Monte Carlo com médias ponderadas ranqueadas (RWAMC).

Exemplo: Comparação entre Monte Carlo bruto e WAMC

Seja, por exemplo, uma equação de estado limite definida pela função "chapéu", cujas variáveis aleatórias são descritas na Tabela 1:

$$
g(\mathbf{X})=20-\left(X_{1}-X_{2}\right)^{2}-8\left(X_{1}+X_{2}-4\right)^{3}
$$

Tabela 1: Dados das variáveis aleatórias no exemplo da função chapéu.

\begin{tabular}{llll}
\hline VA & Distribuição & Média & DP \\
\hline$X_{1}$ & Normal & 0.25 & 1 \\
$X_{2}$ & Normal & 0.25 & 1 \\
\hline
\end{tabular}

A amostragem feita da maneira usual e a amostragem uniforme do método das médias ponderadas são ilustradas nas Figuras 6 e 7. A probabilidade de falha deste exemplo é da ordem de $10^{-4}$, e portanto, com base na Equação 2.33, seria necessário um $n_{s i}$ da ordem de $10^{6}$ utilizando-se Monte Carlo bruto, a fim de se obter um resultado confiável. 


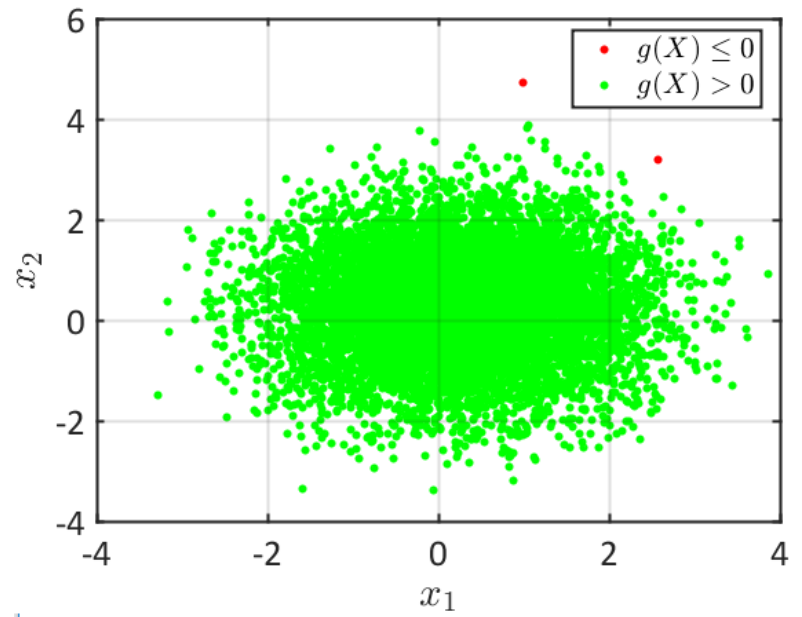

Figura 6: Amostragem e avaliação das amostras para Monte Carlo bruto.

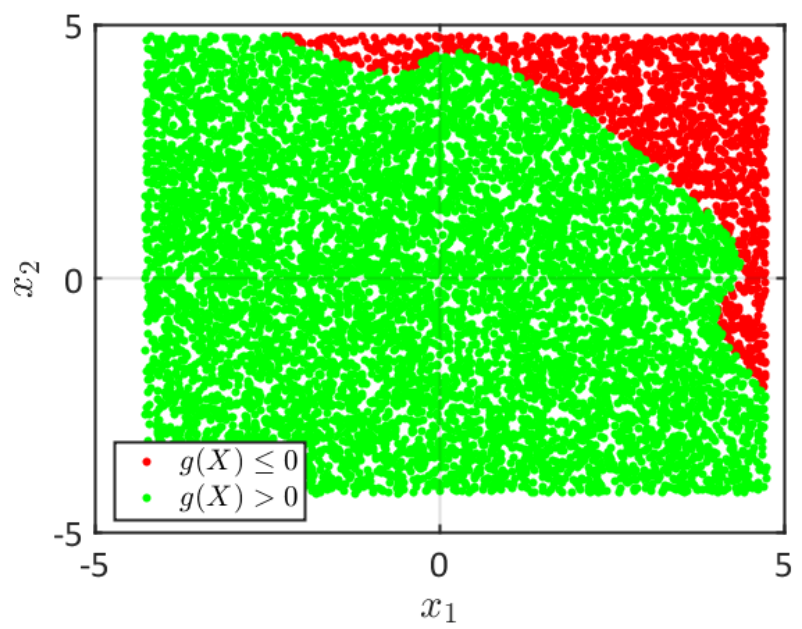

Figura 7: Amostragem e avaliação das amostras para Monte Carlo com médias ponderadas.

Foram realizadas $10^{7}$ simulações com Monte Carlo bruto, obtendo-se uma $P_{f}=$ $3,86 \cdot 10^{-4}$. Com $10^{4}$ simulações utilizando-se WAMC, o resultado obtido foi $P_{f}=3,95.10^{-4}$. A convergência da probabilidade de falha para o WAMC é ilustrada na Figura 8. 


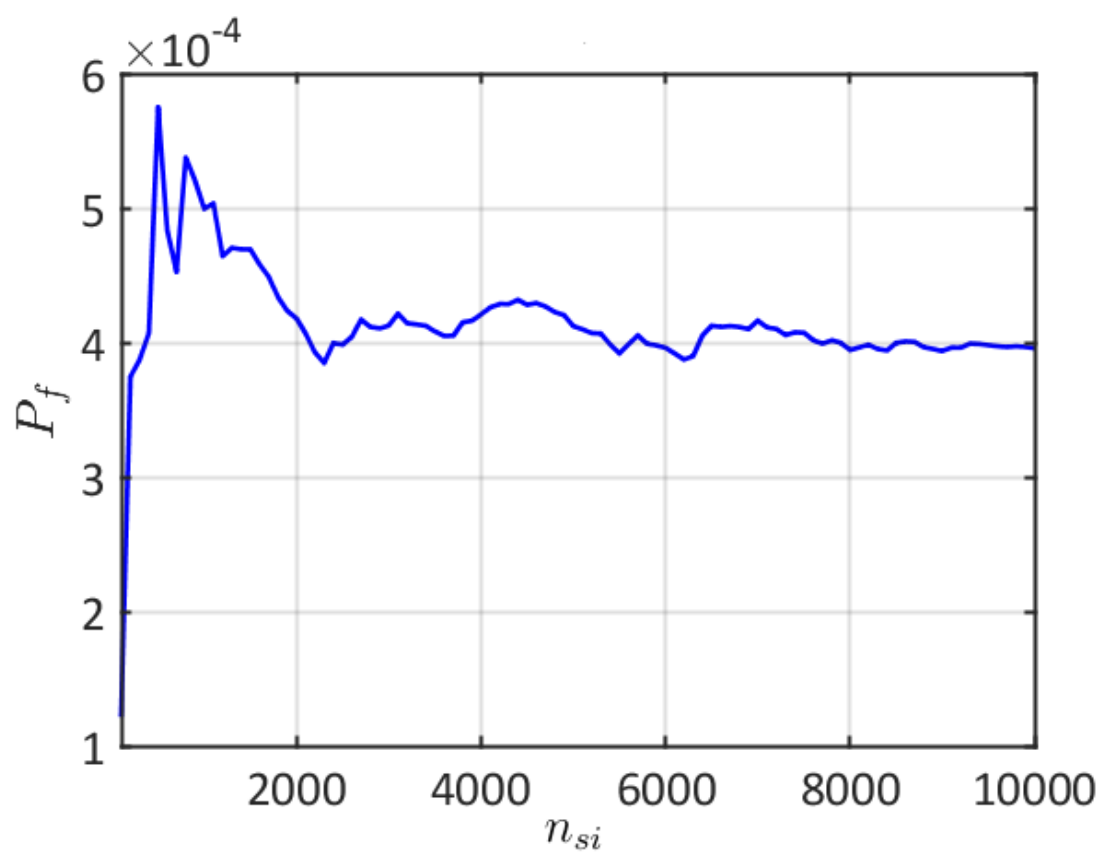

Figura 8: Convergência de $P_{f}$ com o tamanho da amostra. 



\section{OTIMIZAÇÃO DE ESTRUTURAS SOB INCERTEZAS}

Otimização é o ato de se obter o melhor resultado possível sob determinadas circunstâncias (RAO, 1996). Na engenharia, é muito comum a necessidade de se otimizar sistemas e componentes, uma vez que os recursos disponíveis para se resolver os problemas são finitos. A consideração de incertezas em problemas de otimização é de extrema importância, sobretudo para a engenharia de estruturas. Muito se pesquisa sobre otimização estrutural por meio de abordagens determinísticas, ignorando-se o fato de que tais abordagens, muitas vezes, diminuem o nível de segurança da estrutura otimizada. Otimização determinística (Deterministic Design Optimization - DDO) é toda aquela que não leva em consideração as incertezas envolvidas no problema, ou que as leva em conta apenas indiretamente, por meio da consideração de coeficientes de segurança nas suas restrições. A formulação básica de um problema de otimização envolve a definição de uma função objetivo a ser minimizada, $f($.$) , e de nenhuma, uma, ou mais restrições que a função objetivo precisa$ respeitar para que o seu resultado seja considerado factível. Tal função objetivo costuma representar o volume de materiais componentes da estrutura, um preço associado a eles ou dimensões de elementos estruturais. A Equação 3.1 exemplifica essa formulação para o caso da otimização determinística:

$$
\boldsymbol{d}^{*}=\operatorname{argmin}\left[f(\boldsymbol{d}) \mid \sigma(\boldsymbol{d})<\frac{f_{y}}{\lambda_{s}}\right]
$$

para uma hipotética tensão $\sigma(\boldsymbol{d})$ limitada a uma tensão de escoamento $f_{y}$, a qual está associado um coeficiente de segurança $\lambda_{s}$. O vetor $\boldsymbol{d} \in \mathbb{D}$ reúne as $n_{d}$ variáveis de projeto, parâmetros do problema cujo valor se pretende otimizar, com $\mathbb{D}$ sendo o conjunto dos valores possíveis para $\boldsymbol{d}$. O vetor contendo os valores ótimos é representado por $\boldsymbol{d}^{*}$. Esta notação será mantida ao longo deste trabalho, inclusive ao se tratar de otimização não determinística.

Na DDO, a aferição da probabilidade de falha da estrutura não é realizada em momento algum, porém espera-se que a consideração do coeficiente $\lambda_{s}$ garanta sua segurança. Apesar disso, essa abordagem pode levar a diversos problemas. A otimização de uma estrutura hiperestática dificilmente levará em conta a redistribuição de esforços quando da perda do seu primeiro grau de hiperestaticidade, podendo assim negligenciar a dimensão de elementos estruturais que tem função secundária na situação da estrutura íntegra, mas se fazem importantes para mitigar o colapso progressivo, por exemplo. Essa possível mudança do nível de segurança seria mais facilmente considerada por uma análise de confiabilidade de sistemas, que não se faz presente na DDO.

A otimização determinística é ainda hoje alvo de muita pesquisa, uma vez que 
mesmo os problemas determinísticos se tornam bastante complexos quando envolvem muitas variáveis e muitos mínimos locais. Ainda assim, o tema já foi bastante estudado, havendo disponíveis tratados que o exploram de forma bastante ampla, como Rao (1996) e Arora (2016). Da mesma forma, inúmeros métodos foram propostos para a solução de problemas desse tipo.

O interesse de pesquisadores em otimização estocástica é um advento relativamente recente, com apenas alguns poucos artigos esparsos anteriores à década de 90. As primeiras aplicações de meta-modelagem a este problema datam dos anos 2000. Apesar dos recentes avanços no campo, ainda hoje as formulações apresentam muitas limitações.

\subsection{Revisão da literatura}

\subsubsection{Primeiras abordagens}

A ideia de se otimizar estruturas data pelo menos do século XIX, conforme retratado em Vanderplaats (1982). Os primeiros trabalhos que abordaram o problema de forma analítica são quase tão antigos. Eles focavam desenvolvimentos teóricos visando fornecer limites inferiores para o peso de treliças Michell (1904), Maxwell (1952). A primeira vez em que a ideia de se minimizar o custo total de uma estrutura foi proposta provavelmente no trabalho de Forsell (1924). A otimização estrutural avançou de forma substancial ao longo do século XX, e alguns trabalhos considerando a ideia de se levar em conta a segurança de estruturas em termos de probabilidades de falha surgiram nos anos 50 e 60 . Hilton e Feigen (1960) derivaram expressões analíticas para a otimização de estruturas sujeitas a cargas aleatórias. Sua abordagem foi generalizada por Kabala (1962), que incluiu custos de materiais como restrições adicionais ao problema de otimização, já aplicando algoritmos computacionais à solução. Pouco depois, Switzky (1964), Switsky (1965), Broding W. C. (1964) aplicaram técnicas inovadoras ao problema de minimizar o peso da estrutura, utilizando fatores de segurança como uma maneira prática de se levar em conta a segurança das estruturas estudadas. Propostas incipientes de otimização baseada em confiabilidade podem ser encontradas em Ghista (1966), Kiner (1966), Moses (1977). A consideração de risco em sistemas complexos foi introduzida pela agência espacial americana, que começou a aplicar tal abordagem após a falha ocorrida no teste da Apollo, em 1967 (SUDRET, 2015a).

Na década de 80, observou-se que a otimização determinística havia avançado muito por meio da aplicação de soluções numéricas aos problemas, mas um avanço muito menor havia ocorrido na área de otimização considerando incertezas. Pesquisadores tinham pontos de vistas diferentes no que diz respeito ao que seria um ponto ótimo em um problema de otimização estocástica. Após uma grande revisão da literatura, Frangopol (1985) apresentou três equações, resumindo as diferentes visões que existiam na época 
sobre como deveria ser formulado um problema de otimização considerando incertezas:

$$
\begin{gathered}
U_{t}=B-C_{0}-L \\
C_{t}=C_{0}+C_{f} P_{f} \\
\boldsymbol{d}^{*}=\arg \min \left[f(\boldsymbol{d}) \mid P_{f} \leq P_{f_{t}}\right]
\end{gathered}
$$

A Equação. 3.2 consiste na maximização de uma função de utilidade da estrutura, em que $C_{0}$ são seus custos iniciais, $B$ representa o benefício derivado da existência da estrutura, e $L$ representa as perdas esperadas considerando a possibilidade da falha da estrutura. A Equação 3.3 representa o custo total da estrutura, que deve ser minimizado. Ele engloba os custos iniciais $C_{0}$ e os custos esperados de falha, dados pelo produto entre o custo da falha $C_{f}$ e sua probabilidade de ocorrência $P_{f}$. Esta formulação ainda é adotada nas formulações chamadas de otimização de risco (RO) ou otimização dos custos do ciclo de vida. Esta abordagem foi considerada de interesse muito limitado à época, devido à grande dificuldade em se definir e trabalhar com os custos mencionados. A Equação. 3.4 consiste em uma função objetivo determinística a ser minimizada levando em conta restrições de probabilidade, representadas por $P_{f_{t}}$. Esta foi a formulação mais explorada dentre as três, e é conhecida hoje como otimização baseada em confiabilidade (RBDO). As duas últimas abordagens ainda são exploradas em trabalhos recentes, cada uma trazendo vantagens e desvantagens em suas formulações. Entende-se hoje que, desde que os custos associados ao ciclo de vida possam ser bem definidos, a segunda abordagem fornece a formulação mais geral das três.

É possível considerar incertezas em um problema de otimização buscando-se configurações de projeto que sejam pouco sensíveis a incertezas. Esta proposta é desenvolvida na abordagem conhecida como Otimização Robusta (BEYER; SENDHOFF, 2007; SCHUËLLER; JENSEN, 2009). Basicamente, define-se um problema de otimização multi-objetivo, no qual alguma medida de desempenho do sistema estudado deve ser maximizada, enquanto busca-se minimizar a variância desta mesma medida. Esta abordagem não será tratada nesta tese.

\subsubsection{Trabalhos recentes}

Esta seção objetiva descrever alguns trabalhos recentes de especial relevância na área de otimização considerando incertezas, sem entrar em muitos detalhes quanto às formulações propostas, que tendem a ser bastante orientadas ao problema específico tratado em cada trabalho. A noção de "recente" é usada aqui para retratar principalmente trabalhos publicados na última década. 
Para uma representação completa do comportamento de uma estrutura ao longo do tempo, a degradação estrutural sofrida pelos materiais precisa ser considerada. Um fenômeno que deve levado em conta neste contexto é a corrosão causada por agentes químicos no caso de estruturas de concreto, e a corrosão e a fadiga no caso de estruturas metálicas. Joanni e Rackwitz (2008) desenvolveram ferramentas para otimizar estratégias de projeto e manutenção de componentes estruturais. Os autores definem modelos de falha dependente do tempo para a deterioração, que são usados em estratégias que orientam a inspeção e o reparo, considerados como termos na função de objetivo do ciclo de vida da estrutura. Estes resultados são estendidos para o reparo ótimo de estruturas existentes em Streicher, Joanni e R. (2008). Ainda, a otimização do custo-benefício considerando três estratégias diferentes de manutenção é apresentada em Rackwitz e Joanni (2009).

Uma aplicação interessante é estudada em Holicky (2009), onde é abordada a otimização de parâmetros do ciclo de vida de túneis rodoviários. O número de rotas de fuga é otimizado com o auxílio de redes bayesianas, e é feita uma discussão sobre a quantificação das consequências econômicas e sociais de falhas. O processo de otimização leva em conta um risco social, definido como uma função do valor esperado de um certo "valor estatístico da vida", que é considerado uma compensação em valor aceitável para o caso da ocorrência de uma fatalidade. O tempo de vida da estrutura e o número esperado de mortes derivadas de sua utilização (consideradas como funções do número de rotas de fuga do túnel) são levados em conta. Neste estudo, é considerado apenas um estado limite, e nenhum custo de manutenção ou inspeção.

Biondini e Frangopol (2009) estudaram otimização considerando a corrosão das armaduras de estruturas de concreto em ambientes agressivos. A corrosão do aço é modelada em função do tempo. Na formulação em RBDO, é considerada uma função objetivo determinística do peso do concreto, sujeita a restrições de probabilidade de falha. A ideia de "ciclo de vida" é abordada na dependência temporal das restrições de probabilidade, que devem ser satisfeitas ao longo de toda a vida útil da estrutura. Um método de otimização baseado em gradiente é utilizado, associado à avaliação das restrições por meio de simulações de Monte Carlo. Okasha e Frangopol (2009) propuseram um procedimento para otimizar simultaneamente intervalos de manutenção e a estratégia de manutenção adotada para uma estrutura. Em um contexto de otimização multi-objetivo, dois indicadores de desempenho são levados em conta: o índice de confiabilidade do sistema e uma medida da redundância do sistema estrutural. Um código digital é gerado para cada cenário de manutenção, incluindo o tipo de manutenção, o componente da estrutura ao qual tal manutenção se aplica, e um dígito binário representando a aplicação ou não da ação codificada. Um algoritmo genético é então executado para selecionar o cenário mais favorável. Os custos iniciais da estrutura e os custos de falha não são otimizados, uma vez que os parâmetros da geometria e dos materiais que compõem a estrutura não são considerados como variáveis de projeto. 
Uma abordagem abrangente é apresentada em Taflanidis e Beck (2009). São propostas técnicas para a estimativa e otimização dos custos do ciclo de vida de dispositivos de dissipação. Os custos considerados incluem medidas de engenharia sísmica baseadas em desempenho, custos iniciais, custos de reparo e de substituição. Uma abordagem de simulação denominada otimização de subconjunto estocástico é proposta para estabelecer uma análise de sensibilidade global usando um número relativamente pequeno de análises do sistema. Algoritmos clássicos de otimização são então empregados para um refinamento da solução. Em 2010, uma nova revisão sobre o tema da otimização estrutural sob incertezas foi publicada (VALDEBENITO; SCHUËLLER, 2010). Uma seção desta revisão foi dedicada à aplicação de metamodelos a este problema, na qual trabalhos envolvendo redes neurais artificiais, máquinas de vetores de suporte e Krigagem são comentados. Não há menção à otimização de risco, sendo que todos os trabalhos consideram a abordagem RBDO. Uma das principais limitações das estratégias de solução de problemas de RBDO é endereçada em Torii, Lopez e Miguel (2016), onde um modelo de desacoplamento da solução independente da utilização do método de confiabilidade de primeira ordem é proposto.

Trabalhos sem desenvolvimentos teóricos propriamente ditos, mas trazendo aplicações da otimização com consideração de incertezas também têm se popularizado. Wen e Kang (2001b) estudam um edifício de nove andares sujeito a cargas de terremoto e vento. As ocorrências são descritas como processos de Poisson, e a metodologia de otimização descrita em Wen e Kang (2001a), baseada em otimização de risco, é aplicada. Saad et al. (2016) apresentam uma aplicação detalhada da otimização de risco a pontes de concreto armado considerando a degradação da estrutura com o tempo. Li e Hu (2014) utilizam algoritmos heurísticos para resolver problemas de otimização de risco multiobjetivo de engenharia baseada em desempenho. Elementos de otimização de risco são frequentemente usados no projeto de turbinas eólicas, onde a adoção de estratégias de manutenção eficientes são de particular importância na composição dos custos totais do sistema. Um visão geral da aplicação de RO na engenharia de turbinas eólicas é apresentada em Nielsen J.S.; Sorensen (2014).

A ideia de se utilizar metamodelos para assistir à solução de problemas de otimização considerando incertezas foi abordada em alguns trabalhos, como em Dubourg, Sudret e Bourinet (2011b) e Bichon et al. (2013), que propuseram metodologias envolvendo Krigagem adaptativa, e Torii, Lopez e Miguel (2017), que propuseram um método baseado em gradiente utilizando expansões em polinômios de caos. Moustapha et al. (2016) utilizaram Krigagem adaptativa em uma nova estratégia de otimização para resolver problemas de RBDO. Ao invés de considerar as restrições como limites para probabilidades de falha, estas são convertidas em quantis de medidas de desempenho. Em Gomes e Beck (2013), redes neurais artificiais são treinadas para representar equações de estado limite associadas a falhas estruturais, se valendo de um algoritmo híbrido para realizar a otimização. Um algoritmo de enxame de partículas (PSO) (BANSAL et al., 2011) é empregado na 
otimização. Apenas custos iniciais e custos esperados de falha são levados em conta no trabalho. A desconsideração dos demais custos associados ao ciclo de vida da estrutura parece ser uma prática comum. Aissani, Chateauneuf e Saad (2014) explicam que a maioria dos demais custos podem ser razoavelmente bem estimados a priori, mas que os custos de falha são particularmente importantes para a solução final, devido a sua dificuldade de avaliação e à alta sensibilidade da solução ótima com relação a eles. Sendo assim, os demais custos podem ser considerados constantes em muitos casos, sem um efeito significativo na solução do problema. No mesmo trabalho, a ideia de se considerar custos de falha não lineares é apresentada. No modelo proposto, os custos de falha crescem linearmente com a probabilidade de falha até um certo limite, a partir do qual eles passam a crescer exponencialmente. A ideia é que falhas catastróficas sejam capturadas pelo modelo, representando os custos adicionais devido a danos sociais e ambientais. Metamodelos foram empregados em Carreras et al. (2016) para considerar o consumo de energia de um prédio. Um problema de otimização multi-objetivo considerando a adaptação do edifício por meio da instalação de materiais de isolamento foi construído, de modo a considerar vários aspectos que influenciam no custo da construção. O tipo de material e a espessura das camadas de isolamento são considerados variáveis de projeto, de modo a se otimizar o desempenho econômico e ambiental do edifício. Aspectos estruturais não são considerados, mas a formulação do problema se assemelha bastante a algumas das abordadas nesta tese. Os autores se utilizam de splines cúbicas como metamodelos para reduzir o custo computacional da análise. A otimização do custo do ciclo de vida considerando eficiência energética de construções também foi estudada em Eisenhower et al. (2012), onde máquinas de vetores de suporte são utilizadas para auxiliar na solução do problema. Uma abordagem mais geral para otimização estocástica assistida por metamodelagem foi proposta em Zhang, Taflanidis e Medina (2017). Um algoritmo de otimização com aproximações sequenciais é utilizado, partindo-se de uma configuração inicial arbitrária. Então, ciclos de otimização restrita utilizando Krigagem são realizados em sub-regiões, que devem convergir para o ponto ótimo procurado. A mesma ideia foi estendida para a consideração de problema de otimização multi-objetivo em Zhang e Taflanidis (2017).

Problemas de otimização envolvendo confiabilidade dependente do tempo são endereçados com o auxílio de Krigagem adaptativa em Li, Bai e Wang (2018a). Os resultados apresentam alguma similaridade, e foram provavelmente desenvolvidos ao mesmo tempo daqueles apresentados no Capítulo 8 desta tese. Em todo caso, há bastante distinção entre as abordagens. No trabalho de Li, Bai e Wang (2018a), as análises se restringem a problemas de RBDO, a dependência temporal dos problemas tratados se resume à consideração das cargas como processos estocásticos (enquanto a metodologia desenvolvida aqui permite também a consideração de degradação da resistência) e o método apresentado computa menos informações sobre as probabilidades de falha do que o desenvolvido aqui, o que permite que a abordagem do Capítulo 8 capture comportamentos 
específicos de problemas de confiabilidade de sistemas.

\subsection{Otimização baseada em confiabilidade - RBDO}

Quando um problema de otimização é elaborado com restrições em função de probabilidades de falha, tem-se a abordagem da Otimização Baseada em Confiabilidade (RBDO). Essa abordagem leva em consideração a confiabilidade daquilo que se está otimizando, permitindo a minimização de uma função objetivo análoga àquelas dos problemas de DDO, mas com a garantia de que um nível de segurança estabelecido para a estrutura seja respeitado. Há duas formas usuais de se enunciar o problema:

$$
\boldsymbol{d}^{*}=\arg \min \left[f(\boldsymbol{d}) \mid P_{f_{i}}(\boldsymbol{d}) \leq P_{f T i}, i=1, \ldots, n l s\right]
$$

em que limites para probabilidades de falha são restrições do problema, e nls é o número de estados limites do problema, ou ainda com restrições escritas com índices de confiabilidade alvo $\left(\beta_{T i}\right)$ :

$$
\boldsymbol{d}^{*}=\arg \min \left[f(\boldsymbol{d}) \mid \beta_{i}(\boldsymbol{d}) \geq \beta_{T i}, i=1, \ldots, n l s\right]
$$

Esta abordagem é conveniente para se evitar problemas numéricos, que podem derivar do fato de que as probabilidades de falha tratadas em problemas de engenharia de estruturas são, em geral, números bastante próximos a zero. Adicionalmente, as variáveis de projeto podem ser também restritas dentro de limites, aos quais se convencionou chamar de restrições "suaves" (soft constraints), em oposição às restrições em confiabilidade, chamadas de restrições "severas" (hard constraints). Apesar de mais sofisticada, essa abordagem não tem o poder de garantir que a estrutura calculada apresente o melhor compromisso entre segurança e economia. Os resultados do problema dependem dos índices de confiabilidade definidos nas restrições, que não são em si considerados como variáveis de projeto. Além disso, a metodologia de RBDO não aborda a definição das probabilidades de falha alvo. Beck e Gomes (2012) mostraram que os custos de manufatura de estruturas analisadas podem ser minimizados por esta abordagem, porém não há garantias de que o custo total da estrutura não irá aumentar no processo. No contexto da otimização sob incertezas, a expressão 2.15 deve ser reescrita, pois cada configuração estrutural, representada por valores diferentes adotados pelos parâmetros em $\boldsymbol{d}$, pode estar associada a um domínio de falha diferente. Desse modo, a definição dos domínios do problema de confiabilidade da estrutura a ser otimizada são escritos como:

$$
\begin{aligned}
& D_{f}(\boldsymbol{d})=\{\boldsymbol{d}, \boldsymbol{x}: g(\boldsymbol{x}, \boldsymbol{d}) \leq 0\} \\
& D_{s}(\boldsymbol{d})=\{\boldsymbol{d}, \boldsymbol{x}: g(\boldsymbol{x}, \boldsymbol{d})>0\}
\end{aligned} \quad \text { é o o domínio de falhánio de segurança. }
$$

A solução de um problema de otimização requer que sua função objetivo seja resolvida diversas vezes, para diferentes configurações de $\boldsymbol{d}$. A cada uma dessas soluções é necessário verificar se a configuração estrutural considerada viola ou não as restrições do problema. 
Isso significa que um problema de confiabilidade precisa ser resolvido a cada etapa da solução do problema de otimização. Por consequência, o custo da solução de problemas deste tipo por meio de simulações de Monte Carlo é bastante elevado, e os primeiros algoritmos propostos especificamente para RBDO foram baseados no FORM.

\subsubsection{Abordagens de laço duplo}

Recuperando-se a Equação 2.16, tem-se que:

$$
P_{f}(\boldsymbol{d})=\mathbb{P}[g(\boldsymbol{d}, \boldsymbol{X}) \leq 0]=\int_{g(\boldsymbol{d}, \boldsymbol{x}) \leq 0} f_{\boldsymbol{X}}(\boldsymbol{x}) \boldsymbol{d} \boldsymbol{x} \approx \Phi(-\beta)
$$

É possível utilizar o mesmo raciocínio para definir uma medida da probabilidade de a estrutura assumir não uma falha, mas uma outra medida de desempenho $g$ qualquer:

$$
\Phi\left(-\beta_{g}\right) \approx F_{G}(g)=\mathbb{P}[g(\boldsymbol{d}, \boldsymbol{x}) \leq g]=\int_{g(\boldsymbol{d}, \boldsymbol{x}) \leq g} f_{\boldsymbol{X}}(\boldsymbol{x}) \boldsymbol{d} \boldsymbol{x}
$$

obtendo-se assim um índice de confiabilidade generalizado $\beta_{g}$. Desse modo, configurações que não tornem as restrições em probabilidade ativas terão ainda uma medida associada a elas, pois a equação de estado limite assumirá um valor diferente de zero. Nesse contexto, a equação de estado limite passa a ser chamada de função de desempenho. A partir daí, pode-se elaborar uma formulação que busque aproximar $\beta_{g}$ de $\beta_{T}$, e uma restrição do problema de RBDO pode ser escrita da forma:

$$
F_{G}(0) \leq \Phi\left(-\beta_{T}\right)
$$

o que é conveniente para o problema de RBDO. Claramente, o índice de confiabilidade é recuperado para $g=0$. A partir dessas preliminares, o problema de otimização pode ser definido com duas abordagens diferentes. Na abordagem conhecida como Reliability Index Approach (RIA), as restrições são trabalhadas em termos da minimização da distância entre a origem do espaço das variáveis aleatórias e o ponto de projeto, para cada $\boldsymbol{d}$ :

$$
\boldsymbol{\xi}_{R I A}^{*}=\operatorname{argmin}[\|\boldsymbol{\xi}\| \mid g(\boldsymbol{d}, \boldsymbol{x})=0]
$$

Outra abordagem, conhecida como performance measure approach (PMA) consiste na minimização da medida de desempenho avaliada sobre a esfera de índice de confiabilidade, definida como a coleção de pontos do espaço das variáveis aleatórias que respeitam a relação $\left(\boldsymbol{\xi}^{T} \boldsymbol{\xi}\right)^{1 / 2}=\beta_{T}$. Como o índice de confiabilidade alvo representa a mesma distância em todas as direções, tal coleção assume a forma de uma hiperesfera, por isso seu nome. As restrições pela abordagem PMA são então escritas para cada $\boldsymbol{d}$ da forma:

$$
\boldsymbol{\xi}_{P M A}^{*}=\operatorname{argmin}\left[\left(g(\boldsymbol{d}, \boldsymbol{x}) \mid\|\boldsymbol{\xi}\|=\beta_{T}\right]\right.
$$

em que $\boldsymbol{\xi}_{P M A}^{*}$ é denominado ponto de menor performance. A adoção do PMA se baseia no princípio de que é mais simples otimizar uma função objetivo complexa sujeita a 
restrições simples do que uma função objetivo simples sujeita a restrições complexas (AOUES; CHATEAUNEUF, 2010). De fato, observa-se que essa abordagem se apresenta mais robusta para a solução da maioria dos problemas.

Seja qual for a abordagem adotada, as minimizações definidas nas Equações 3.11 ou 3.12 devem ser executadas a cada iteração do algoritmo de otimização aplicado sobre a função objetivo do problema de RBDO.

\subsubsection{Abordagem do laço único}

A presença de laços acoplados na solução de problemas de RBDO é uma grande desvantagem em termos de custo computacional. Esse problema levou diversos pesquisadores a buscar algoritmos de solução que desacoplassem os laços. Na chamada Abordagem do Laço Único (SLA - Single Loop Approach), o laço interno do RIA ou do PMA é substituído por restrições que buscam valores ótimos, de maneira que a convergência das variáveis $\boldsymbol{d}$ e $\boldsymbol{\xi}$ aconteçam concomitantemente. Alguns algoritmos propostos segundo essa lógica (KUSCHEL; RACKWITZ, 2000; AGARWAL et al., 2007) apresentam-se pouco eficientes, pois requerem derivadas de segunda ordem e se utilizam de variáveis adicionais para a solução, aumentando a dimensão do problema. Uma abordagem de laço único mais robusta foi proposta (J.; MOURELATOS; TU, 2004). A formulação do SLA pode ser escrita da seguinte forma (MELCHERS; BECK, 2018):

$$
\boldsymbol{d}^{*}=\arg \min \left[f(\boldsymbol{d}) \mid g_{i}\left(\boldsymbol{d}, \boldsymbol{x}_{i}\right) \geq 0, i=1, \ldots, n_{L S}\right]
$$

onde, para cada iteração $k$

$$
\boldsymbol{x}_{i k}=\left(\boldsymbol{\mu}_{\boldsymbol{x}}\right)_{k}-\alpha_{i k} \boldsymbol{\sigma}_{\boldsymbol{x}} \beta_{T_{i}}
$$

sendo $\boldsymbol{x}_{i k}$ uma aproximação linear do ponto de menor performance, $\boldsymbol{\mu}_{\boldsymbol{x}}$ o vetor com as médias de $\boldsymbol{x}, \boldsymbol{\sigma}_{\boldsymbol{x}}$ o vetor com os desvios padrão, e $\alpha_{i k}$ a direção de maior decréscimo do gradiente:

$$
\alpha_{i k}=\frac{\boldsymbol{\sigma}_{x} \nabla g_{i}\left(\boldsymbol{d}, \boldsymbol{x}_{i k-1}\right)}{\left\|\boldsymbol{\sigma}_{x} \nabla g_{i}\left(\boldsymbol{d}, \boldsymbol{x}_{i k-1}\right)\right\|}
$$

ou seja, a restrição do problema de otimização mais geral é em si uma iteração do que anteriormente seria o laço interno, e a busca pelo ponto ótimo $\boldsymbol{d}$ acontece ao mesmo tempo que as restrições consideram pontos que iterativamente convergem para o ponto de menor performance. Sendo assim, trata-se de um método aproximativo, robusto, mas que pode não convergir em alguns casos, sobretudo para funções objetivo altamente não-lineares. Em todo caso, uma comparação feita por, Aoues e Chateauneuf (2010) inicou que o SLA é superior em eficiência e robustez quando comparado com diversos métodos concorrentes. 


\subsection{Otimização de Risco - RO}

A ideia de se minimizar o peso de uma estrutura está associada à hipótese de que o peso é proporcional ao seu custo. Por mais que isso esteja correto com relação à sua construção, custos de operação, manutenção e principalmente custos associados à falha da estrutura podem representar uma parcela importante do custo total. Wübbenhorst (1986) usou o termo "efeito iceberg" para se referir ao modo como os demais custos não são óbvios à primeira vista, mas representam uma grande parte dos custos totais. Desse modo, quando se tem interesse no custo total de uma estrutura, uma abordagem geral deve levar em conta os demais custos sobre o ciclo de vida. Na Otimização de Risco (Risk Optimization $\mathrm{RO})$ diferentes termos de custo, associados a diferentes fases da vida da estrutura, podem ser considerados. Desse modo, a função objetivo do problema é a composição do seu custo total:

$$
C_{T}(\boldsymbol{d})=C_{I}(\boldsymbol{d})+C_{O}(\boldsymbol{d})+C_{I \& M}(\boldsymbol{d})+C_{E F}(\boldsymbol{d}),
$$

sendo considerados custos Iniciais $C_{I}$, custos de Operação $C_{O}$, custos de Inspeção e Manutenção $C_{I \& M}$, e os custos Esperados de Falha $C_{E F}$, sendo estes últimos definidos como:

$$
C_{E F}=\sum_{j=1}^{n l s} P_{f_{j}} C_{f_{j}},
$$

em que $j=\{1, \ldots, n l s\}$ conta os estados limites associados à probabilidade de falha $P_{f_{j}}$, cujo custo é $C_{f_{j}}$. Restrições podem ser consideradas, tanto nas variáveis de projeto quanto nas probabilidades de falha. Sendo assim, o problema pode ser enunciado da seguinte forma:

$$
\begin{array}{cl} 
& \boldsymbol{d}^{*}=\arg \min _{\boldsymbol{d} \in \mathbb{D}} C_{T}(\boldsymbol{d}), \\
\text { sujeito a: } & P_{f_{j}} \leq \bar{P}_{f_{j}}, \quad j=\left\{1, \ldots, N_{l s}\right\} .
\end{array}
$$

Apesar da formulação abranger a possibilidade da existência de restrições, estas são em muitos casos desnecessárias. A consideração explícita das probabilidades de falha na função objetivo produz um conflito que, de certa forma, restringe o problema: uma diminuição no peso da estrutura tende a diminuir seus custos iniciais, mas aumentar seus custos esperados de falha, valendo a recíproca.

Uma vez que o ciclo de vida de uma estrutura costuma se estender por anos ou mesmo décadas, os custos envolvidos no problema de otimização não podem ser tratados diretamente. Efeitos econômicos que incidem através do tempo, como a inflação, fazem com que valores fixos associados a custos tornem-se pouco representativos. Para considerar 
estes efeitos, pode-se discretizar o tempo de vida útil da estrutura em períodos nos quais os custos são considerados constantes, e então trazê-los para o valor presente, aplicandose as taxas referentes ao tempo considerado. Dessa maneira, as probabilidades de falha acumuladas associadas a cada período são utilizadas para compor um custo esperado de falha ponderado pelas taxas econômicas, da seguinte forma (SAAD et al., 2016):

$$
C_{E F}^{P V}(\mathcal{T})=\sum_{j=1}^{N_{l s}} \sum_{n=1}^{\mathcal{T}} \frac{P_{f c_{j n}} C_{f_{j n}}}{(1+\eta)^{n}},
$$

em que $C_{E F}^{P V}$ é o custo esperado de falha em valor presente, $P_{f_{c_{j n}}}$ e $C_{f_{j n}}$ são, respectivamente, a probabilidade de falha acumulada e o custo de falha do $j$-ésimo estado limite no período $n, \mathcal{T}$ é o número de períodos considerados, e $\eta$ é uma taxa financeira. As Equações 3.16 e 3.19 podem então ser aplicadas à Equação 3.18, definindo um problema geral de otimização de risco:

$$
\begin{aligned}
& \boldsymbol{d}^{*}=\arg \min _{\boldsymbol{d} \in \mathbb{D}}\left[C_{I}(\boldsymbol{d})+C_{O}(\boldsymbol{d})+C_{I \& M}(\boldsymbol{d})+\sum_{j=1}^{N_{l s}} \sum_{n=1}^{\mathcal{T}} \frac{P_{f c_{j n}}(\boldsymbol{d}) C_{f_{j n}}(\boldsymbol{d})}{(1+\eta)^{n}}\right], \\
& \text { sujeito a: } \quad P_{f_{j}} \leq \bar{P}_{f_{j}}, \quad j=\left\{1, \ldots, N_{l s}\right\} .
\end{aligned}
$$

Uma comparação entre as três formulações estudadas: DDO, RBDO e RO, torna claro o fato de a otimização de risco ser a abordagem mais geral entre elas. Ainda assim, a RBDO tem sido mais estudada nos últimos anos. Nos primeiros trabalhos sobre otimização na presença de incertezas, não se fazia distinção entre RO e RBDO. Aparentemente, a tendência de se optar pela RBDO começou ao final dos anos 90. Frangopol (1998) concluiu sua revisão sobre otimização estrutural estocástica declarando que:

"O objetivo último da otimização estrutural probabilística é atingir um ótimo em termos de custo esperado de ciclo de vida. Contudo, esta área ainda está na sua infância. Apesar de que os índices de confiabilidade alvo deveriam ser baseados nos custos de ciclo de vida, a complexidade deste problema ainda não foi inteiramente explorada."

O cenário não mudou muito para a otimização de risco até o presente, e, portanto, há bastante espaço para desenvolvimento nessa área. 



\section{COMPARAÇÃO DE TÉCNICAS DE METAMOdELAGEM NO CONTEXTO DA CONFIABILIDADE ESTRUTURAL}

Este capítulo é baseado no artigo:

\section{Henrique M. Kroetz, Rodolfo K. Tessari e André T. Beck (2017)}

Performance of global metamodeling techniques in solution of structural reliability problems

- Advances in Engineering Software, Volume 114, Pages 394-404, ISSN 0965-9978

\subsection{Principais contribuições do autor}

- Revisão da literatura e programação das três técnicas de metamodelagem no software StRAnD.

- Comparação do desempenho das técnicas através de sua aplicação em problemas envolvendo confiabilidade estrutural.

\subsection{Introdução}

Metamodelos são aproximações analíticas que simulam o comportamento de modelos mais complexos. A partir do conhecimento dos outputs do modelo original (e.g. um modelo numérico), para alguns conjuntos de dados de entrada, o metamodelo é ajustado, podendo então ser analisado em substituição ao modelo original. Os conjuntos de dados de entrada utilizados para este fim são chamados "pontos de suporte". Metamodelos eficazes fornecem, para conjuntos de dados de entrada específicos, uma resposta próxima o suficiente daquela que seria oferecida ao se avaliar o modelo que se está tentando representar. Seja $\mathcal{M}$ um modelo "caixa preta", i.e. apenas a relação entre dados de entrada e de saída do modelo serão consideradas. A partir destas relações, define-se um metamodelo $\tilde{\mathcal{M}}$ :

$$
\tilde{\mathcal{M}}(\boldsymbol{x}) \approx \mathcal{M}(\boldsymbol{x})=\boldsymbol{y}
$$

Por se tratarem de aproximações analíticas, a avaliação dos metamodelos tende a ser consideravelmente mais barata em termos de custo computacional, quando comparada à avaliação de modelos numéricos complexos. Desse modo, sua utilização se faz bastante útil em problemas nos quais um modelo precise ser resolvido muitas vezes, como no caso da determinação de uma probabilidade de falha por meio de simulações de Monte Carlo. A adoção de metamodelos objetiva a obtenção de resultados precisos avaliando-se o modelo original $\mathcal{M}(\boldsymbol{x})$ o menor número de vezes possível, ou seja, utilizando-se um pequeno 
número de pontos de suporte. A precisão do modelo é afetada pelo número de pontos de suportes utilizados em sua construção, e principalmente pelo modo com tais pontos são escolhidos. Portanto, a escolha dos pontos de suporte desempenha um papel crítico nas abordagens de metamodelagem. Neste capítulo, a seleção dos pontos será feita por meio da amostragem por hipercubos latinos (LHS) (OLSSON; SANDBERG; DAHLBLOM, 2003), utilizada para a obtenção automática de uma distribuição esparsa dos pontos de suporte no espaço das variáveis aleatórias. Detalhes sobre a técnica e dicas de programação podem ser encontrados em Kroetz (2015).

\subsection{Revisão da literatura}

As primeiras aplicações de metamodelos em confiabilidade estrutural envolviam superfícies de resposta polinomiais. Nesse contexto, os primeiros métodos ficaram conhecidas como "métodos de superfície de resposta" (RSM) (FARAVELLI, 1989). A partir da observação do modelo original $\mathcal{M}$ em alguns pontos, os coeficientes de um polinômio escolhido para representar o problema são obtidos por meio do método dos mínimos quadrados. A busca de soluções eficientes levou os métodos de superfície de resposta a serem combinados com FORM, sendo necessária a reconstrução da superfície de resposta diversas vezes durante a busca do ponto de projeto, uma vez que a aproximação do método é apenas local, Leonel, Beck e Venturini (2011). Como ambas as aproximações adotadas nesta estratégia são de caráter local, e consideradas as limitações do FORM, este tipo de abordagem prosperou pouco, sendo hoje muito mais comum a utilização de simulações de Monte Carlo quando da utilização de metamodelos.

Hornik, Stinchcombe e White (1989) provaram que redes neurais artificiais (RNA) do tipo "feed-forward" suficientemente complexas são capazes de aproximar qualquer função mensurável de maneira arbitrariamente satisfatória, o que abriu caminho para sua utilização como técnica de metamodelagem. RNA foram aplicadas à confiabilidade estrutural pela primeira vez em Papadrakakis, Papadopoulos e Lagaros (1996), e posteriormente aplicada a problemas de otimização baseada em confiabilidade (PAPADRAKAKIS; LAGAROS, 2002). A utilização de RNA como metamodelos no contexto da confiabilidade foi um avanço significativo, e portanto diversos trabalhos adotaram essa abordagem. Hurtado e Alvarez (2001) compararam o desempenho de diferentes tipos de redes neurais em problemas de confiabilidade estrutural, e Gomes e Awruch (2004) compararam o uso de RNA com metamodelos baseados em expansões em polinômios de caos. Análises de confiabilidade envolvendo terremotos utilizando RNA foram realizadas por Zhang e Foschi (2004). Papadrakakis, Lagaros e Plevris (2005) aplicaram pela primeira vez esse tipo de metamodelo em otimização baseada em confiabilidade para modelos estruturais de grande complexidade, e diversos outros problemas foram explorados por Cardoso et al. (2008). Firouzi e Rahai (2012) propuseram um modo de se inspecionar pontes de concreto 
armado a partir do tamanho de fissuras induzidas por corrosão em um método baseado em confiabilidade que emprega redes neurais artificiais, concluindo que tal ferramenta foi capaz de reduzir significativamente o custo computacional da análise, mantendo-se a qualidade dos resultados. Problemas de otimização global na presença de incertezas, utilizando redes neurais artificiais para substituir suas funções objetivo foram estudados por Gomes e Beck (2013), que também foram bem sucedidos na solução do problema envolvendo menor custo computacional. Uma ampla revisão da literatura sobre a aplicação da RNA em problemas de confiabilidade estrutural pode ser encontrada em Chojaczyk et al. (2015).

Expansões em polinômios de caos (PCE) foram aplicadas pela primeira vez à análise estrutural por Ghanem e Spanos (1990), naquilo que se convencionou chamar de método dos elementos finitos estocásticos (SFEM). A partir de então, a abordagem foi utilizada em várias aplicações, sendo utilizada também como técnica de metamodelagem. Sachdeva, Nair e Keane (2006) estudaram a eficiência da abordagem das PCE na acomodação de uma fundação apoiada em um solo aleatoriamente heterogêneo. Ngah e Young (2007) utilizaram o SFEM para prever campos de tensão e deformação em materiais compósitos, com variação espacial nas propriedades dos materiais. Diversos estudos recentes endereçaram problemas de confiabilidade estrutural utilizando expansões em polinômios de caos, destacandose os trabalhos de Sudret (2015b) e Marelli e Sudret (2015). Blatman e Sudret (2008) desenvolveram um algoritmo para reduzir algumas limitações presentes na utilização das expansões em polinômios de caos em problemas envolvendo muitas variáveis aleatórias, construindo bases esparsas para as expansões. Desse modo, termos de menor relevância são ignorados, reduzindo-se substancialmente a dimensão do problema. Spiridonakos e Chatzi (2015) estudaram sistemas dinâmicos não lineares de estruturas, adaptando as PCE para esse tipo de problema.

A terceira técnica de metamodelagem explorada neste trabalho é a Regressão por Processos Gaussianos, ou Krigagem. Esta técnica data da década de 1950, quando o engenheiro de mineração sul-africano Daniel Krige propôs algumas melhorias nos procedimentos adotados para se prever a quantidade de minério que poderia ser obtida em terrenos a serem explorados. Até então, a média da quantidade encontrada em uma área muito extensa era a estimativa para a quantidade que se deveria encontrar em áreas menores pertencentes à mesma região. Krige (que empresta seu nome à técnica) propôs que as informações sobre os campos adjacentes àquele cuja quantidade de minério se queria estimar deveriam ser consideradas mais relevantes do que aquelas referentes aos campos mais distantes. Ou seja, a informação estaria espacialmente correlacionada. Detalhes sobre esta história, bem como uma revisão sobre os primeiros trabalhos envolvendo Krigagem podem ser encontrados em Cressie (1990). Metamodelos de Krigagem foram provavelmente aplicados à confiabilidade estrutural pela primeira vez no trabalho de Romero, Swiler e Giunta (2004). Kaymaz (2005) comparou o desempenho de metamodelos de Krigagem 
com aqueles baseados em superfícies de resposta polinomiais. Echard, Gayton e Lemaire (2011) propuseram um método de aprendizado adaptativo, no qual pontos do projeto de experimento vão sendo adicionados ao metamodelo conforme sua precisão em regiões de interesse é demandada. Dubourg, Sudret e Bourinet (2011a) aplicaram a Krigagem à solução de problemas de otimização baseada em confiabilidade, metamodelando funções objetivo. Echard et al. (2013) acomplaram metamodelos de Krigagem com simulações de Monte Carlo com amostragem por importância, e mostraram que tal abordagem é eficaz mesmo para tratar problemas envolvendo probabilidades de falha pequenas e sistemas numéricos complexos. Jia e Taflanidis (2013) aplicaram este tipo de metamodelo para prever o comportamento de furacões, e compararam seu desempenho com previsões feitas por meio do método dos mínimos quadrados móveis. Uma vasta revisão sobre a aplicação de metamodelos de Krigagem a problemas de confiabilidade estrutural é encontrada em Gaspar, Teixeira e Guedes Soares (2014).

Muitos trabalhos investigaram a utilização de metamodelos nas mais diversas aplicações, inclusive dentro da confiabilidade estrutural. Porém além da comparação entre RSM e RNA feita por Gomes e Awruch (2004), e entre RSM e Krigagem feita por Kaymaz (2005), há poucos trabalhos dedicados à comparação do desempenho de diferentes tipos de metamodelos. Gano, Kim e Brown (2006) compararam Krigagem com regressões de segunda ordem, utilizando uma aplicação comercial chamada Datascape. A Krigagem foi também comparada com metamodelos de funções de base radial e de regressão adaptativa em um problema específico no trabalho de Babaei e Pan (2016). Ainda assim, não havia trabalho publicado comparando o desempenho de redes neurais artificiais, expansões em polinômios de caos e Krigagem, sobretudo no contexto da confiabilidade estrutural. Neste capítulo, as três técnicas são comparadas na solução de dois problemas de confiabilidade estrutural envolvendo modelos mecânicos numéricos. Detalhes de implementação, vantagens e limitações de cada técnica também são discutidos.

\subsection{Técnicas de metamodelagem}

\subsubsection{Redes Neurais Artificiais}

Redes neurais artificiais (ANN) são algoritmos numéricos inspirados na estrutura do cérebro humano. Sua aplicação à engenharia de estruturas data do início dos anos 90 (BERKE; HAJELA, 1992; BENTO, 1998), e à confiabilidade estrutural, de 1996 (PAPADRAKAKIS; PAPADOPOULOS; LAGAROS, 1996). Uma ANN é uma organização de neurônios artificiais em camadas que se comunicam entre si. Um neurônio artificial é uma estrutura lógica que recebe informação e a processa de acordo com alguma regra interna. Diversos tipos de neurônios artificiais e regras de processamento foram propostos na literatura (FAUSETT, 1994). Neste trabalho, são adotados os neurônios que aplicam uma combinação linear de suas informações de entrada, em que um neurônio $n^{(r n)}$ na 
camada $(k)$, recebe como entrada o vetor $\boldsymbol{x}^{(r n)}$ cujas componentes são fornecidas através de $M$ canais de entrada. Em seguida, o neurônio multiplica cada $x_{i}^{(r n)}$ por pesos característicos $w^{(r n)}$, fazendo então o somatório dos produtos. Um fator denominado bias é adicionado à soma, de modo que a resposta produzida pelos neurônios possa ser diferente de zero, mesmo que todas as suas entradas sejam nulas. Ou seja as informações de entrada $x_{i}^{(r n)}$ são trabalhadas de modo a compor o valor de ativação $a_{n k}^{(r n)}$ :

$$
a_{n k}^{(r n)}=\sum_{i=1}^{M} w_{i n k}^{(r n)} x_{i}^{(r n)}+b_{n k}^{(r n)}
$$

em que $w_{i n k}^{(r n)}$ é o peso na conexão entre o n-ésimo neurônio da k-ésima camada, e o i-ésimo neurônio da camada anterior. O sobrescrito ${ }^{(r n)}$ é utilizado por motivo de clareza, ao se referir a símbolos relacionados à rede neural artificial. A informação de saída a ser disparada pelo neurônio é obtida por meio da aplicação do valor de ativação a uma função de ativação $f_{a}^{(r n)}$, usualmente uma função cujo gráfico tem formato de "S" como em funções hiperbólicas, sigmoides, tangentes, ou similares. Neste trabalho, a função logística é adotada:

$$
f_{a}^{(r n)}\left(x^{(r n)}\right)=\frac{1}{1+e^{-\lambda^{(r n)} x^{(r n)}}}
$$

em que $\lambda^{(r n)}$ é um parâmetro de declividade, que é fixado em $\lambda^{(r n)}=1$. A partir dessas preliminares, é possível definir o metamodelo de RNA para uma rede com 3 camadas, contendo $M$ neurônios na primeira cama, $h^{(r n)}$ na camada intermediária, e um na última camada:

$$
\tilde{\mathcal{M}}^{(r n)}(\boldsymbol{x})=\sum_{j=1}^{h} w_{j 13}^{(r n)} f_{a}\left(a_{j 2}^{(r n)}\right) .
$$

A capacidade de reconhecimento de padrões de uma rede neural artificial, e portanto a eficácia do metamodelo, depende não só das características de cada neurônio individual, mas é muito influenciada pela arquitetura da rede. A arquitetura consiste na disposição e no número de neurônios, incluindo a quantidade de camadas da rede, o número de neurônios em cada camada e as regras de comunicação entre diferentes camadas. Mais uma vez, inúmeras propostas de arquitetura existem na literatura. Neste trabalho, são adotadas as chamadas redes feed-forward, significando que os neurônios de uma camada enviam sua informação de saída apenas para (todos) os neurônios da camada imediatamente posterior. A saída do neurônio da última camada é a própria resposta do metamodelo. A Figura 9 ilustra o tipo de rede neural utilizado. Os parâmetros de uma rede neural são os pesos característicos em cada conexão entre dois neurônios $w_{i n k}^{(r n)}$ e os fatores de bias $b_{n k}^{(r n)}$ de cada neurônio. Na literatura sobre RNA, o processo de se definir estes parâmetros de modo que o metamodelo $\tilde{\mathcal{M}}^{r n}$ simule adequadamente o modelo estudado $\mathcal{M}$ é denominado treinamento. Este processo usualmente é realizado separando-se o projeto de experimento em dois conjuntos: um conjunto de treinamento e um conjunto de verificação, utilizado para testar a precisão do metamodelo conforme o treinamento é realizado. Diversos algoritmos 


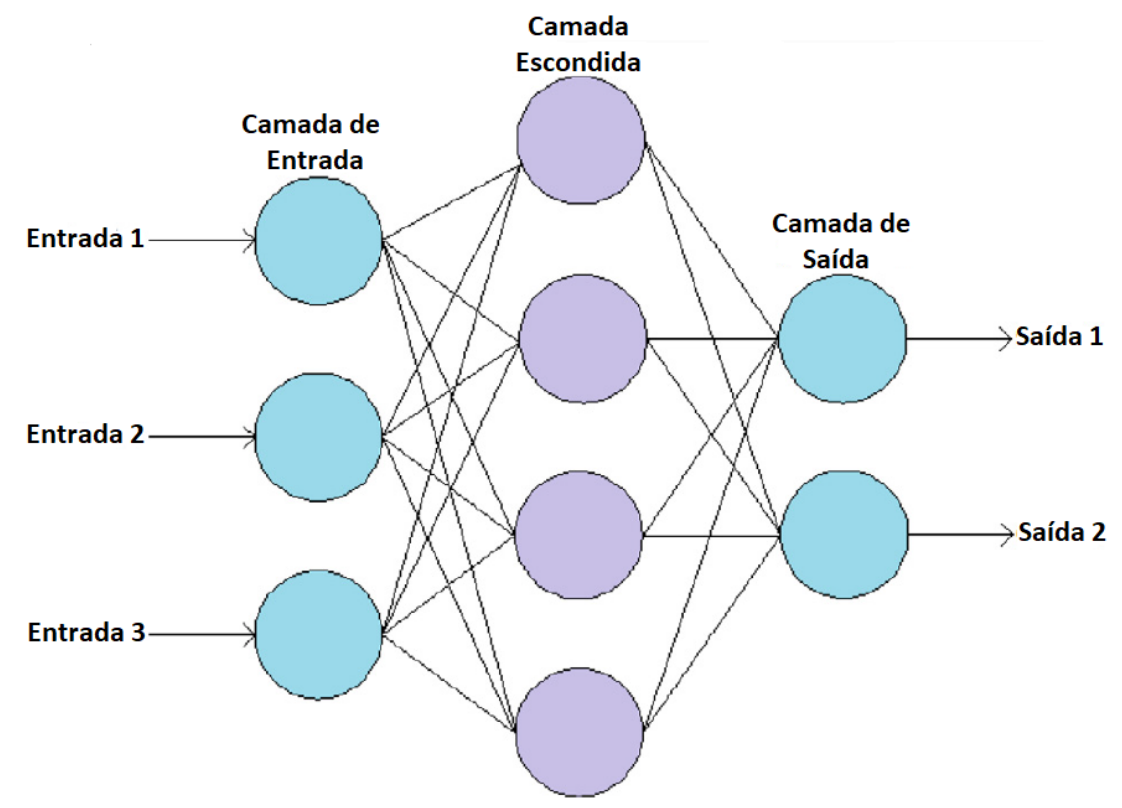

Figura 9: Arquitetura de uma rede neural, adaptada de (KROETZ; TESSARI; BECK, 2017).

de treinamento foram propostos na literatura. Neste trabalho, o treinamento é realizado por meio do algoritmo de Levenberg-Marquardt, apresentado por Marquardt (1963). Uma revisão abrangente envolvendo detalhes sobre este e outros algoritmos de treinamento é apresentada em Haykin et al. (2009). Por fim, outra decisão que influencia no desempenho do metamodelo é o valor inicial de seus parâmetros. É comum que todos os pesos sejam iniciados em um valor arbitrário, ou que suas inicializações sejam simplesmente aleatórias. Neste trabalho, a abordagem de Nguyen e Widrow (1990) é utilizada para inicializar os pesos.

\subsubsection{Expansões em polinômios de caos}

Expansões em polinômios de caos (PCE) vêm sendo usadas desde a década de 1990 na solução de problemas estruturais, no chamado método dos elementos finitos estocásticos. Foi apenas nos anos 2000 que as expansões passaram a ser encaradas como metamodelos no contexto da confiabilidade estrutural. Uma ampla revisão da literatura sobre o tema pode ser encontrada em Panayirci e Schuëller (2011). Nesta seção, por uma questão de simplicidade, as variáveis aleatórias de entrada serão consideradas independentes.

A principal ideia subjacente às expansões em polinômios de caos é a de que a resposta do modelo a ser aproximado é considerada também uma variável aleatória, pertencente ao espaço das variáveis aleatórias com variância finita. Sendo assim, a resposta pode ser representada por meio de uma base desse espaço:

$$
\tilde{\mathcal{M}}^{(p c)}(\boldsymbol{x})=\mathcal{Y}^{p c}(\boldsymbol{x})=\sum_{\boldsymbol{\alpha}} a_{\boldsymbol{\alpha}}^{p c} \boldsymbol{\psi}_{\boldsymbol{\alpha}}^{p c}(\boldsymbol{x})
$$


em que $\boldsymbol{\psi}_{\boldsymbol{\alpha}}^{p c}$ são os polinômios multivariados que compõem a base. Em geral, considera-se polinômios que são ortogonais com relação às funções de densidade $f_{\boldsymbol{X}}(\boldsymbol{x})$, ou seja:

$$
E\left[\boldsymbol{\psi}_{\eta}^{p c}(\boldsymbol{X}), \boldsymbol{\psi}_{\zeta}^{p c}(\boldsymbol{X})\right]=\delta_{\eta \zeta}
$$

sendo que $\delta_{\eta \zeta}=1$ se $\eta=\zeta$, e 0 caso contrário. As coordenadas $a_{\alpha}^{p c}$ são coeficientes a serem determinados. Na notação adotada, $\boldsymbol{\alpha}=\left[\alpha_{1}, \alpha_{2}, \ldots, \ldots, \alpha_{M}\right]$ sendo cada $\alpha_{i}$ o grau do i-ésimo polinômio unidimensional que compõe o produto $\psi_{\alpha}=\left(\psi_{1}^{\alpha_{1}} \psi_{2}^{\alpha_{2}}, \ldots, \psi_{M}^{\alpha_{M}}\right)$. Algumas famílias de polinômios são conhecidas por apresentarem ortogonalidade com relação a determinadas funções densidade de probabilidade, como os polinômios de Hermite probabilísticos que são ortogonais com relação à FDP normal padrão. Sendo assim, as variáveis aleatórias de entrada do problema podem ser transformadas para o espaço normal padrão, de maneira que o vetor $\boldsymbol{X}$ seja representado pelo vetor normal padrão $\boldsymbol{\Xi}=\left[\xi_{1}, \xi_{2}, \ldots, \xi_{M}\right]^{T}$. Pode-se então utilizar polinômios de Hermite para a composição da base ortogonal. Como a expansão completa pressupõe um número infinito de termos, para que possa ser representada computacionalmente é necessário truncá-la. Desse modo, costuma-se adotar uma série com grau máximo multi-índice $p^{p c}$. Assim, para $p=\sum_{i=1}^{M} \alpha_{i}$ apenas os polinômios com $p \leq p^{p c}$ são considerados. A capacidade de representação de uma expansão em polinômios de caos está fortemente relacionada ao seu grau de truncamento $p^{p c}$, porém a complexidade do metamodelo cresce rapidamente com o incremento do grau. Expansões de grau baixo dificilmente são capazes de representar modelos complexos, porém expansões de grau muito alto podem levar a um sobreajuste (overfitting), e assim, a resultados também insatisfatórios (GOMES; BECK; HAUKAAS, 2013). Uma base representativa para a resposta do modelo estudado pode ser obtida pela tensorização das expansões truncadas de cada variável de entrada que compõe $\boldsymbol{X}$ (SOIZE; GHANEM, 2004). Segundo esta regra, o número de funções $P^{p c}$ na base da resposta, e, portanto, o número de termos do metamodelo, é dado em função do número de variáveis de entrada $M$ e do grau máximo multi-índice adotado:

$$
P^{p c}=\frac{\left(M+p^{p c}\right) !}{M ! p^{p c !}} .
$$

Um procedimento prático para a construção desse tipo de base é apresentado em Sudret, Berveiller e Lemaire (2006), e explicado com mais detalhes em Kroetz (2015). Os coeficientes $a_{\boldsymbol{\alpha}}^{p c}$ podem ser obtidos de forma não intrusiva por meio de uma regressão com mínimos quadrados. Para que isso seja possível, o número de pontos de suporte $N^{\text {sup }}$, que define a dimensão do vetor $\mathcal{Y}=\left\{\mathcal{Y}^{(i)}=\mathcal{M}\left(\boldsymbol{x}^{(i)}\right)\right\}, i=1, \ldots, N^{\text {sup }}$ deve ser no mínimo $P^{p c}$.

$$
\boldsymbol{a}^{p c}=\boldsymbol{\Psi}^{\boldsymbol{T}} \boldsymbol{\Psi}^{-1} \boldsymbol{\Psi}^{T} \mathcal{Y}
$$

sendo $\boldsymbol{a}^{p c}$ o vetor que reúne os coeficientes $a_{\boldsymbol{\alpha}}^{p c}$ e $\boldsymbol{\Psi}$ é a matriz de dados definida por:

$$
\Psi_{i j}=\psi_{\alpha_{j}}\left(\boldsymbol{x}_{i}^{\text {sup }}\right)
$$


em que $i=1,2, \ldots, N^{\text {sup }}$ e $j=1,2, \ldots, p^{p c}$, e $\boldsymbol{x}_{i}^{\text {sup }}$ é o i-ésimo ponto de suporte. Como as funções da base são linearmente independentes, $\boldsymbol{\Psi}$ deve ser inversível. Ainda assim, a natureza aleatória dos conjuntos de dados advindos de um problema de confiabilidade estrutural pode implicar em uma configuração dos dados que se aproxime da dependência linear, resultando em matrizes mal condicionadas. Ainda, a depender da estratégia de seleção dos pontos que compõem o DOE, teoricamente um ponto poderia ser selecionado duas vezes, gerando assim uma matriz não inversível. Nestes casos, pode-se ainda recorrer à regularização da matriz (KAKADE; SHALEV-SHWARTZ; TEWARI, 2012), à utilização de matrizes pseudo-inversas, ou simplesmente à uma nova solução a partir de um novo DOE. Uma vez que as funções da base estejam definidas e os coeficientes estejam determinados, a expansão pode ser utilizada diretamente como um metamodelo, por meio da Equação 4.5 .

\subsubsection{Krigagem}

Krigagem (SANTNER; WILLIAMS; NOTZ, 2003), também conhecida como regressão por processos gaussianos (RASMUSSEN; WILLIAMS, 2006), é um metamodelo que considera que o modelo computacional de interesse pode ser aproximado por meio da realização de um processo estocástico gaussiano subjacente:

$$
\mathcal{M}^{k r i g}(\boldsymbol{x})=\sum_{j=1}^{p} \beta_{j}^{k r i g} f_{j}^{k r i g}(\boldsymbol{x})+Z(\boldsymbol{x}),
$$

em que o primeiro termo é uma média determinística denominada tendência (trend), e o segundo termo é um processo gaussiano de média constante e nula. A tendência pode assumir várias formas, a depender do tipo de Krigagem considerada. O caso mais geral, e considerado neste capítulo, é a Krigagem universal, na qual a tendência é composta por uma combinação linear de $p$ pesos $\boldsymbol{\beta}^{k r i g}=\left\{\beta_{j}^{k r i g}, j=1, \ldots, p\right\}$ e funções de regressão $\boldsymbol{f}^{k r i g}=\left\{f_{j}^{k r i g}, j=1, \ldots, p\right\}$. Muitos trabalhos utilizam a chamada Krigagem ordinária, caso particular em que $p=1$ e $f^{k r i g}(\boldsymbol{x})=1$. O processo gaussiano $Z(\boldsymbol{x})$ é definido por sua função de autocovariância $\operatorname{Cov}\left[Z(\boldsymbol{x}), Z\left(\boldsymbol{x}^{\prime}\right)\right]=\sigma^{2} R\left(\boldsymbol{x}, \boldsymbol{x}^{\prime} ; \boldsymbol{\theta}\right)$ em que $\sigma^{2}$ é a variância do processo e $R$ sua função de autocorrelação com hiperparâmetros $\boldsymbol{\theta}$.

O treinamento de um metamodelo de Krigagem se dá a partir das informações dos pontos do DOE: $\mathcal{X}=\left\{\boldsymbol{\chi}^{(i)}, i=1, \ldots, n\right\}$ cujas avaliações são $\mathcal{Y}=\left\{\mathcal{Y}^{(i)}=\mathcal{M}\left(\boldsymbol{\chi}^{(i)}\right), i=\right.$ $1, \ldots, n\}$. A partir destes dados, pode ser feita uma estimativa geral dos pesos utilizando-se o método dos mínimos quadrados:

$$
\widehat{\boldsymbol{\beta}}^{k r i g}(\boldsymbol{\theta})=\left(\boldsymbol{F}^{T} \boldsymbol{R}^{-1} \boldsymbol{F}\right)^{-1} \boldsymbol{F}^{T} \boldsymbol{R}^{-1} \mathcal{Y},
$$

bem como pode ser definido um estimador para a variância:

$$
\widehat{\sigma}^{2}(\boldsymbol{\theta})=\frac{1}{N}\left(\mathcal{Y}-\boldsymbol{F} \widehat{\boldsymbol{\beta}}^{k r i g}\right)^{T} \boldsymbol{R}^{-1}\left(\mathcal{Y}-\boldsymbol{F} \widehat{\boldsymbol{\beta}}^{k r i g}\right) .
$$


Nas Equações, 4.11 e 4.12, $\boldsymbol{F}$ é uma matriz que reúne as funções de regressão avaliadas nos pontos do DOE, i.e. $F_{i j}=f_{j}^{k r i g}\left(\chi^{(i)}\right)$ e $\boldsymbol{R}$ é a matriz de autocorrelação definida de modo que $R_{i j}=R\left(\chi^{(i)}, \chi^{(j)} ; \boldsymbol{\theta}\right)$.

Uma vez que o modelo estiver definido, a previsão para qualquer novo ponto $\boldsymbol{x}$ segue uma distribuição normal, i.e. $\widetilde{\mathcal{M}}^{k r i g} \sim \mathcal{N}\left(\mu_{\widetilde{\mathcal{M}}}(\boldsymbol{x}), \sigma_{\widetilde{\mathcal{M}}}^{2}(\boldsymbol{x})\right)$ em que a média e a variância são, respectivamente:

$$
\begin{aligned}
\mu_{\widetilde{\mathcal{M}}}(\boldsymbol{x}) & =f^{T}(\boldsymbol{x}) \boldsymbol{\beta}+\boldsymbol{r}^{T}(\boldsymbol{x}) \boldsymbol{R}^{-1}\left(\boldsymbol{y}-\boldsymbol{F}^{T} \boldsymbol{\beta}\right), \\
\sigma_{\widetilde{\mathcal{M}}}^{2}(\boldsymbol{x}) & =\sigma^{2}\left(1-\boldsymbol{r}^{T}(\boldsymbol{x}) \boldsymbol{R}^{-1} \boldsymbol{r}(x)+\boldsymbol{u}^{T}(\boldsymbol{x})\left(\boldsymbol{F}^{T} \boldsymbol{R}^{-1} \boldsymbol{F}\right)^{-1} \boldsymbol{u}(\boldsymbol{x})\right), \\
\operatorname{com} \boldsymbol{r}(\boldsymbol{x}) & =\left[R\left(\boldsymbol{x}, \boldsymbol{\chi}^{(1)}\right), \ldots, R\left(\boldsymbol{x}, \boldsymbol{\chi}^{(n)}\right)\right] \text { e } \boldsymbol{u}(\boldsymbol{x})=\boldsymbol{F}^{T} \boldsymbol{R}^{-1} \boldsymbol{r}(\boldsymbol{x})-\boldsymbol{f}(\boldsymbol{x}) .
\end{aligned}
$$

Assim, resta ainda a definição dos hiperparâmetros da função de autocorrelação. Diversos métodos foram propostos para a seleção de um conjunto adequado de parâmetros, destacando-se a validação cruzada ("cross-validation") e o estimativa de máxima verossimilhança ("maximum likelihood estimation") (BACHOC, 2013). Neste trabalho, será considerada esta última abordagem, que basicamente, consiste na solução do seguinte problema de otimização (DUBOURG, 2011):

$$
\widehat{\boldsymbol{\theta}}=\arg \min _{\boldsymbol{\theta} \in n_{\theta}} \mathcal{L}(\boldsymbol{\theta})=\widehat{\sigma}^{2}(\boldsymbol{\theta})|\boldsymbol{R}(\boldsymbol{\theta})|^{\frac{1}{n}},
$$

em que $\mathcal{L}$ é a chamada função de possibilidade reduzida "reduced likelihood function", $n_{\theta}$ é o número de hiperparâmetros a serem calibrados, e |.| denota o operador determinante.

Um dos aspectos mais importantes de um metamodelo de Krigagem é a sua variância (Equação. 4.13b), que pode ser interpretada como uma medida local da precisão do metamodelo. Essa informação pode ser utilizada para atualizações do metamodelo por meio da adição de novos pontos, refinando-se as regiões de maior interesse. Tais abordagens serão exploradas no capítulo 8.

\subsection{Aplicações}

Nesta seção, as técnicas apresentadas são comparadas em dois exemplos numéricos. Todas as redes neurais adotadas são do tipo feed forward, com apenas uma camada escondida (conforme Hornik, Stinchcombe e White (1990) mostraram ser suficiente). A primeira camada conta com um neurônio para cada variável aleatória do problema estudado, e a camada de saída, com um neurônio para cada resposta do modelo. O número de neurônios da camada intermediária é definido como o dobro do número de neurônios da primeira camada mais um, regra conhecida como teorema de Kolmogorov-Nielsen (LENI; FOUGEROLLE; TRUCHETET, 2010). A função de ativação logística é adotada para os neurônios da camada intermediária, e funções lineares são utilizadas para compor os 
neurônios das demais camadas. O número de pontos de suporte relatados nos exemplos é o número total, do qual $20 \%$ dos pontos são usados como pontos de validação. O algoritmo de Levenberg-Marquardt é utilizado no treinamento das redes (mais detalhes sobre o algoritmo podem ser encontrados em Gomes e Beck (2013)). Nos metamodelos de Krigagem, a função de correlação adotada é sempre a isotrópica gaussiana, e a Krigagem é sempre universal, com tendência definida por meio de uma superfície de resposta composta por polinômios de até segunda ordem, sem termos cruzados. Os hiperparâmetros são definidos por meio do método da máxima verossimilhança. Para todos os metamodelos, o mesmo projeto de experimento é utilizado, obtido a partir de uma amostragem por hipercubo latino. Assim, os diferentes metamodelos são comparados para números crescentes de pontos dos mesmos projetos de experimento, sendo possível observar seu comportamento para diversos $N^{\text {sup }}$. Para os casos em que a amostragem resultou em matrizes mal condicionadas, simplesmente adicionou-se mais um ponto aleatório ao projeto de experimento, o que resolveu o problema. Como as variáveis aleatórias de entrada representam grandezas de magnitudes diferentes, adotou-se uma estratégia para adimensionalizar as variáveis aleatórias: todas as VAs a compor o projeto de experimento foram dividas pela própria média. Caso a média fosse nula, ao invés disso, elas eram divididas pelo próprio desvio padrão. Esta simples abordagem foi suficiente para evitar problemas numéricos ao se montar matrizes com variáveis de ordens de grandeza muito diferentes. Simulações de Monte Carlo Bruto foram utilizadas para se calcular as probabilidades de falha, de modo que a precisão da solução do problema fosse garantida, sendo possível aferir o desempenho dos metamodelos. Adicionalmente, todos os problemas foram resolvidos também utilizando-se SMC bruto sobre o modelo original $\mathcal{M}$, obtendo-se assim um valor de referência para as análises.

\subsubsection{Treliça plana}

Uma treliça bidimensional composta por 23 barras e 13 nós é considerada, conforme ilustrado na Figura 10. Esta estrutura foi estudada por Blatman, Sudret e Berveiller (2007).

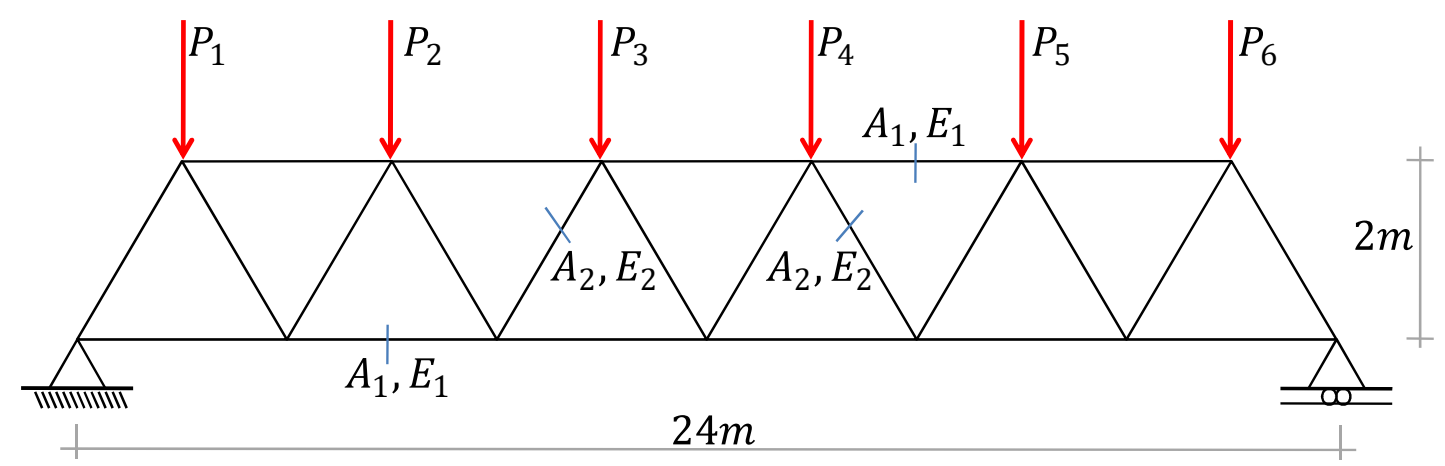

Figura 10: Treliça plana de 23 barras.

A treliça é sujeita a 6 cargas aleatórias verticais em seus nós superiores. Os parâmetros 
aleatórios de entrada deste problema são descritos na Tabela 2. A equação de estado limite é definida implicitamente por um modelo de elementos finitos, e é escrita em termos do deslocamento vertical do nó posicionado na metade do seu vão. Considera-se um deslocamento máximo de 0.1 m neste ponto:

$$
g(\mathbf{X})=0.1-\left|V_{1}(\mathbf{X})\right|
$$

Metamodelos são construídos utilizando-se as três técnicas abordadas na seção 4.4. A solução de referência é obtida por meio da realização de $10^{4}$ simulações de Monte Carlo bruto, e comparada com o mesmo número de simulações considerando-se os metamodelos. A expansão em polinômios de caos adotada é de grau multi-índice máximo 3, conforme adotado pelos autores originais do problema. Adota-se como índice de confiabilidade de referência o valor obtido em Blatman, Sudret e Berveiller (2007), $\beta_{\text {ref }}=1.71$. Os índices de confiabilidade obtidos com as três técnicas de metamodelagem, variando-se o número de pontos de suporte, são mostrados na Figura 11. A Tabela 3 apresenta uma comparação entre os tempos de processamento para as diferentes técnicas com diferentes tamanhos de DOE. Os tempos de computação apresentadas são compostos pelo tempo total da análise, ou seja, pelo tempo de avaliação do modelo original nos pontos de suporte, tempo da construção do metamodelo e ainda o tempo da avaliação da probabilidade de falha por simulação bruta de Monte Carlo sobre o metamodelo.

Tabela 2: Variáveis aleatórias do problema da treliça plana

\begin{tabular}{llll}
\hline Variável & Distribuição & Média & DP \\
\hline$E_{1}(\mathrm{GPa})$ & Lognormal & 210 & 21 \\
$E_{2}(\mathrm{GPa})$ & Lognormal & 210 & 21 \\
$A_{1}\left(m^{2}\right)$ & Lognormal & $2 \times 10^{-3}$ & $2 \times 10^{-4}$ \\
$A_{2}\left(m^{2}\right)$ & Lognormal & $1 \times 10^{-3}$ & $1 \times 10^{-4}$ \\
$P_{1}-P_{6}(k N)$ & Gumbel & 50 & 7,5 \\
\hline
\end{tabular}

A partir da Figura 11, pode-se notar que todos os metamodelos passam a fornecer resultados precisos a partir dos 300 pontos de suporte, se aproximando do valor de referência conforme o número de pontos de suporte aumenta. Quanto aos tempos de processamento, fica evidente o ganho de eficiência na adoção de qualquer um dos três metamodelos. A expansão em polinômios de caos teve um desempenho ligeiramente melhor que as demais técnicas, mas sofre da desvantagem de poder ser definida apenas a partir de um número relativamente alto de pontos de suporte. Os metamodelos de RNA e Krigagem apresentam resultados bastante precisos a partir dos 50 pontos de suporte. As redes neurais artificiais ganharam precisão com maior velocidade, porém seu treinamento foi o que apresentou mais problemas, tendo sido necessário adicionar pontos ao projeto de experimento algumas vezes. Além disso, em todos os casos, foi o metamodelo cuja análise levou mais tempo. 


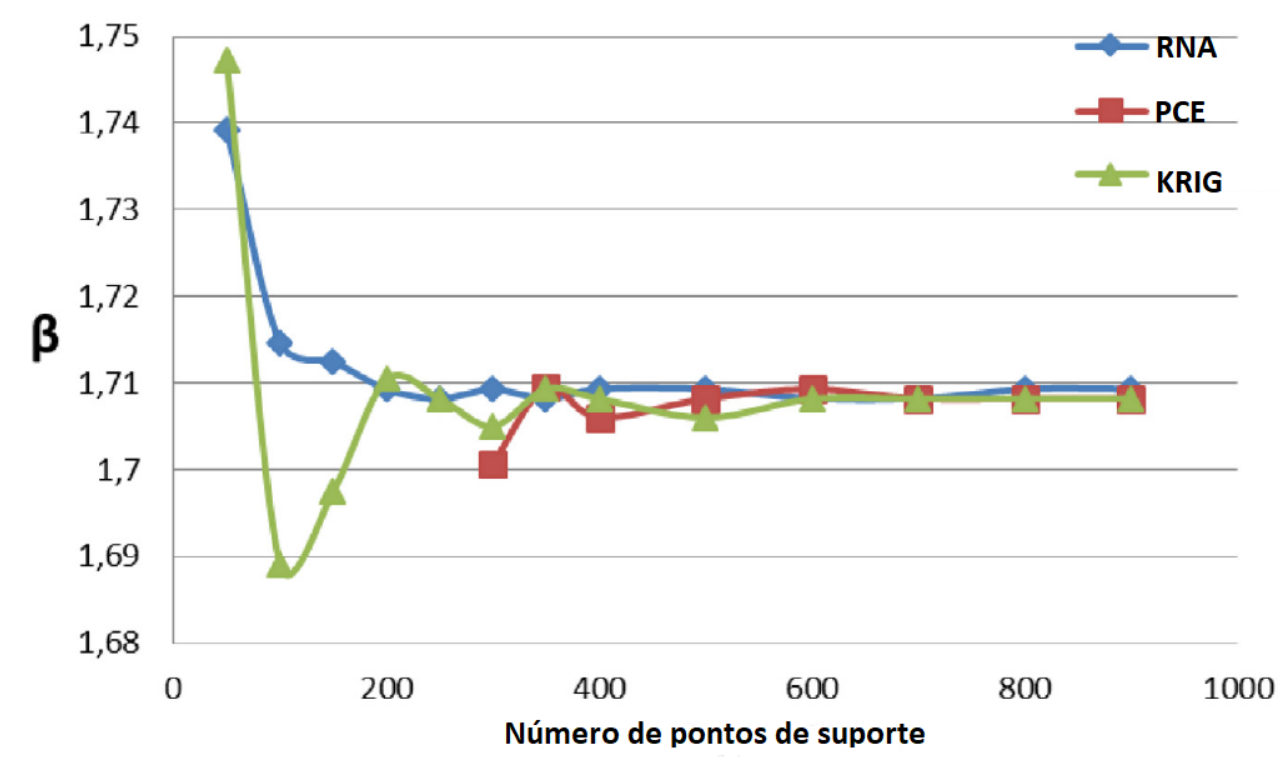

Figura 11: Índices de confiabilidade para vários projetos de experimento (Fonte:(KROETZ; TESSARI; BECK, 2017)).

Tabela 3: Tempo de computação para diferentes técnicas com diferentes projetos de experimento para o problema da treliça plana

\begin{tabular}{lll}
\hline Número de Pontos de Suporte & Técnica & Tempo(s) \\
\hline 50 (mínimo RNA e Krigagem) & RNA & 1,63 \\
& PCE & - \\
& Krigagem & 1,52 \\
\hline 286 (mínimo PCE) & RNA & 19,4 \\
& PCE & 9,3 \\
& Krigagem & 16,9 \\
\hline 600 & RNA & 28,8 \\
& PCE & 16,9 \\
& Krigagem & 24,9 \\
\hline 10000 & Referência & 191,3 \\
\hline
\end{tabular}

\subsubsection{Torre tridimensional envolvendo confiabilidade de sistema}

Torres metálicas autoportantes têm sido muito utilizadas nas últimas décadas, para transmissão de energia, suporte para antenas, turbinas eólicas e até como monumentos (e.g. Torre del Reformador na Guatemala, Torre Eiffel em Paris). Este exemplo numérico é baseado em uma torre metálica treliçada autoportante existente na cidade de Porto Velho, RO. A empresa de montagem forneceu os dados da geometria da estrutura, e a operadora responsável pela torre forneceu a posição e os pesos das antenas e de outros acessórios sustentados pela estrutura. A torre é composta por dois trechos distintos, ambos com seção transversal triangular, como ilustrado na Figura 12. O trecho inferior forma um tronco de pirâmide, com uma abertura de $5.7 \mathrm{~m}$ em sua base, e $1.5 \mathrm{~m}$ no topo. O trecho superior é reto. A torre é composta por 26 módulos, Os montantes foram executados em perfis de 


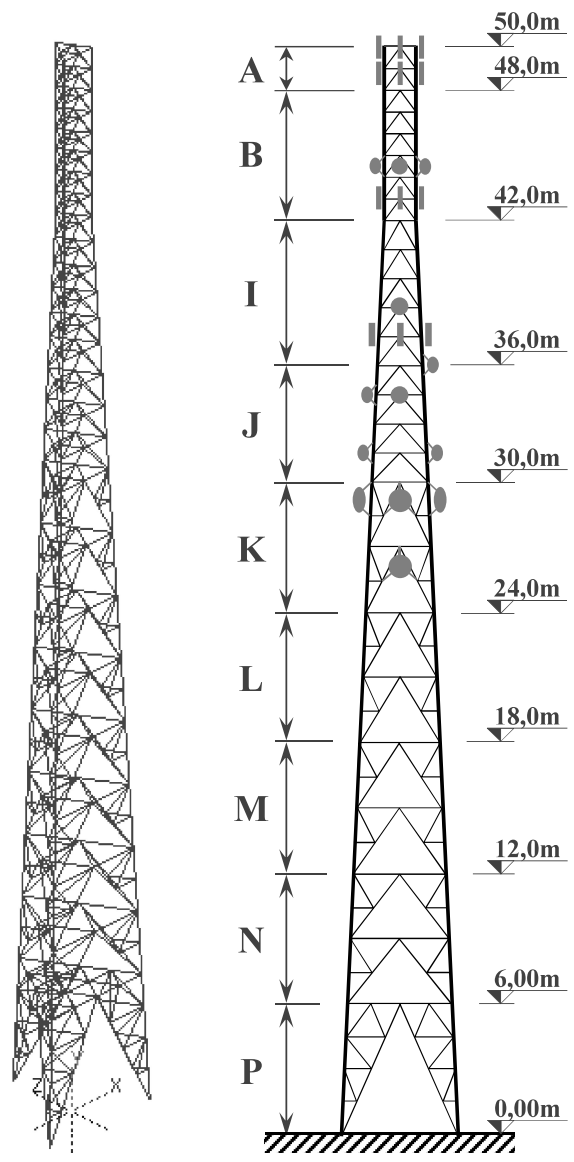

Figura 12: Representação plana e tridimensional da torre treliçada.

seção "ômega" e as diagonais e travamentos horizontais em perfis cantoneira de abas iguais, todos em aço ASTM-A36. A estrutura é sujeita a cargas de vento aleatórias. Detalhes sobre os efeitos das pressões do vento nas antenas, acessórios e membros estruturais da torre são apresentados em Tessari, Kroetz e Beck (2017).

Para representar a torre, foi adotado um modelo de elementos finitos tridimensional, com formulação baseada em posições, permitindo a consideração de não linearidades geométricas. O modelo é composto por 798 elementos de treliça. 13 seções transversais diferentes são consideradas no modelo, conforme o projeto original. O peso próprio da torre e as cargas de vento são representados por meio de forças nodais. Um esquema do modelo de elementos finitos também é mostrado na Figura 12. A companhia que opera a torre garante que as antenas estarão operacionais desde que não sofram uma inclinação excessiva, que se traduz em um deslocamento máximo admissível de $\delta_{A D M}=1.45 \mathrm{~m}$ para os nós superiores da torre. Desse modo, a equação de estado limite de serviço considerada é dada por:

$$
g_{1}(\mathbf{X})=\delta_{A D M}-\delta(\boldsymbol{X})=1.45-\delta(\boldsymbol{X})
$$

Além disso, o escoamento e a flambagem de qualquer barra de travamento é também considerada uma falha de serviço, uma vez que não implica no colapso da estrutura, mas 
diminui sua segurança. Uma falha em um dos montantes, as barras principais, é considerada a violação de um estado limite último. Neste exemplo, apenas as falhas de serviço serão consideradas, de modo a compor um sistema que descreve todas as falhas de serviço do sistema. Sendo assim, as demais equações de estado limite de serviço consideradas são dadas por:

$$
g_{i}(\mathbf{X})=\left\{\begin{array}{l}
f_{y} A-N_{b a r}=0 \quad \text { se } N_{b a r}>0 \\
\frac{\pi^{2} E I_{\min }}{L_{e f}^{2}}+N_{b a r}=0 \quad \text { se } N_{b a r} \leq 0
\end{array}\right.
$$

sendo $E$ o módulo de elasticidade, $f_{y}$ a tensão de escoamento, $A$ a área da seção transversal, $I_{\text {min }}$ o menor momento de inércia da seção transversal e $L$ o comprimento efetivo de uma barra. $N_{b a r}$ é a força normal no membro de travamento em questão. As variáveis aleatórias do problema são apresentadas na Tabela 4. A equação de serviço das antenas 4.16 e as 687 equações referentes aos membros de travamento 4.17 compõem um sistema em série com 688 equações de estado limite de serviço. Um mesmo metamodelo global é utilizado neste exemplo para representar a união de todos os domínios de falha.

Tabela 4: Variáveis aleatórias do problema da torre tridimensional

\begin{tabular}{llll}
\hline Variável & Distribuição & Média & DP \\
\hline Velocidade do vento & Gumbel & 25.8557 & 0.2557 \\
Direção de incidência & Normal & 1.5707 & 0.5235 \\
Fator de peso próprio & Normal & 1.05 & 0.10 \\
Fator do módulo de elasticidade & Lognormal & 1.03 & 0.03 \\
Fator da tensão de escoamento & Lognormal & 1.10 & 0.07 \\
Fator de rajada & Normal & 1.00 & 0.125 \\
Rugosidade & Normal & 1.00 & 0.150 \\
\hline
\end{tabular}

A solução de referência é obtida por meio de uma amostra de tamanho $10^{5}$ com Monte Carlo bruto realizado sobre o modelo de elementos finitos original. O índice de confiabilidade obtido dessa forma é $\beta_{R E F}=2.6105$. Metamodelos de Krigagem, expansões em polinômios de caos e redes neurais artificiais foram construídos considerando-se diferentes projetos de experimento. A Figura 13 mostra o ganho de precisão na resposta de cada técnica conforme o número de pontos no projeto de experimento considerado aumenta.

Para as RNA, o tamanho do projeto de experimento foi aumentado até que o erro relativo de tornasse inferior a $0.5 \%$ : $\left|\beta_{R N A}-\beta_{\text {ref }}\right| / \beta_{\text {ref }}<0,5 \%$. Com apenas 100 pontos de treinamento ou teste, o resultado razoavelmente preciso de $\beta=2,8057$ foi obtido, o que representa um erro de $7.48 \%$ com relação à referência. Com 300 pontos de suporte, o erro já era de apenas $0.14 \%$, com $\beta=2.6068$. Ainda assim, apesar das RNA terem apresentado uma grande eficiência na solução do problema, observou-se que os resultados são muito sensíveis à divisão que se faz nos pontos de informação disponível entre treinamento e teste: para um DOE do mesmo tamanho, divisões ligeiramente diferentes podem comprometer bastante o resultado. A dependência torna-se menor conforme o número total de pontos 


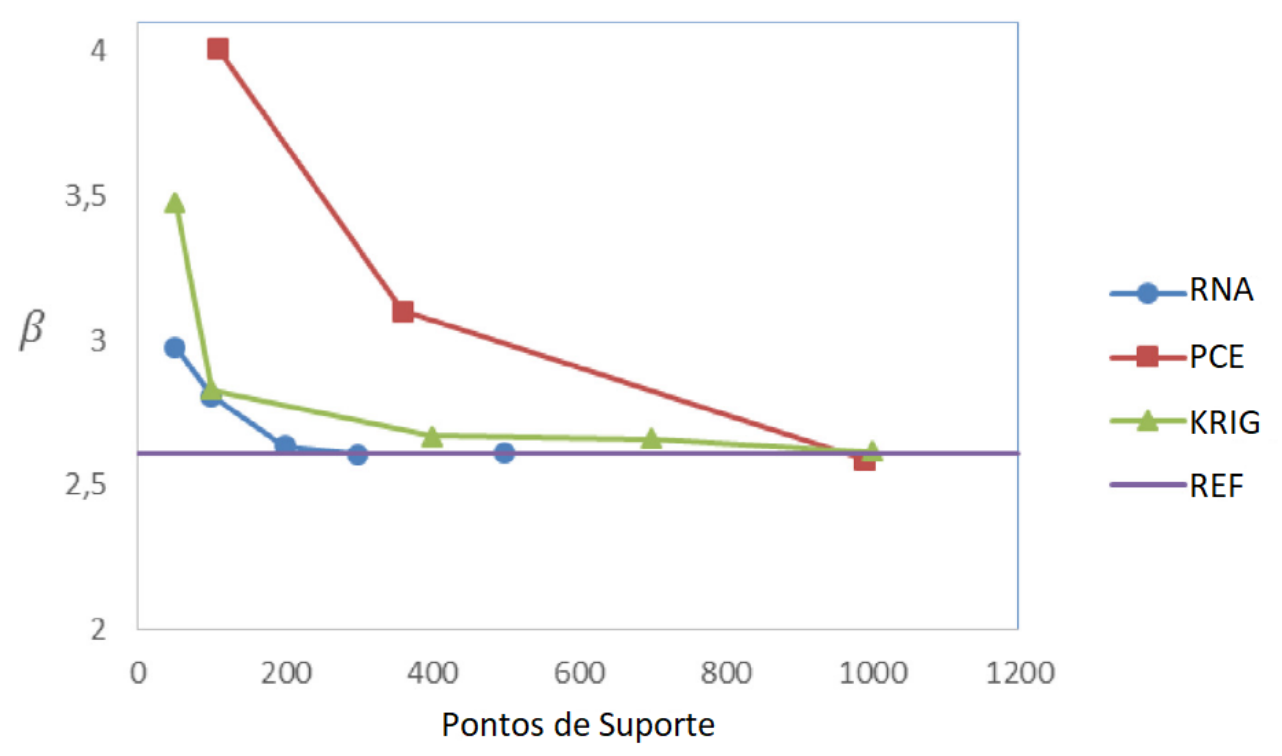

Figura 13: Índices de confiabilidade para vários projetos de experimento (Fonte:(KROETZ; TESSARI; BECK, 2017)).

aumenta, mas a necessidade de muitos pontos é contrária ao princípio da adoção de metamodelos.

Expansões em polinômios de caos de graus multi-índice máximos diferentes foram adotadas, de modo a se aproveitar bem a informação dos DOE disponíveis em cada análise. Desse modo, expansões com grau máximo entre 2 e 4 foram consideradas, utilizando-se um DOE de tamanho múltiplo do mínimo requerido, de acordo com a Equação 4.7. Essa prática é recomendada por McKay, Beckman e Conover (1979). O polinômio de segunda ordem é claramente simples demais para capturar o comportamento complexo da estrutura. O de terceira ordem, construído a partir de 360 pontos de suporte, já apresenta razoável precisão, com um erro de $18 \%$. O polinômio de quarta ordem apresenta resultados precisos, com erros menores que $1 \%$ e 990 pontos de suporte.

Os metamodelos de Krigagem apresentaram melhoria monotônica na precisão, com erros de aproximadamente $3 \%$ quando construídos a partir de 400 pontos de suporte, e erros menores que $0.1 \%$ para o máximo de 1000 pontos de suporte. Apesar do tempo de processamento maior para os casos em que Krigagem foi utilizada, essa abordagem se mostrou a mais robusta e menos sensível à composição do DOE por LHS. Além disso, a definição dos hiperparâmetros foi feita com o auxílio de um algoritmo não muito eficiente de busca baseado em gradientes calculados como diferenças finitas, responsável pela maior parte do tempo da análise. A relevância de uma boa seleção dos hiperparâmetros do problema também foi investigada neste exemplo. A partir de um projeto de experimento com 1000 pontos, o problema foi resolvido com Krigagem sem a etapa da otimização dos hiperparâmetros, mas assumindo-se para eles diversos valores arbitrários. A precisão da previsão foi então plotada no gráfico da Figura 14 para 50 valores diferentes dos 
hiperparâmetros $\boldsymbol{\theta}$. Como a função de correlação adotada é isotrópica, os valores podem ser representados no gráfico por um escalar. Na figura, são ilustrados também os valores assumidos pela Equação 4.14 para cada valor considerado para os hiperparâmetros, ficando ilustrada assim a importância de uma minimização adequada para a função de possibilidade reduzida quando esta abordagem é escolhida para a determinação dos valores dos hiperparâmetros.

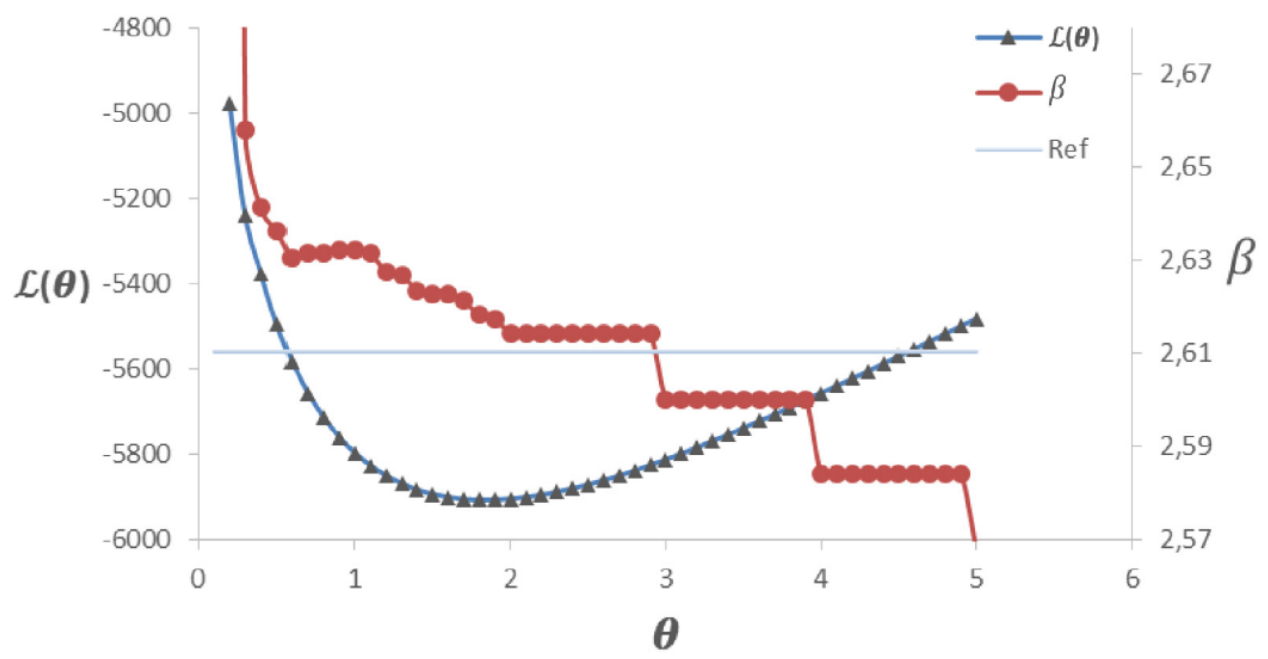

Figura 14: Variação do parâmetro $\theta$ e sua influência na precisão do metamodelo de Krigagem (Fonte:(KROETZ; TESSARI; BECK, 2017)).

Tabela 5: Tempo de computação para diferentes técnicas com diferentes projetos de experimento para o problema da torre tridimensional

\begin{tabular}{lll}
\hline Número de Pontos de Suporte & Técnica & Tempo \\
\hline 100 & RNA & 1 min $01 \mathrm{~s}$ \\
& PCE & - \\
& Krigagem & $54 \mathrm{~s}$ \\
\hline 300 & RNA & 1 min $32 \mathrm{~s}$ \\
& PCE & 1 min $31 \mathrm{~s}$ \\
& Krigagem & 1 min $8 \mathrm{~s}$ \\
\hline 700 & RNA & $2 \min 40 \mathrm{~s}$ \\
& PCE & 2 min $48 \mathrm{~s}$ \\
& Krigagem & 5 min $35 \mathrm{~s}$ \\
\hline 1000 & RNA & 3 min $44 \mathrm{~s}$ \\
& PCE & 4 min $1 \mathrm{~s}$ \\
& Krigagem & 12 min $15 \mathrm{~s}$ \\
\hline $10^{5}$ & Referência & 6 h $12 \mathrm{~min}$
\end{tabular}

Os tempos de computação para cada análise realizada são mostrados na Tabela 5. Para este exemplo computacionalmente exigente, fica evidente uma grande economia de tempo oriunda da adoção de técnicas de metamodelagem. Deve-se notar também que a natureza do problema, envolvendo um complexo sistema de equações de estado limite, 
não suscita uma solução razoável via FORM, o que reforça a adoção de uma abordagem de simulação associada a metamodelagem. Neste exemplo, as RNA ganharam precisão mais rapidamente em comparação com as outras técnicas, mas também apresentaram mais problemas até ser possível sua adequada utilização. As expansões em polinômios de caos também apresentaram respostas que se aproximaram rapidamente da referência, mas tiveram alguns problemas de precisão: além de um resultado pior com relação a outras técnicas, testou-se uma PCE de quinto grau, e observou-se o fenômeno de sobreajuste. Desse modo, apesar da complexidade da etapa de seleção dos hiperparâmetros, a Krigagem apresentou o melhor desempenho quando consideradas a precisão e o potencial do metamodelo para resolver problemas de diferentes naturezas.

\subsection{Conclusões}

A partir dos exemplos estudados, foi possível observar que as três técnicas de metamodelagem levam a resultados precisos, desde que um projeto de experimento adequado seja selecionado para sua construção. Em todos os casos, foi obtida boa precisão em um tempo de processamento muito menor do que aquele referente à utilização de simulação de Monte Carlo bruto utilizando o modelo numérico original. Entre as técnicas estudadas, as expansões em polinômios de caos foram as que demandaram mais pontos de suporte para a obtenção de resultados precisos. Ainda assim, um número excessivo de pontos levou ao sobreajuste do polinômio de quinto grau no exemplo da torre, o que leva à conclusão de que, apesar dos méritos da técnica, ela não é a mais adequada para futuras utilizações em problemas de otimização na presença de incertezas. A adoção de expansões esparsas pode contornar este problema. As redes neurais artificiais apresentaram o ganho de precisão mais rápido com relação ao número de pontos de suporte adotados. Ainda assim, por diversas vezes foi necessária a adição de um ponto de suporte no DOE, e uma grande dependência entre o modo como se faz a divisão entre pontos de treinamento e de teste foi verificada. Em alguns casos, trocar apenas um ponto de conjunto implicava em um resultado não representativo. A Krigagem apresentou boa precisão, tendo como única desvantagem um maior tempo de processamento associado. Notou-se, porém, que a maior parte do tempo era gasta durante a otimização dos hiperparâmetros, o que poderia ser contornado por meio da adoção de algoritmos de otimização mais eficientes. Além disso, as informações sobre a variância do metamodelo constantes na formulação da Krigagem, que facilitam a construção de estratégias adaptativas, são uma grande vantagem desta técnica. Com base nisso, tomou-se a decisão de que as abordagens utilizando metamodelagem em problemas de otimização na presença de incertezas, apresentadas em capítulos posteriores, seriam investigadas com o auxílio da Krigagem. 



\section{CALIBRAÇÃO DE NORMAS TÉCNICAS BASEADA EM RBDO}

Este capítulo é baseado no artigo:

\section{Wagner C. Santiago, Henrique M. Kroetz e André T. Beck (2018)}

Uma Primeira Tentativa de Calibração Baseada em Confiabilidade das Normas Brasileiras Usadas em Projetos de Estruturas de Concreto. - 60 Congresso Brasileiro do Concreto, 2018, Foz do Iguaçu - Anais do 60 Congresso Brasileiro do Concreto. São Paulo, SP.

Uma versão mais completa do artigo foi submetida e aceita na Revista IBRACON de Estruturas e Materiais, mas ainda não publicada.

\subsection{Principais contribuições do autor}

- Revisão da literatura sobre otimização na presença de incertezas e suas aplicações à calibração de coeficientes parciais de segurança.

- Programação de um módulo de calibração de normas técnicas no software StRAnD, utilizado pelo primeiro autor do referido artigo para a calibração dos coeficientes parciais de segurança de diferentes normas técnicas brasileiras.

\subsection{Introdução}

A tarefa mais importante dos projetistas de estruturas é a a garantia de que elas sejam seguras. Apesar do considerável desenvolvimento da área de confiabilidade estrutural, muito pouco dos recentes avanços é aplicado no dimensionamento de estruturas na prática. De fato, as abordagens que permitem a determinação de probabilidades de falha apresentam um grau de sofisticação que, até o presente, inviabiliza sua aplicação. O projeto de estruturas é, em geral, orientado por normas técnicas nas quais constam diversas verificações de segurança que a estrutura projetada deve atender para ser considerada segura. O método adotado na maioria das normas técnicas atualmente é o método dos estados limites, no qual coeficientes parciais de segurança são aplicados para a minoração da resistência e majoração das cargas atuantes sobre as estruturas (em oposição à adoção de um único coeficiente global de segurança, admitido em métodos mais antigos). Desse modo, cria-se uma margem de segurança com relação às principais fontes de incerteza que podem afetar o comportamento da estrutura projetada. Quando as normas técnicas americanas migraram para o formato de projeto baseado em estados limites, houve a preocupação de fazer uma calibração baseada 
em confiabilidade estrutural dos coeficientes de segurança (NOWAK; NOWAK; SZERSZEN, 2003; SZERSZEN; NOWAK, 2003; NOWAK; RAKOCZY; SZELIGA, 2011). Já nas normas brasileiras, os valores dos coeficientes foram adaptados dos códigos americanos e europeus, não tendo sido devidamente calibrados (JUNIOR, 2009). Sendo assim, se faz importante uma calibração baseada nos dados sobre materiais e solicitações concernentes à realidade brasileira.

Este capítulo apresenta um estudo preliminar que considera uma extensa coleta de dados brasileiros para compor os modelos de confiabilidade a serem considerados na calibração dos coeficientes. É apresentada também uma metodologia de calibração baseada em RBDO, visando a determinação de um conjunto de coeficientes parciais de segurança. A otimização é realizada de maneira que os índices de confiabilidade de estruturas projetadas seguindo as normas NBR 8681 (ABNT, 2003) e NBR 6118 (ABNT, 2014) se aproximem de um índice de confiabilidade alvo adotado $\beta_{T}$. Desse modo, espera-se obter coeficientes parciais de segurança mais adequados à realidade brasileira, que podem ser considerados nas próximas revisões normativas. Neste trabalho, restringe-se a análise à calibração dos coeficientes parciais de segurança para o projeto de vigas de concreto armado.

A coleta e o tratamento dos dados foram realizados pelo primeiro autor do artigo em que este capítulo se baseia, cabendo ao autor desta tese um estudo sobre calibração de normas baseada em confiabilidade e a implementação da ferramenta utilizada para a obtenção dos coeficientes parciais de segurança.

\subsubsection{O software StRAnD}

O procedimento de calibração adotado neste capítulo foi programado de modo genérico no software estrutural StRAnD, para que seja uma ferramenta para a calibração de outras normas técnicas no futuro. Trata-se do software de confiabilidade desenvolvido no departamento de engenharia de estruturas (SET) da Universidade de São Paulo (USP), que vem sendo constantemente aprimorado por meio da contribuição de alunos de pós graduação do departamento. Alguns recursos do programa são comparáveis aos recursos dos melhores softwares de confiabilidade do mundo. O autor desta tese é um dos contribuidores do StRAnD, tendo programado o módulo de metamodelagem do programa, bem como o novo módulo de otimização estrutural na presença de incertezas, juntamente com um colega.

O módulo de calibração do StRAnD está operacional, permitindo a análise paramétrica de milhares de equações de estado limite em uma mesma execução do programa.

\subsection{Dados sobre variáveis de resistência e solicitação}

Conforme visto na seção 2.1.1, a primeira etapa de um problema de quantificação de incertezas é a definição dos modelos estatísticos a serem utilizados no estudo. Como o 
objeto de estudo deste capítulo é o dimensionamento de estruturas de concreto armado, diversas empresas da área foram consultadas. Várias delas colaboraram com este trabalho, fornecendo coleções de dados de ensaios que realizaram, auxiliando na definição das variáveis aleatórias que serão consideradas no processo de calibração. Uma VA resistência à compressão do concreto $f_{c}$ foi construída a partir de resultados de ensaios de resistência à compressão axial aos 28 dias de idade, realizados em mais de 39000 corpos de prova cilíndricos moldados in loco, em obras das cinco regiões do Brasil, entre os anos de 2011 e 2016. Cinco classes de resistência de concreto foram consideradas, conforme consta na Tabela 6. Estes resultados são discutidos em Santiago e Beck (2017). A VA que representa a resistência ao escoamento de barras de aço $f_{y}$ foi construída com base em resultados de ensaios de tração realizados em aproximadamente 9000 amostras de aço CA-50 de diferentes diâmetros, oriundas de diversos lotes produzidos no Brasil em 2016. São consideradas ainda as variáveis "base da seção transversal da viga" $b^{\text {viga }}$ e "altura útil da peça" $h^{\text {viga }}$. Devido à escassez de dados experimentais sobre realizações destas variáveis, elas foram construídas a partir das recomendações do Joint Committee on Structural Safety (2002) (JCSS). Por fim, uma variável "erro de modelo" $E_{M}^{R}$ foi definida para representar a possibilidade de haver erro no modelo de resistência. Esta variável segue os parâmetros indicados em Nowak, Rakoczy e Szeliga (2011), uma vez que os modelos de cálculo para dimensionamento de vigas de concreto armado são essencialmente os mesmos no Brasil e nos Estados Unidos. Essa variável representa as discrepâncias observadas entre as previsões nos modelos adotados para a resistência dos elementos estruturais e os resultados observados em ensaios.

Variáveis aleatórias de solicitação também foram construídas de forma criteriosa para esta aplicação. Para a determinação do peso próprio das vigas foi proposto um edifício residencial genérico, com características de projeto arquitetônico, acabamentos, materiais de revestimento, entre outras, comuns aos prédios mais comumente construídos no país. Este projeto foi enviado a vários projetistas de estruturas de concreto armado, que determinaram os pesos próprios das estruturas. Os carregamentos assim obtidos foram utilizados para a construção da variável "peso próprio" $g$. Duas variáveis foram definidas para o carregamento acidental, a partir da simulação de processos estocásticos para um período de 50 anos, a partir de recomendações do JCSS. A variável $q_{a p t}$ foi então construída para valores instantâneos da simulação, representando cargas acidentais médias, e a variável $q_{50}$ foi definida considerando os máximos temporais das simulações, representando o carregamento acidental máximo esperado em um período de 50 anos. Foram construídas ainda as variáveis $w_{1}$ e $w_{50}$, para representar a pressão do vento máxima nos períodos de 1 e 50 anos, respectivamente. Para estas variáveis, simplesmente foram adotados os parâmetros recomendados por Beck e Junior (), que conduziram um estudo específico sobre as cargas de vento no território brasileiro. Por fim, uma variável erro de modelo $E_{M}^{S}$ foi definida também para as variáveis de solicitação, baseada nas recomendações do JCSS. As características das variáveis aleatórias construídas são reunidas na Tabela 6 . 
Tabela 6: Variáveis aleatórias construídas para o problema de calibração de norma

\begin{tabular}{cccc}
\hline VA & Distribuição & Média & CV \\
$f_{c}^{\mathrm{C} 20}$ & Normal & $1.30 f_{c k}$ & 0.20 \\
$f_{c}^{\mathrm{C} 30}$ & Normal & $1.22 f_{c k}$ & 0.15 \\
$f_{c}^{\mathrm{C} 40}$ & Normal & $1.16 f_{c k}$ & 0.11 \\
$f_{c}^{\mathrm{C} 50}$ & Normal & $1.11 f_{c k}$ & 0.10 \\
$f_{c}^{\mathrm{C} 60}$ & Normal & $1.10 f_{c k}$ & 0.09 \\
$f_{y}$ & Normal & $1.11 f_{y k}$ & 0.04 \\
$b^{\text {viga }}$ & Normal & $b_{n}$ & $\left(4+0.006 b_{n}\right) / b_{n}$ \\
$h^{\text {viga }}$ & Normal & $d_{n}$ & $10 / d_{n}$ \\
$E_{M}^{R}$ & Normal & 1.02 & 0.06 \\
\hline$g$ & Normal & $1.06 g_{n}$ & 0.12 \\
$q_{a p t}$ & Gamma & $0.25 q_{n}$ & 0.55 \\
$q_{50}$ & Gumbel & $1.00 q_{n}$ & 0.40 \\
$w_{1}$ & Gumbel & $0.33 w_{n}$ & 0.47 \\
$w_{5} 0$ & Gumbel & $0.90 w_{n}$ & 0.34 \\
$E_{M}^{S}$ & Lognormal & 1.00 & 0.10 \\
\hline
\end{tabular}

\subsection{Procedimento de calibração}

Os coeficientes parciais de segurança a serem determinados neste trabalho, segundo as especificações normativas, dizem respeito à minoração da resistência dos materiais e à majoração de carregamentos. Isso significa que os mesmos coeficientes são aplicados a peças e configurações estruturais diferentes. $\mathrm{O}$ exemplo abordado aqui diz respeito apenas ao projeto de vigas de concreto armado dimensionadas à flexão, o que é suficiente para abranger várias configurações de projeto diferentes. Sendo assim, diversas situações são consideradas na função objetivo do problema: a calibração realizada leva em conta todas as combinações possíveis entre cinco classes de resistência do concreto (C20, C30, C40, C50 e C60), três relações entre tamanho de base e tamanho de altura útil (0.25, 0.50 e 0.75$)$, e três taxas de armadura: 0.5\%, a mínima, e a máxima estabelecidas pela NBR 6118. Além disso, diversas razões de carregamento " $i$ "entre carregamento acidental e carregamento permanente são consideradas, bem como diversas razões " $j$ "entre carregamento devido ao vento e carregamento permanente. Como as cargas acidentais podem ser inclusive nulas, alguns termos da equação de estado limite podem ser suprimidos para algumas combinações. Finalmente, baseando-se na regra de Turkstra (TURKSTRA; MADSEN, 1980), a equação de estado limite utilizada no cálculo dos índices de confiabilidade considerados no problema é definida pelo sistema em série apresentado na Equação 5.1:

$$
\left\{\begin{array}{l}
g_{1}(\mathbf{X}, \boldsymbol{d})=E_{M}^{R}\left[A_{s} \frac{f_{y}}{\gamma_{s}}\left(d-\frac{\left(\frac{\lambda_{c}}{2}\right) A_{s}\left(\frac{f_{y}}{\gamma_{s}}\right)}{\alpha_{c} \lambda_{c} b\left(\frac{f_{c}}{\gamma_{c}}\right)}\right)\right]-E_{M}^{S}\left[\left(M_{g} \gamma_{g}\right)+\left(M_{q_{50}} \gamma_{q}\right)+\left(M_{w_{1}} \gamma_{w} \psi_{w}\right)\right] \\
g_{2}(\mathbf{X}, \boldsymbol{d})=E_{M}^{R}\left[A_{s} \frac{f_{y}}{\gamma_{s}}\left(d-\frac{\left(\frac{\lambda_{c}}{2}\right) A_{s}\left(\frac{f_{y}}{\gamma_{s}}\right)}{\alpha_{c} \lambda_{c} b\left(\frac{f_{c}}{\gamma_{c}}\right)}\right)\right]-E_{M}^{S}\left[\left(M_{g} \gamma_{g}\right)+\left(M_{w_{50}} \gamma_{w}\right)+\left(M_{q_{a p t}} \gamma_{q} \psi_{q}\right)\right] .
\end{array}\right.
$$


Vale destacar que o problema assim definido trata de uma aplicação prática do módulo computacional desenvolvido, mas que quaisquer outras equações de estado limite poderiam ser consideradas, inclusive aquelas definidas implicitamente a partir de modelos numéricos. Durante o processo de otimização, as equações 5.1 são utilizadas para o dimensionamento das ações nominais, em um procedimento inverso ao processo usual de projeto. No dimensionamento são utilizados os coeficientes parciais "candidatos", bem como valores característicos e nominais das variáveis aleatórias. Na análise de confiabilidade, as equações 5.1 são utilizadas com coeficientes parciais unitários.

Uma vez que as variáveis aleatórias e as equações de estado limite que regem o problema estejam definidas, formula-se um problema baseado em RBDO. Afere-se a confiabilidade estrutural de todas as classes de resistência do concreto, taxas de armadura e relações geométricas consideradas. O procedimento de otimização impõe a proximidade entre os índices de confiabilidade alvo assim calculados e um índice de confiabilidade alvo $\beta_{T}$. Cada caso é ponderado pela frequência relativa da combinação entre tipos de carregamentos que representa. Sendo assim, o problema de otimização pode ser escrito como:

$$
\boldsymbol{d}^{*}=\left[\gamma_{c}^{*}, \gamma_{g}^{*}, \gamma_{q}^{*}, \gamma_{s}^{*}, \gamma_{w}^{*}, \psi_{q}^{*}, \psi_{w}^{*}\right]^{T}=\arg \min \sum_{i=1}^{r_{q}} \sum_{j=1}^{r_{w}} \sum_{k=1}^{R_{c}} \sum_{l=1}^{\rho_{c}} \sum_{m=1}^{C_{g}}\left[\left(\beta_{t}-\beta_{i j k l m}\right)^{2} w_{i j}\right] .
$$

Para $r_{q}$ razões entre carregamento acidental e permanente, $r_{w}$ razões entre carga de vento e permanente, $R_{c}$ classes de resistência do concreto, $\rho_{c}$ taxas de armadura e $C_{g}$ relações geométricas consideradas, sendo que, para dadoss $i, j, k, l, m$ :

$$
\beta_{i j k l m}=\Phi^{-1}\left(\mathbb{P}\left[\min \left(g_{1}(\boldsymbol{X}), g_{2}(\boldsymbol{X})\right) \leq 0\right]\right) .
$$

Apesar do grande número de equações de estado limite a ser analisado, todas as equações são analíticas e relativamente simples. Sendo assim, optou-se pela obtenção dos índices de confiabilidade por meio do método de confiabilidade de primeira ordem. Devido ao baixo esforço computacional envolvido nas soluções dos problemas de confiabilidade, optou-se ainda pela solução do problema de otimização utilizando-se o algoritmo PSO (BANSAL et al., 2011). 30 partículas por iteração foram adotadas, até a convergência, considerada quando o valor da função objetivo é inferior a $10^{-3}$.

\subsection{Resultados}

Os índices de confiabilidade para todas as combinações consideradas foram calculados adotando-se os fatores parciais de segurança normativos. Desse modo, foram obtidos valores referência. Após a otimização, todos os índices de confiabilidade foram novamente calculados, levando-se em conta os fatores calibrados. A Tabela 7 mostra uma comparação entre os valores dos coeficientes recomendados por norma e os valores obtidos por meio da calibração. 
Tabela 7: Comparação entre valores normativos e calibrados dos coeficientes parciais de segurança

\begin{tabular}{ccc}
\hline Coeficiente & Valor original & Valor calibrado \\
\hline$\gamma_{c}$ & 1.40 & 1.35 \\
$\gamma_{s}$ & 1.15 & 1.14 \\
$\gamma_{g}$ & 1.40 & 1.24 \\
$\gamma_{q}$ & 1.40 & 1.67 \\
$\gamma_{w}$ & 1.40 & 1.62 \\
$\psi_{q}$ & $0.50 / 0.70 / 0.80$ & 0.32 \\
$\psi_{w}$ & 0.60 & 0.29 \\
\hline
\end{tabular}

É possível notar que a calibração baseada em confiabilidade implicou em uma diminuição nos valores dos coeficientes $\gamma_{c}, \gamma_{g}, \gamma_{s}, \psi_{q}, \psi_{w}$, que foi compensada pelo aumento nos valores dos coeficientes $\gamma_{q}$ e $\gamma_{w}$. De modo similar aos resultados observados por Beck e Junior (), os coeficientes calibrados neste trabalho majoram as ações consideradas principais e em contrapartida reduzem as ações consideradas secundárias nas combinações de projeto. As Figuras 15 e 16 mostram uma comparação entre os índices de confiabilidade com e sem calibração, conforme as taxas de carregamento acidentais e de vento, respectivamente, variam. Nas figuras, foram plotados apenas o maior e o menor índice de confiabilidade para todas as combinações estudadas, mantendo-se constantes apenas as razões de carregamento indicadas.

Observa-se que o processo de calibração produziu coeficientes que levam a índices de confiabilidade mais uniformes para diferentes situações de projeto e combinações de carregamentos. O processo de calibração ainda elevou o índice de confiabilidade médio de todas as análises de 2.95 para 3.00 .

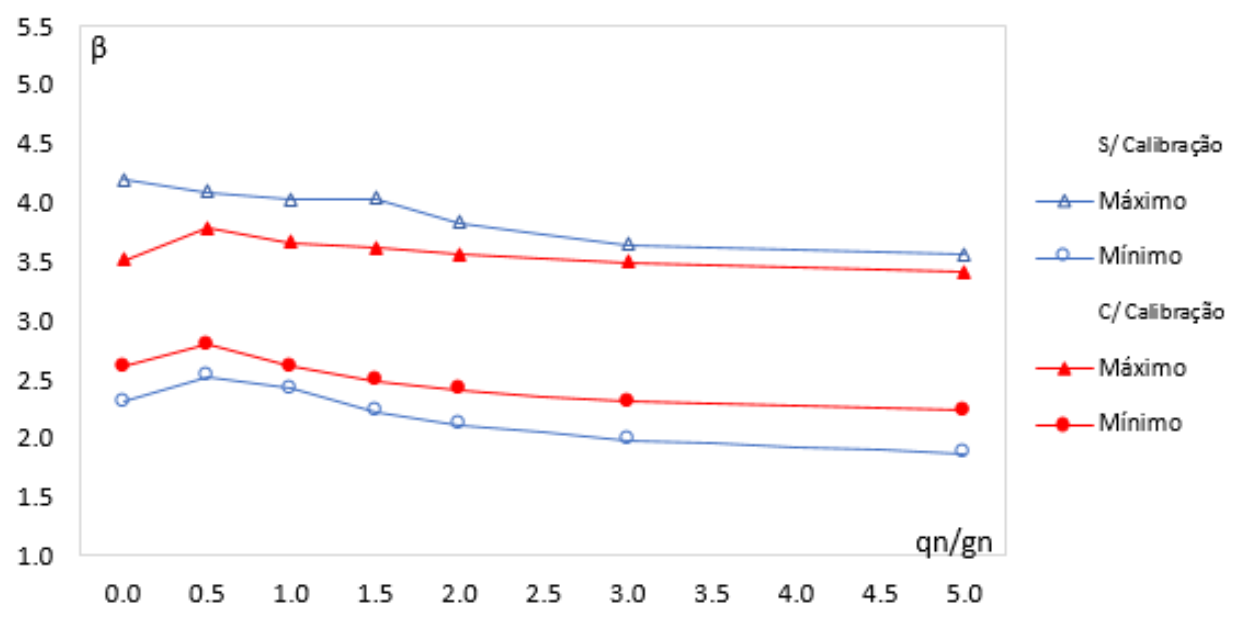

Figura 15: Comparação entre os índices de confiabilidade com e sem calibração, variando-se o carregamento acidental (Fonte:(SANTIAGO; KROETZ; BECK, 2018)). 


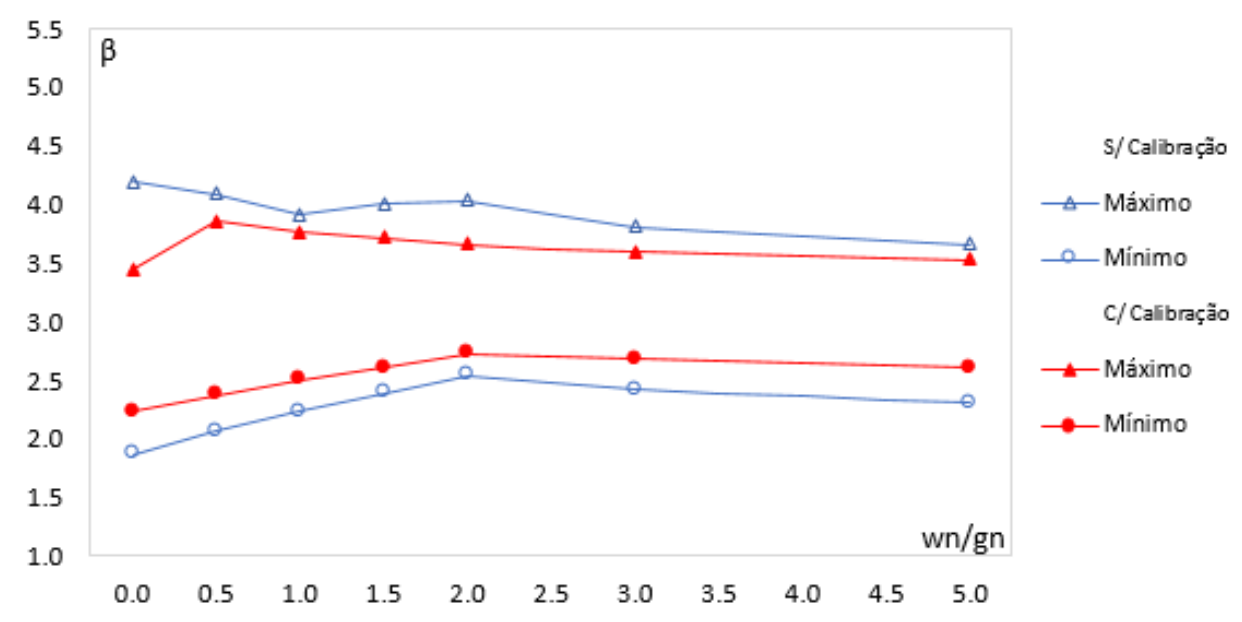

Figura 16: Comparação entre os índices de confiabilidade com e sem calibração, variando-se o carregamento proveniente do vento (Fonte:(SANTIAGO; KROETZ; BECK, 2018)).

\subsection{Conclusões}

Este capítulo apresentou um algoritmo para a calibração dos coeficientes parciais de segurança associados ao projeto de vigas de concreto armado, segundo normas brasileiras. O procedimento foi apresentado com o auxílio de um exemplo de aplicação do módulo de calibração de normas do software StRAnD. Nota-se que não apenas o programa está operacional e adequado para a utilização por outros usuários, mas que os resultados obtidos a partir dele foram coerentes, comparáveis a uma referência da literatura que realizou um estudo similar (BECK; JUNIOR, ). Os resultados ressaltam ainda a importância da calibração de normas baseada em confiabilidade, uma vez que os coeficientes calibrados conduziram a um cenário de maior segurança, se comparados aos resultados obtidos a partir dos coeficientes normativos da norma vigente. 



\section{MÉTOdO HÍBRIDO PARA A SOLUÇÃO DE PROBLEMAS DE RBDO}

Este capítulo é baseado no artigo:

\section{Rodolfo K. Tessari, Henrique M. Kroetz e André T. Beck (2017)}

Hybrid Method for Accurate and Efficient Solution of RBDO Problems - 12th International Conference on Structural Safety \& Reliability ICOSSAR, 2017, Viena. Reliability, Risk, Resilience and Sustainability of Structures and Infrastructure, 2017. p. 1123-1132

\subsection{Principais contribuições do autor}

- Concepção de parte da etapa de simulação do método para o caso de variáveis do tipo "Z", e da etapa de simulação para o caso de variáveis do tipo "D".

- Programação e estudo de um exemplo.

- Acoplamento da técnica proposta com metamodelagem.

\subsection{Introdução}

Este capítulo apresenta uma proposta de algoritmo para a solução de problemas de otimização estrutural estocástica, pautada em um compromisso entre a precisão dos resultados e o custo computacional do processamento. É conhecido o fato de que as abordagens de solução de problemas de RBDO propostos na seção 3.2 podem apresentar problemas de precisão associados ao FORM. Por outro lado, procedimentos que se utilizam de simulações de Monte Carlo para a verificação das probabilidades de falha tendem a ter custo computacional proibitivo. Sendo assim, o método proposto divide a solução dos problemas de RBDO em duas etapas. Primeiro, uma solução comum é executada, por meio da abordagem do laço único (seção 3.2.2). O ponto ótimo assim obtido é considerado como ponto inicial da segunda etapa, na qual o método se divide em duas possibilidades. Nos problemas que envolvem variáveis de projeto que são momentos das variáveis aleatórias do problema, aqui denominadas variáveis do tipo "Z", realiza-se uma programação quadrática sequencial (SQP) (seção 6.3) com as restrições de probabilidade calculadas pelo método das médias ponderadas (seção 2.4.2). Este método tem características que podem ser exploradas para facilitar a solução de problemas de otimização com variáveis do tipo "Z", conforme detalhado na seção 6.4. Por outro lado, nos problemas em que as variáveis de 
projeto são independentes das variáveis aleatórias, aqui denominadas variáveis do tipo "D", uma aproximação linear da probabilidade de falha é definida e utilizada para caminhar em direção ao ponto ótimo. Por fim, metamodelagem é utilizada para reduzir o custo da análise.

\subsection{Programação quadrática sequencial}

O algoritmo proposto neste trabalho utiliza em uma de suas etapas a técnica de otimização conhecida como Programação Quadrática Sequencial (SQP). Esta técnica é utilizada para a solução de problemas de otimização não linear. Ela consiste, basicamente, na solução de uma sequência de problemas simplificados. Em cada um deles, ao invés de se considerar a formulação original do problema, considera-se uma aproximação quadrática da função objetivo e uma linearização de suas restrições. Esta técnica foi definida para a solução de problemas de otimização determinística, mas sua formulação se aplica também à RBDO, bastando-se considerar as restrições como limites de probabilidades de falha. Sendo assim, um problema de otimização enunciado como:

$$
\boldsymbol{d}^{*}=\arg \min [f(\boldsymbol{d})]
$$

sujeito a restrições de igualdade e desigualdade:

$$
\begin{array}{r}
h_{i}^{S Q P}(\boldsymbol{d})=0 \\
g_{j}^{S Q P}(\boldsymbol{d}) \geq 0 \\
\boldsymbol{d}_{\text {inf }} \leq \boldsymbol{d} \leq \boldsymbol{d}_{\text {sup }}
\end{array}
$$

é resolvido considerando-se uma sequência de problemas do tipo:

$$
\boldsymbol{s}^{*}=\arg \min \left[\frac{1}{2} \boldsymbol{s}^{T} Q \boldsymbol{s}+\nabla f\left(\boldsymbol{d}_{k}\right)^{T} \boldsymbol{s}\right] .
$$

Sujeitos a:

$$
\begin{gathered}
\nabla h_{i}^{S Q P}\left(\boldsymbol{d}_{k}\right)^{T} \boldsymbol{s}+h_{i}^{S Q P}\left(\boldsymbol{d}_{k}\right)=0 \\
\nabla g_{j}^{S Q P}\left(\boldsymbol{d}_{k}\right)^{T} \boldsymbol{s}+g_{j}^{S Q P}\left(\boldsymbol{d}_{\boldsymbol{k}}\right) \geq 0
\end{gathered}
$$

sendo $Q$ a Hessiana da função objetivo, e $k$ a iteração atual. Como essa formulação é válida para cada ponto $\boldsymbol{d}_{k}$, os valores das variáveis de projeto passam a ser constantes, e a variável a ser otimizada é a direção de busca $s$. Uma vez essa direção determinada, o ponto $\boldsymbol{d}_{k}$ é atualizado:

$$
\boldsymbol{d}_{k+1}=\boldsymbol{d}_{k}+\alpha \boldsymbol{s}_{k}
$$

em que $\alpha$ é um coeficiente a ser determinado por uma busca linear (line search), de modo que o decréscimo da função objetivo seja o maior possível na direção de busca definida. $\mathrm{O}$ processo se repete até que o algoritmo convirja, se estabilizando em um valor ótimo de $\boldsymbol{d}$. 


\subsection{Procedimento proposto}

A primeira etapa do procedimento proposto consiste na solução completa do problema de RBDO por meio da abordagem do laço único, conforme descrito na seção 3.2.2 A partir do resultado, parte-se para a segunda etapa, que depende da natureza das variáveis de projeto do problema. Caso as variáveis de projeto sejam médias de variáveis aleatórias do problema de confiabilidade associado às restrições do problema de otimização, é possível aproveitar algumas características da WAMC para se obter uma solução precisa e econômica, uma vez que a mesma amostragem pode ser considerada para configurações estruturais diferentes. Para tal, basta atualizar os pesos associados a cada ponto. Desse modo, não é necessário reavaliar a função indicadora do WAMC, mesmo quando uma configuração estrutural diferente é avaliada (RASHKI; MIRI; MOGHADDAM, 2014). Caso as variáveis de projeto não tenham relação com as variáveis aleatórias, um procedimento diferente é adotado, valendo-se da suposição de que o resultado fornecido pelo SLA é próximo ao ótimo real procurado, conforme será detalhado na seção 6.4.2.

\subsubsection{Otimização para variáveis do tipo Z}

Se a função objetivo do problema considerado for composta por variáveis do tipo "Z", o ponto $\boldsymbol{d}_{S L A}$, resultante da primeira etapa deste procedimento, é usado como ponto central da amostragem uniforme a ser realizada para a WAMC. Assim, define-se um intervalo segundo os limites admitidos para as variáveis de projeto no início do problema. Sendo $\boldsymbol{b}_{\boldsymbol{l}}$ e $\boldsymbol{b}_{\boldsymbol{u}}$ vetores que definem os limites inferiores e superiores admitidos para as variáveis de projeto, os limites $\boldsymbol{L}$ considerados para a realização da otimização são definidos como:

$$
\begin{aligned}
& \boldsymbol{l}_{\boldsymbol{m}}=0.01\left(\boldsymbol{b}_{\boldsymbol{l}}-\boldsymbol{b}_{\boldsymbol{u}}\right) \\
& \boldsymbol{L}=\left[\boldsymbol{d}_{S L A}-\boldsymbol{l}_{\boldsymbol{m}}, \boldsymbol{d}_{S L A}+\boldsymbol{l}_{\boldsymbol{m}}\right] .
\end{aligned}
$$

Dentro desse intervalo, é realizada uma otimização SQP, conforme descrito na seção 6.3, com as restrições de probabilidade do problema e seus gradientes sendo calculados por meio de WAMC. Para tanto, uma amostragem é realizada ao redor do intervalo $\boldsymbol{L}$, da seguinte forma: cria-se um hipercubo latino, centrado em $\boldsymbol{d}_{S L A}$, com pontos distribuídos uniformemente no maior intervalo entre 10 vezes os limites $\boldsymbol{L}$, ou um intervalo equivalente a:

$$
\left[\boldsymbol{d}_{S L A}-\left(\beta_{T}+2\right) \boldsymbol{S}_{\text {dev }}, \boldsymbol{d}_{S L A}+\left(\beta_{T}+2\right) \boldsymbol{S}_{\text {dev }}\right],
$$

sendo $\boldsymbol{S}_{\boldsymbol{d e v}}$ um vetor que reúne os desvios padrão das variáveis aleatórias do problema de confiabilidade. Ou seja, a amostragem é realizada no ponto central do intervalo $\boldsymbol{L}$ mais ou menos o índice de confiabilidade alvo mais dois, vezes o desvio padrão de cada variável aleatória. Adota-se, então, o maior intervalo entre estes dois. Estes limites para a amostragem se revelaram importantes, uma vez que amostrar em intervalos menores pode comprometer a precisão do método das médias ponderadas, que para funcionar 
precisa ter informação de pontos correspondentes ao domínio de falha. A definição destes limites é uma adaptação das recomendações de Rashki, Miri e Moghaddam (2012) ao problema estudado. A otimização SQP segue iterativamente até que o resultado viole os limites do intervalo $\boldsymbol{L}$. Se isso acontecer, este ponto torna-se o ponto central de uma nova amostragem, a ser realizada considerando novos intervalos. A definição dos novos intervalos é feita seguindo-se um regra adaptativa, denominada limites móveis (moving bounds). Considerando que o primeiro ponto resultando da SQP não pertencente a $\boldsymbol{L}$ seja $\boldsymbol{d}_{\boldsymbol{K}}^{*}$, os novos limites passam a ser, em cada dimensão $i$ :

$$
L_{k_{i}}=\left[d_{k_{i}}^{*}-C_{i} l_{m_{i}}, d_{k_{i}}^{*}+C_{i} l_{m_{i}}\right]
$$

em que $C_{i}$ é um escalar de correção do tamanho dos limites. Nas três primeiras gerações de amostras, o valor é considerado unitário: $\boldsymbol{C}=\mathbf{1}$. A partir da quarta iteração, com base no histórico dos resultados $\boldsymbol{d}_{k-2}^{*}, \boldsymbol{d}_{k-1}^{*}$ e $\boldsymbol{d}_{k}^{*}$, o valor de cada componente $C_{i}$ passa a ser 0.7 caso se observe oscilação no resultado entre as iterações. Caso contrário, admite-se que o intervalo está sendo bem explorado naquela dimensão e pode aumentar, e $C_{i}$ assume o valor de 1.1, ou seja:

$$
\begin{aligned}
& \left(d_{k_{i}}^{*}-d_{k-1_{i}}^{*}\right)\left(d_{k-1_{i}}^{*}-d_{k-2_{i}}^{*}\right)<0 \quad \Longrightarrow C_{i}=0.7, \\
& \left(d_{k_{i}}^{*}-d_{k-1_{i}}^{*}\right)\left(d_{k-1_{i}}^{*}-d_{k-2_{i}}^{*}\right) \geq 0 \quad \Longrightarrow C_{i}=1.1 .
\end{aligned}
$$

Um novo hipercubo latino é definido ao redor de $\boldsymbol{d}_{k}^{*}$, novamente, em um intervalo equivalente a 10 vezes os limites $\boldsymbol{L}_{k}$, ou no intervalo:

$$
\left[\boldsymbol{d}_{k}-\left(\beta_{T}+2\right) \boldsymbol{S}_{\boldsymbol{d e v}}, \boldsymbol{d}_{k}+\left(\beta_{T}+2\right) \boldsymbol{S}_{\boldsymbol{d e v}}\right]
$$

o que for maior entre os dois. A otimização segue, gerando novos pontos $\boldsymbol{d}_{k}$ quando necessário, até que uma tolerância seja atingida. Considera-se a tolerância atingida quando os valores das variáveis "Z" e o valor da função objetivo ambos se estabilizam. Desse modo, o algoritmo chegará a um resultado que respeita as restrições, mas nada se faz com relação às variáveis de projeto independentes das variáveis aleatórias do problema, as chamadas variáveis do tipo "D". Isso significa que o resultado encontrado não é necessariamente o mais ótimo possível para problemas que contam com os dois tipos de variáveis, "D" e "Z", concomitantemente. Ainda assim, o resultado obtido é um refinamento daquele obtido apenas com o SLA. A suposição adotada aqui é de que as variáveis de projeto com alguma incerteza envolvida serão mais relevantes à análise e farão a resposta convergir mais rapidamente para o atendimento das restrições probabilísticas. A distinção entre os tipos de variáveis é importante, porque dentro dos conjuntos de iterações que acontecem em um mesmo $\boldsymbol{L}_{k}$, a mesma amostragem de Monte Carlo é válida. Devido às características da WAMC, como apenas as médias das variáveis aleatórias foram alteradas, uma nova amostragem não é necessária, bastando-se alterar os pesos de cada amostra, definidos pela função densidade de probabilidade conjunta das variáveis aleatórias do problema naquele 
ponto. Desse modo, as restrições do problema podem ser avaliadas sem novas soluções das equações de estado limite, o que aumenta a eficiência do método.

\subsubsection{Otimização para variáveis do tipo D}

Caso o problema não tenha variáveis do tipo "Z" em sua formulação, o algoritmo segue para a otimização das variáveis "D". Nesse caso, adota-se a hipótese de que a distância entre o ponto ótimo real $\boldsymbol{d}^{*}$ e o ponto atual $\boldsymbol{d}_{k}$ é proporcional à distância entre a probabilidade de falha alvo e a probabilidade de falha da configuração atual da estrutura. Essa hipótese não é exata, mas se sustenta no fato de que o resultado do SLA costuma estar próximo ao ponto ótimo verdadeiro da estrutura, e a aproximação linear pode apontar para uma direção que, iterativamente, convirja para o ótimo. O algoritmo funciona da seguinte forma: primeiramente, o gradiente das restrições é calculado no ponto resultante do SLA. Caminha-se então uma medida arbitrariamente pequena no sentido contrário ao do seu versor (adotou-se um centésimo do versor além do ponto inicial). Obtém-se então a $P_{f}$ nestes dois pontos. Segue-se, a partir daí, um método de bissecção utilizando-se como parâmetros as probabilidades de falha. O objetivo é fazer as variáveis do tipo "D"avançarem, a partir do ponto inicial, até um valor ao qual esteja associado à probabilidade de falha alvo do problema $P_{f_{T}}$. Para isso, define-se um passo:

$$
\text { step }=\frac{P_{f_{T}}-P_{f_{k-1}}}{P_{f_{k}}-P_{f_{k-1}}},
$$

em que $P_{f_{k}}$ é a probabilidade calculada na iteração atual, e $P_{f_{0}}$ é a probabilidade de falha para os valores $\boldsymbol{d}_{S L A}$. Caso step $<0.5$, a $P_{f_{T}}$ está situada entre $P_{f_{k-1}}$ e $P_{f_{k}}$, porém mais próxima de $P_{f_{k-1}}$. Assim, o novo ponto $\boldsymbol{d}_{k+1}$ é obtido da seguinte forma:

$$
\boldsymbol{d}_{k+1}=\boldsymbol{d}_{k-1}+\operatorname{step}\left(\boldsymbol{d}_{k}-\boldsymbol{d}_{k-1}\right)
$$

ou seja, se a probabilidade de falha variar na mesma taxa que a distância entre os pontos $\boldsymbol{d}$, o problema atinge o valor exato em um passo. Buscando fazer aproximações menores, para que o modelo linear seja mais representativo, ao invés de se caminhar a partir do ponto inicial $\boldsymbol{d}_{k-1}$, caminha-se a partir do ponto $\boldsymbol{d}_{k}$ para os casos em que step $>0,5$. Nestes casos, há duas possibilidade. Se o ponto $\boldsymbol{d}_{k+1}$ corresponder a uma $P_{f}$ intermediária entra as probabilidades do ponto $\boldsymbol{d}_{k}$ e a $P_{f_{T}}$, o valor do passo é atualizado para

$$
\text { step }=\text { step }-1 .
$$

Por outro lado, se a probabilidade do ponto $\boldsymbol{d}_{k}$ ultrapassar $P_{f_{T}}$, a atualização do passo é feita de forma que permita voltar até a probabilidade de falha alvo:

$$
\text { step }=-(1-\text { step }),
$$

após a atualização do passo, o novo ponto é calculado da forma:

$$
\boldsymbol{d}_{k+1}=\boldsymbol{d}_{k}+\operatorname{step}\left(\boldsymbol{d}_{k}-\boldsymbol{d}_{k-1}\right) .
$$


O processo continua até que a probabilidade de falha associada ao ponto atual esteja suficientemente próxima à probabilidade de falha alvo do problema, verificada por simulação de Monte Carlo.

\subsubsection{Exemplo - Múltiplas equações de estado limite}

Um problema bastante comum envolvendo otimização baseada em confiabilidade, que serve como benchmark para o teste de novos métodos, é o problema das múltiplas equações de estado limite. Ele trata da minimização de uma função objetivo linear sujeita a três restrições não lineares, e é resolvido para três índices de confiabilidade alvo $\beta_{T}=2$, 3 e 4. Deseja-se minimizar a seguinte função:

$$
f(\boldsymbol{d})=d_{1}+d_{2}
$$

sujeita a:

$$
\begin{aligned}
& g_{1}(\boldsymbol{X})=\frac{X_{1}^{2} X_{2}}{20}-1 \\
& g_{2}(\boldsymbol{X})=\frac{\left(X_{1}+X_{2}-5\right)^{2}}{30}+\frac{\left(X_{1}-X_{2}-12\right)^{2}}{120}-1 \\
& g_{3}(\boldsymbol{X})=\frac{80}{X_{1}^{2}+8 X_{2}+5}-1 .
\end{aligned}
$$

Neste problema, $d_{1}=\mu_{X_{1}}, d_{2}=\mu_{X_{2}}$, e as variáveis $X_{1}$ e $X_{2}$ seguem distribuição normal padrão. Portanto, trata-se de um problema de variáveis de projeto do tipo "Z". A Tabela 8 mostra os resultados obtidos para este problema em Aoues e Chateauneuf (2010), utilizando a abordagem do índice de confiabilidade (RIA) e a abordagem do laço único (SLA):

Tabela 8: Resultados obtidos por Aoues e Chateauneuf (2010)

\begin{tabular}{ccccc}
\hline & $\beta_{T}$ & 2 & 3 & 4 \\
\hline RIA & $f\left(\boldsymbol{d}^{*}\right)$ & 6.19 & 6.72 & 7.26 \\
& $\boldsymbol{\beta}$ & 2.00 & 3.00 & 3.99 \\
& & & & \\
\hline SLA & $f\left(\boldsymbol{d}^{*}\right)$ & 6.19 & 6.75 & 7.26 \\
& $\boldsymbol{\beta}$ & 1.99 & 2.99 & 3.99 \\
\hline
\end{tabular}

O mesmo problema foi resolvido pelo método híbrido apresentado neste capítulo. Na referência, os autores não mostram em seus resultados o valor ótimo de cada variável de projeto, mas apenas o valor da função objetivo. Resultados muito próximos aos apresentados na Tabela 8 foram recuperados pela primeira etapa do algoritmo híbrido, conforme mostrado na Tabela 9:

Estes valores foram verificados em termos de índice de confiabilidade a partir de $10^{7}$ simulações de Monte Carlo bruto, e descobriu-se que as restrições de probabilidade estavam violadas. Ou seja, os pontos representados nas tabelas 8 e 9 são não factíveis. Uma 
Tabela 9: Resultados obtidos com a SLA

\begin{tabular}{cccc}
\hline$\beta_{T}$ & 2 & 3 & 4 \\
\hline$d_{1}$ & 3.29 & 3.44 & 3.61 \\
$d_{2}$ & 2.89 & 3.29 & 3.65 \\
$f(\boldsymbol{d})$ & 6.18 & 6.73 & 7.26 \\
\hline
\end{tabular}

vez que a segunda etapa do algoritmo híbrido se utiliza de dados de entrada aleatórios, a resposta final obtida por meio dele não é sempre exatamente a mesma. A Tabela 10 apresenta as médias e os coeficientes de variação obtidos ao resolver este problema 10 vezes pelo método híbrido completo, utilizando-se amostra de tamanho $10^{4}$ em cada simulação de Monte Carlo executada na segunda etapa do algoritmo. Os índices de confiabilidade associados aos resultados obtidos na primeira etapa do algoritmo híbrido também são exibidos na Tabela 10, e representados por $\beta_{S L A}$. Resultados mais conservadores, porém muito mais precisos, foram encontrados ao final da execução completa do algoritmo, e são representados por $\beta_{H y b}$. Os resultados obtidos ficam muito próximos da ativação das

Tabela 10: Resultados obtidos com a utilização do método híbrido

\begin{tabular}{ccccccc}
\hline$\beta_{T}$ & $f\left(\boldsymbol{d}^{*}\right)$ & $C V\left(f\left(\boldsymbol{d}^{*}\right)\right)$ & $\boldsymbol{d}^{*}$ & $C V\left(\boldsymbol{d}^{*}\right)$ & $\beta_{S L A}$ & $\beta_{H y b}$ \\
\hline 2 & 6.3305 & $0.2 \%$ & $\{3.325,3.006\}$ & $0.4 \%$ & 1.697 & 1.997 \\
3 & 6.8252 & $0.1 \%$ & $\{3.439,3.386\}$ & $0.3 \%$ & 2.789 & 3.000 \\
4 & 7.3502 & $0.1 \%$ & $\{3.619,3.731\}$ & $0.2 \%$ & 3.893 & 4.003 \\
\hline
\end{tabular}

restrições de probabilidade, mostrando a importância do refinamento.

\subsection{Acoplamento com metamodelagem}

Tanto para os casos de otimização das variáveis "Z" quanto "D", o método apresentado requer a execução de simulações de Monte Carlo. Apesar da maior precisão que o refinamento contido no algoritmo apresentado possibilita ao resultado, isso faz com que ele seja muito mais caro em termos de custo computacional com relação a apenas a execução do SLA. Para se mitigar este problema, metamodelos podem ser construídos, verificando-se assim as restrições em probabilidade do problema com simulações Monte Carlo sobre os metamodelos.

\subsubsection{Exemplo - Método híbrido acoplado a Krigagem}

Este problema trata da minimização de uma função objetivo não linear sujeita a uma restrição também não linear. Enuncia-se:

$$
f(\boldsymbol{d})=d_{1}^{2}+d_{2}^{2}
$$


sujeita a:

$$
\begin{aligned}
& \mathbb{P}\left[\frac{1}{5} d_{1} d_{2} X_{2}^{2}-X_{1}\right]<0.01 \\
& \mathbf{0}<\boldsymbol{d}<\mathbf{1 5} .
\end{aligned}
$$

ou seja, o índice de confiabilidade deve ser $\beta>2.32$. A variável $X_{1}$ segue uma distribuição Normal, com média 5 e CV 0.3, e a variável $X_{2}$ segue uma distribuição Normal, com média 3 e CV 0.3. Aoues e Chateauneuf (2010) resolveram este problema utilizando vários métodos aproximativos diferentes, entre eles o RIA, PMA e SLA. Para todos os casos, obtiveram como resultado para a função objetivo o mesmo valor $f\left(\boldsymbol{d}^{*}\right)=63.88$. Utilizandose a primeira parte do algoritmo híbrido, obtém-se com o método SLA o resultado de $\boldsymbol{d}^{*}=[5.65 ; 5.65]^{T}$, o que recupera um valor para a função objetivo de 63.88 obtido pelo artigo usado como referência. Resolvendo-se o problema de confiabilidade, para esses valores de $\boldsymbol{d}^{*}$, obtém-se com $10^{6}$ simulações com Monte Carlo bruto o valor de $\beta=2.335$. Nesse caso, a solução obtida pelos autores originais é factível.

Neste exemplo, o problema é, primeiramente, resolvido 10 vezes com o método híbrido completo. As médias dos resultados obtidos para as variáveis de projeto foram $\boldsymbol{d}^{*}=[5.576 ; 5.576]^{T}$, que correspondem a um valor menor da função objetivo: 62.18 . O coeficiente de variação dos 10 resultados é de apenas 1.5\%. O índice de confiabilidade obtido para este resultado é $\beta=2.322$, com $10^{6}$ simulações com Monte Carlo bruto. Isso significa que o resultado encontrado é melhor, pois respeita a restrição com menos folga enquanto está associado a um valor menor da função objetivo. Portanto, o método híbrido apresentou melhores resultados com relação aos métodos aproximativos mais uma vez. Em média, a restrição probabilística precisou ser avaliada 32315 vezes. Em seguida, estudou-se a aplicação de metamodelos sobre a equação de estado limite, afim de se reduzir o número de avaliações necessário para a solução do problema. Um metamodelo de Krigagem foi montado com 200, 300, 400 e 500 pontos de suporte. A amostragem foi feita com um hiper-cubo latino, considerando-se a distribuição das variáveis aleatórias, e uma distribuição uniforme para as variáveis de projeto, com limites dados pelas restrições laterais do problema. Sendo assim, trata-se da utilização de um metamodelo global. Os valores encontrados para a função objetivo a partir da utilização de cada metamodelo foram comparados com o valor obtido pelo método híbrido sem metamodelos, usado como referência. Os erros obtidos para as Krigagens, em relação à função objetivo, 200, 300, 400 e 500 pontos de suporte foram, respectivamente, $3.73 \%, 2.01 \%, 0.11 \%$ e $0.04 \%$. Ressalta-se que mesmo a solução do problema que se utiliza do metamodelo com 500 pontos de suporte necessita de apenas 500 avaliações da restrição na segunda parte do algoritmo, além das 87 chamadas presentes em todos os casos, necessárias ao SLA. Isso significa que o metamodelo mais caro utilizado avalia o modelo geral apenas aproximadamente $1 \%$ do número de vezes necessário ao método híbrido puro, com resultados bastante precisos. 


\subsection{Conclusão}

Afim de se unir os benefícios de precisão de métodos de otimização baseados em simulação de Monte Carlo e a agilidade de métodos baseados em FORM, um método híbrido foi proposto neste capítulo. O método parte da solução do problema por meio da abordagem SLA, e a refina a partir da aplicação de estratégias dependentes da natureza das variáveis de projeto de cada problema considerado. Metamodelos podem ser facilmente acoplados ao método proposto, de modo a se ganhar ainda mais eficiência no processo de otimização. Dois exemplos de benchmark foram utilizados para testar o método. Em ambos os casos, os resultados obtidos foram melhores do que as referências, que consistiam em soluções dos mesmos problemas baseadas em métodos aproximativos. 



\section{OTIMIZAÇÃO DE RISCO BASEADA EM KRIGAGEM E SIMULAÇÃO DE MONTE CARLO COM MÉDIAS PONDERADAS}

Este capítulo é baseado no artigo:

Henrique M. Kroetz, Rodolfo K. Tessari e André T. Beck (2017)

Kriging-assisted Risk Optimization with Ranked Weighted Average Simulation - 12th International Conference on Structural Safety \& Reliability ICOSSAR, 2017, Viena. Reliability, Risk, Resilience and Sustainability of Structures and Infrastructure, 2017. p. $217-226$

\subsection{Principais contribuições do autor}

- Revisão da literatura.

- Concepção da metodologia proposta.

- Programação e estudo dos exemplos.

\subsection{Introdução}

A abordagem da otimização de risco é aquela que fornece os resultados mais gerais quando comparada a abordagens concorrentes como a DDO e a RBDO. Ainda assim, uma revisão da literatura demonstra que atenção muito maior tem sido dada à RBDO nos últimos vinte anos. A maioria dos trabalhos envolvendo RO são sobre a formulação adequada de um problema específico, e não sobre propostas de solução para problemas gerais deste tipo (FRANGOPOL D.M., 2003; STREICHER; JOANNI; R., 2008; TAFLANIDIS; BECK, 2009; BIONDINI; FRANGOPOL, 2009; SAAD et al., 2016). Na engenharia de estruturas, a maioria dos problemas práticos de otimização são altamente não-lineares, o que costuma implicar na existência de vários mínimos locais (GANDOMI; YANG; ALAVI, 2011). A formulação da otimização de risco aumenta ainda mais a complexidade do problema, pois as funções objetivo são estendidas para a consideração de termos de diferentes naturezas. Modelos numéricos podem estar implícitos devido à consideração das probabilidades de falha nos argumentos da função. Além disso, não há garantia, no caso dos problemas com restrições, que elas estejam ativas na configuração estrutural ótima. Tudo isso dificulta a solução e faz com que muitas das abordagens utilizadas para DDO e RBDO sejam inadequadas para este tipo de problema. Uma forma de se endereçar este tipo de problema é por meio da utilização de algoritmos heurísticos de otimização. Algoritmos desse tipo 
seguem alguma regra que permite a exploração inteligente do espaço de projeto, sendo possível a captura de mínimos locais e dispensando a necessidade do cálculo de gradientes e hessianas. A desvantagem óbvia é o elevado custo computacional, pois a função objetivo precisa ser avaliada muitas vezes até que uma solução seja obtida. O trabalho retratado neste capítulo tem por objetivo a combinação de diversas técnicas de redução de custo computacional, de modo a tornar viável a solução de alguns problemas de otimização de risco por meio de uma abordagem envolvendo meta-heurística.

\subsection{Método dos Vagalumes}

Uma heurística pode ser definida como uma maneira criteriosa de se resolver um problema complexo a partir de tentativas e erros em um tempo razoável (YANG, 2010). Diversos algoritmos foram propostos para a solução de problemas de otimização, visando explorar o espaço de projeto de modo adequado, identificando-se regiões mais importantes, nas quais uma solução mais detalhada é executada. Um método que se revelou particularmente eficiente para problemas de otimização estrutural é o chamado método dos vagalumes (YANG, 2009). Este método foi comparado com diversos outros algoritmos heurísticos em vários problemas de otimização estrutural, como otimização por enxame de partículas (PSO) (EBERHART; KENNEDY, 1995), algoritmos genéticos (GA) (GOLDBERG, 1989), e recozimento simulado (SA) Kirkpatrick, Gelatt e Vecchi (1983), e obteve o melhor desempenho entre todos eles (GANDOMI; YANG; ALAVI, 2011). O método se baseia no comportamento social observado em vagalumes. Um conjunto de pontos (vagalumes) é definido aleatoriamente no espaço de projeto, e avalia-se a função objetivo em cada um deles. Cada ponto avaliado em uma iteração do algoritmo "caminha" a partir de quatro regras básicas (i.e. será avaliado na próxima iteração um ponto correspondente a este vagalume, cuja localização dependerá das quatro regras.):

1. Todos os vagalumes podem ser atraídos por qualquer um dos outros vagalumes;

2. A medida de quão atraente é um vagalume é função de seu brilho. Para cada par de vagalumes, o que tem menos brilho irá se mover em direção ao que tem mais brilho. Se não houver vagalumes mais brilhantes que ele, um vagalume se move aleatoriamente naquela iteração;

3. O brilho percebido diminui conforme a distância entre os vagalumes aumenta;

4. O brilho de cada vagalume é relacionado com o valor da função objetivo no ponto em que o vagalume está.

A distância que cada vagalume irá se mover depende do brilho que ele percebe no vagalume mais brilhante, para o qual se dirigirá. Para os problemas de minimização abordados neste capítulo, define-se que a intensidade do brilho de cada vagalume é dada pelo oposto da 
função objetivo do problema avaliada naquele ponto. Para problemas de otimização de risco, definimos então que a luminosidade $\iota_{0}$ de cada vagalume é obtida em termos do custo total associado ao ponto em que ele se encontra:

$$
\iota_{0}(\boldsymbol{d})=-C_{T}(\boldsymbol{d}) .
$$

A luminosidade $\iota_{i j}$ de um vagalume $i$ percebida por um vagalume $j$ decresce exponencialmente com a distância entre eles:

$$
\iota_{i j}\left(\boldsymbol{d}_{i}, \boldsymbol{d}_{j}\right)=\iota_{0}\left(\boldsymbol{d}_{i}\right) e^{-\left(\left\|\boldsymbol{d}_{i}-\boldsymbol{d}_{j}\right\|\right)^{2}}
$$

O vagalume em questão se move então na direção do vagalume mais luminoso, uma distância proporcional à luminosidade percebida. Um pequeno movimento aleatório é adicionado ao final da trajetória, mantendo a característica estocástica do algoritmo em todas as suas iterações. Gandomi, Yang e Alavi (2011) discutem mais parâmetros que podem ser considerados na formulação da solução, que em geral têm seus valores orientados a cada problema, não considerados neste trabalho. Problemas de otimização de risco que incluem restrições de confiabilidade podem ser facilmente abordados considerando-se uma penalização para os pontos não factíveis, uma vez que a solução do problema já inclui a avaliação das probabilidades de falha associadas ao ponto, e portanto, a verificação das restrições. Restrições laterais também podem ser abordadas diretamente por meio da penalização dos pontos não factíveis.

\subsection{Procedimento proposto}

O procedimento proposto nesta seção objetiva a solução de problemas gerais de otimização de risco. Ele consiste na combinação de técnicas para a redução dos custos computacionais necessários para a solução do problema por meio de um algoritmo heurístico. O algoritmo dos vagalumes é utilizado para a solução do problema de otimização, devido à sua conhecida eficiência. Para cada avaliação da função objetivo, as probabilidades de falha são estimadas por uma simulação de Monte Carlo com médias ponderadas ranqueadas (Seção 2.4.2), de modo que o cálculo possa ser feito com um tamanho reduzido de amostra. Além disso, uma vez que a utilização de algoritmos de ordem 0 tende a exigir muitas avaliações da função objetivo, e portanto muitas WAMC, as simulações não são executadas considerando-se a função objetivo original do problema, mas um metamodelo de Krigagem global, construído no espaço aumentado do problema (DUBOURG; SUDRET; BOURINET, 2011a). O projeto de experimento do metamodelo consiste em uma distribuição uniforme, tanto das variáveis aleatórias quanto das variáveis de projeto. Essa amostragem leva a uma aproximação melhor com relação à amostragem feita segundo a função densidade de probabilidade conjunta das VAs, uma vez que a amostragem da WAMC também é feita de maneira uniforme. O intervalo para as variáveis de projeto é definido a partir das restrições laterais do problema de otimização, e o intervalo das variáveis aleatórias deve ser 
definido com relação a uma estimativa da probabilidade de falha, conforme recomendado em Rashki, Miri e Moghaddam (2012) e comentado na Seção 2.4.2. Desse modo, todas as regiões de interesse do espaço aumentado são consideradas.

\subsection{Exemplos}

7.5.1 Função objetivo e equação de estado limite não lineares

Neste exemplo um problema de otimização de risco com função objetivo e equação de estado limite não lineares é estudado. A função objetivo inclui três tipos de custos. O custo de construção é associado às duas variáveis de projeto do problema, com um parâmetro de custo inicial $C_{b}=100$. São considerados também um custo de manutenção $C_{m}=10$, associado apenas à variável de projeto $d_{2}$, e um alto custo de falha $C_{f}=10^{6}$. O objetivo é minimizar o custo total, dado pela Equação 7.3:

$$
f(\boldsymbol{d})=d_{1} d_{2} C_{b}+d_{2}^{2} C_{m}+P_{f} C_{f},
$$

em que a probabilidade de falha é associada à seguinte equação de estado limite:

$$
g(\boldsymbol{X}, \boldsymbol{d})=d_{1} X_{1}+d_{2} X_{2}-X_{3} X_{4}
$$

sendo que as variáveis aleatórias são normais, e estão descritas na Tabela 11.

Tabela 11: Variáveis aleatórias do problema de otimização de risco

\begin{tabular}{ccc}
\hline VA & Média & DP \\
\hline$X_{1}$ & 1 & 0.1 \\
$X_{2}$ & 1 & 0.1 \\
$X_{3}$ & 80 & 4 \\
$X_{4}$ & 6 & 0.6 \\
\hline
\end{tabular}

O problema conta ainda com restrições para as variáveis de projeto e para o índice de confiabilidade:

$$
\begin{aligned}
& \beta \geq 3 \\
& 100<d_{1}<1000 \\
& 100<d_{2}<1000 .
\end{aligned}
$$

Para a solução, foram utilizadas 30 gerações do algoritmo de otimização, cada um com 30 vagalumes. O metamodelo de Krigagem foi construído a partir de 50 pontos de suporte, conforme descrito na seção 7.4. O problema foi resolvido 20 vezes com a utilização de metamodelos, e mais 20 vezes sem, para que fosse possível comparar os resultados obtidos. Erros quadráticos médios de $g(\boldsymbol{X})$ foram calculados, de modo que todas as vezes que um metamodelo da equação de estado limite foi avaliado, a equação de estado limite original foi avaliada também. Amostras de tamanho 300 foram utilizadas para as WAMC. Realizou-se então processo de ranqueamento das amostras, permitindo um resíduo de 
Tabela 12: Resultados do problema de otimização de risco

\begin{tabular}{ccc}
\hline & $g(\boldsymbol{X})$ & Krigagem \\
\hline$d_{1}$ & $645.27(0.040)$ & $638.72(0.044)$ \\
$d_{2}$ & $100(0)$ & $100(0)$ \\
$C_{T}$ & $7457173(0.035)$ & $7392465(0.037)$ \\
$\beta$ & $3.30(0.090)$ & $3.24(0.073)$ \\
\hline
\end{tabular}

$10^{-8}$ na probabilidade de falha. Desse modo, amostras de tamanho 158, em média, foram consideradas na simulação. As médias dos resultados das 20 análises são reunidos na Tabela 12, em que os coeficientes de variação estão entre parênteses. A primeira coluna mostra os resultados sem a consideração de metamodelos, e a segunda, considerando o metamodelo de Krigagem. O erro quadrático médio para $g(\boldsymbol{X})$ ao longo de todas as 20 análises foi de 0.086, um valor notavelmente pequeno, uma vez que, para todas as configurações de projeto, a equação de estado limite avaliada na médias das VAs assume valores da ordem de $10^{2}$. Para um $\beta=3$ e um coeficiente de variação inferior a $10 \%$ para $P_{f}$, seria necessária a realização de aproximadamente $1.35 \times 10^{5}$ simulações de Monte Carlo bruto. Desse modo, a solução pelo algoritmo dos vagalumes adotada implicaria em $30 \times 30 \times 1.35 \times 10^{5}=1.215 \times 10^{8}$ avaliações de $g(\boldsymbol{X})$. Com a adoção do RWAMC, esse número é reduzido para $1.422 \times 10^{5}$. Obviamente, com a adoção do metamodelo, a equação de estado limite só precisou ser avaliada 50 vezes. Apesar da simplicidade da equação de estado limite deste problema, este resultado ilustra o quão proibitiva seria a solução de problemas deste tipo sem a adoção de técnicas para reduzir o custo computacional.

\subsubsection{Confiabilidade de sistemas}

A otimização de risco de uma coluna de ferro tubular, proposta por Enevoldsen e Sorensen (1994), é estudada neste exemplo. A coluna é solicitada por uma carga vertical $P$. As variáveis de projeto consideradas são o diâmetro $d$ e a espessura $t$, conforme ilustrado na Figura 17.

O problema de otimização consiste na minimização do custo total, dado por $f(\boldsymbol{d})$ :

$$
f(\boldsymbol{d})=C_{I} h \pi t d+P_{f} C_{f}
$$

O problema conta com restrições laterais e no índice de confiabilidade:

$$
\begin{aligned}
& \beta_{\min } \geq 4 \\
& 1<d<3 \\
& 4 \times 10^{-3}<t<15 \times 10^{-3} .
\end{aligned}
$$

O custo inicial é considerado $C_{i}=20000 / \mathrm{m}^{3}$, e o custo de falha é considerado $C_{f}=10^{9}$. $\beta_{\min }$ é o menor índice de confiabilidade admitido para cada uma das equações de estado limite, de modo que $P_{f}$ na equação 7.6 diz respeito a um sistema em série. As equações 

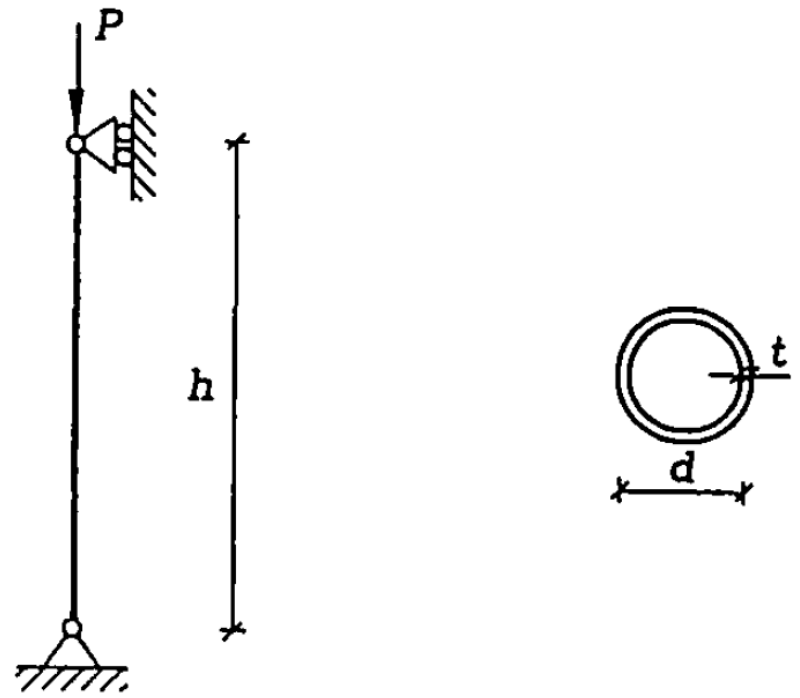

Figura 17: Coluna tubular (Fonte:(ENEVOLDSEN; SORENSEN, 1994)).

de estado limite que formam o sistema são a Equação 7.8, relacionada ao escoamento do material, a Equação 7.9, relacionada à flambagem local, e à Equação 7.10, relacionada à flambagem global:

$$
g_{1}(\boldsymbol{X}, \boldsymbol{d})=f_{y}-\frac{P}{\pi t d},
$$

em que $f_{y}$ é uma variável aleatória.

$$
g_{2}(\boldsymbol{X}, \boldsymbol{d})=\left(1,5-\sqrt{\frac{f_{y}}{2 \theta S_{c}}}\right)-\frac{P}{\pi t d}
$$

em que $\theta=\frac{k_{d}}{\sqrt{1+0.005 \frac{d}{t}}}$ e $S_{c}=\frac{2 E t}{d \sqrt{3\left(1-\nu^{2}\right)}}$

$$
g_{3}(\boldsymbol{X}, \boldsymbol{d})=\left(\gamma-\sqrt{\gamma^{2}-\frac{1}{\lambda_{e}^{2}}}\right) f_{y}-\frac{P}{\pi t d}
$$

em que $\gamma=\frac{1}{2 \lambda_{e}^{2}}\left(\lambda_{e}^{2}+k_{i}\left(\lambda_{e}-0.2\right)+0.8\right)$, e $\lambda_{e}=\frac{h}{0.35 d \pi} \sqrt{\frac{f_{y}}{E}}$. As variáveis aleatórias são apresentadas na Tabela 13 .

Tabela 13: Variáveis aleatórias do problema da coluna tubular

\begin{tabular}{ccccc}
\hline VA & Descrição & Distribuição & Média & CV \\
\hline$P$ & Carga & Normal & 10 & 0.20 \\
$E$ & Módulo de elasticidade & Lognormal & $2.1 \times 10^{5}$ & 0.05 \\
$f_{y}$ & Tensão de escoamento & Lognormal & 650 & 0.05 \\
$k_{d}$ & Fator "knock-down" & Normal & 0.54 & 0.16 \\
$k_{i}$ & Fator de Imperfeição & Normal & 0.49 & 0.10 \\
\hline
\end{tabular}

Com amostras de apenas 80 realizações, foi possível a obtenção de resultados precisos por meio da RWAMC. Quanto ao algoritmo de otimização, foi necessária a utilização 
de 50 iterações, com 60 vagalumes em cada uma delas. O metamodelo de Krigagem foi construído no espaço aumentado com um DOE de 240 pontos. A Tabela 14 compara os resultados de 20 soluções do problema pela abordagem proposta neste capítulo com os resultados originalmente obtidos em Enevoldsen e Sorensen (1994). Pode-se observar que os resultados obtidos foram melhores do que os resultados de referência: um custo total menor foi encontrado, aproximando a estrutura da sua restrição em confiabilidade, mas ainda sem ativá-la.

Tabela 14: Comparação entre a abordagem proposta e a referência

\begin{tabular}{ccc}
\hline & Referência & Obtido \\
\hline$d$ & 1.4 & 1.21 \\
$t$ & 0.01030 & 0.01046 \\
$C_{T}$ & 23000 & 22499 \\
$\beta$ & 4.7 & 4.3 \\
\hline
\end{tabular}

\subsection{Conclusão}

Apesar da escassez de abordagens pregressas para se endereçar problemas de otimização de risco, é possível abordar problemas deste tipo por meio da aplicação de algoritmos heurísticos. Apesar da eficácia, este tipo de estratégia implica em elevado custo computacional. A seleção cuidadosa e combinação de abordagens que diminuem este custo podem ser de grande auxílio na viabilização desse tipo de solução. O procedimento proposto neste capítulo mitiga os custos computacionais da análise sem comprometer sua precisão, conforme demonstrado com a solução de dois exemplos. Em ambos, obteve-se resultados precisos, associados a custos computacionais relativamente baixos. 



\section{KRIGAGEM COM APRENDIZADO ATIVO PARA OTIMIZAÇÃO DE RISCO DEPENDENTE DO TEMPO}

Este capítulo é baseado no artigo submetido:

Henrique M. Kroetz, Maliki Moustapha, André T. Beck e Bruno Sudret (2019) A Two-Level Kriging-Based Approach with Active Learning for Solving Time-Variant Risk Optimization Problems - Reliability Engineering \& System Safety

\subsection{Principais contribuições do autor}

- Este artigo é o resultado do trabalho realizado durante o doutorado sanduíche do autor na chair of risk, safety and uncertainty quantification da Eidgenössische Technische Hochschule Zürich. A concepção e programação da técnica proposta, bem como dos exemplos, foram realizadas pelo autor, seguindo a cuidadosa orientação dos professores Bruno Sudret e André Beck e do pesquisador Maliki Moustapha.

\subsection{Introdução}

A abordagem da otimização de risco permite que não apenas as características físicas da estrutura, mas o próprio nível de segurança do sistema seja otimizado em relação aos seus custos totais. Diferentes custos do ciclo de vida da estrutura podem ser considerados na função objetivo do problema, sendo assim a formulação mais abrangente em comparação com formulações concorrentes. Apesar da escassez de trabalhos sobre o tema, nota-se na literatura uma predisposição à adoção da RO quando possível. Conforme comentado no capítulo anterior, os trabalhos que se utilizam desta formulação costumam endereçar problemas bastante específicos, e não a proposta de métodos para a solução de problemas deste tipo. Observa-se nos problemas práticos abordados que, por vezes, a descrição dos custos do ciclo de vida das estruturas estudadas se dá em função do tempo. Desse modo, busca-se otimizar o custo total da estrutura ao longo de toda sua vida útil. Sendo assim, uma formulação geral para a solução de problemas de otimização de risco deve considerar as incertezas e os custos associados a fenômenos dependentes do tempo. A consideração de degradação da resistência estrutural, de cargas de natureza variável e de taxas de juros atuando sobre os custos aumenta a complexidade do problema. Particularmente, problemas envolvendo confiabilidade de sistemas e cargas descritas como 
processos estocásticos podem gerar dificuldades adicionais na solução, conforme será estudado na Seção 8.8.

A avaliação de estruturas sujeitas a variações temporais requer a utilização de alguma formulação para a determinação de confiabilidades dependentes do tempo. Este tópico foi bastante estudado por volta do ano 2000 (MELCHERS, 1999; SUDRET; KIUREGHIAN, 2000; RACKWITZ, 2001; BECK, 2003). Talvez devido às limitações das abordagens possíveis à época, o tema não recebeu tanta atenção na década seguinte. As abordagens propostas se aplicavam apenas a casos muito limitados, com exceção da avaliação das probabilidades de falha dependentes do tempo por meio de simulação de Monte Carlo, inviável na prática (MELCHERS; BECK, 2018).

Recentes avanços na área de metamodelagem permitiram a utilização de simulações de Monte Carlo em problemas que, até recentemente, eram inviáveis. Echard, Gayton e Lemaire (2011) propuseram um método de aprendizado ativo, combinando Krigagem com SMC para aplicação em problemas de confiabilidade estrutural. Abordagens parecidas foram utilizada por Dubourg, Sudret e Bourinet (2011a) e Moustapha et al. (2016) para a solução de problemas de RBDO. Wang e Chen (2016) introduziram uma transformação para facilitar a consideração de processos estocásticos na avaliação de problemas de confiabilidade estrutural dependente do tempo. Essa abordagem foi aplicada à solução de problemas de RBDO em Li, Bai e Wang (2018b).

Objetivando contribuir com o cenário apresentado, este capítulo propõe um procedimento para a solução de problemas gerais de otimização de risco dependente do tempo. $\mathrm{Na}$ abordagem apresentada, dois níveis de metamodelagem são empregados por meio de Krigagem adaptativa (JONES; SCHONLAU; WELCH, 1998; ECHARD; GAYTON; LEMAIRE, 2011; SCHÖBI; SUDRET; MARELLI, 2017): um para aproximar a função objetivo e outro para aproximar as equações de estado limite. Técnicas de aprendizado ativo diferentes são empregadas, considerando as particularidades de cada nível. Problemas envolvendo confiabilidade dependente do tempo, com estruturas sofrendo degradação e submetidas a carregamentos estocásticos, são apresentados como exemplos para ilustrar o procedimento.

\subsection{Estimativa baseada em Monte Carlo da probabilidade de falha acumulada}

Quando o vetor $\boldsymbol{X}$ inclui variáveis aleatórias e processos estocásticos, as funções de estado limite escritas em função dele adquirem também características de processos estocásticos. Nesse caso, uma realização da função de estado limite é composta pelos valores assumidos por cada $\mathrm{PE}$ ao longo do tempo, e também pelas realizações das variáveis aleatórias de $\boldsymbol{X}$, definindo-se assim o valor constante que cada VA assume ao longo das realizações dos processos estocásticos. A abordagem de simulação utilizada aqui consiste basicamente em uma discretização do domínio do tempo, a partir da qual trajetórias da 
função de estado limite são traçadas. Avalia-se então o número de realizações que implicam em uma falha da estrutura em cada passo de tempo. Para isso, é necessário que trajetórias de cada processo estocástico sejam traçadas, o que pode ser feito por meio da expansão da estimativa linear ótima (Seção 2.3.1).

Considere a função de estado limite dependente de um vetor que inclui processos estocásticos $\boldsymbol{X}$, da configuração de projeto $\boldsymbol{d}$ e do tempo, $g(\boldsymbol{d}, t, \boldsymbol{X}(t, \omega))$, em um determinado intervalo de tempo $[0, \mathcal{T}] . N_{M C}$ amostras de realizações dos processos estocásticos são construídas a partir da EOLE, e obtém-se também um mesmo número de amostras de realizações das variáveis aleatórias. Seja $G$ um vetor com $N$, posições, sendo $N$ o número de instantes em que o intervalo de tempo considerado é discretizado. Os valores da realização da função de estado limite em cada instante são armazenados neste vetor, em que cada posição $i=1, \ldots, N$ corresponde a um tempo $t_{i}=(i-1) \Delta t$, em que $\Delta t=\frac{\mathcal{T}}{N-1}$ é o passo de tempo considerado na discretização. Para cada intervalo de tempo $\left[t_{i}, t_{i+1}\right]$, um contador $k_{i+1}$ é definido. Toda vez que a função de estado limite apresenta a primeira falha, esta falha ocorre em um intervalo $\left[t_{i}, t_{i+1}\right]$, e todos os contadores $k_{n}$, com $n=i+1, \ldots, N$ são incrementados (i.e. todos os contadores remanescentes, do intervalo de tempo posterior à falha, são incrementados). Uma estimativa utilizando-se Monte Carlo bruto para a probabilidade de falha acumulada entre o início do intervalo de tempo considerado e um instante arbitrário $t_{i}$, i.e. $P_{f c_{M C}}\left(0, t_{i}\right)$, é dada por:

$$
P_{f c_{M C}}\left(0, t_{i}\right)=\frac{k_{i}+k_{0}}{N_{M C}}
$$

em que $k_{0}$ conta o número de falhas no instante $t=0$.

\subsection{Otimização global eficiente}

A otimização global eficiente (EGO) foi introduzida por Jones, Schonlau e Welch (1998) como uma maneira de se resolver problemas de otimização por meio da substituição da função objetivo por um metamodelo de Krigagem. A ideia básica consiste em se utilizar a variância da Krigagem de maneira a se balancear a exploração de áreas do espaço de projeto que correspondem a valores menores da função objetivo, o que pode indicar a proximidade do ponto ótimo, com a exploração de áreas em que a variância é alta, o que indica que a previsão da Krigagem não é precisa naquela região. O algoritmo é iniciado a partir da definição de um DOE com alguns pontos espalhados pelo espaço de projeto de maneira esparsa. Constrói-se então um metamodelo da Krigagem a partir dele. Neste capítulo, uma amostragem por hipercubo latino será utilizada para a definição do DOE inicial. Em seguida, uma função de mérito é utilizada para a decisão do próximo ponto a ser adicionado ao DOE, de maneira a trazer mais informações úteis para a solução do problema. Adota-se aqui a função de mérito utilizada em, Jones, Schonlau e Welch (1998), originalmente introduzida no trabalho de Mockus (1974), a chamada função de melhoria 
esperada (EIF- Expected Improvement Function), denotada por EI:

$$
E I(\boldsymbol{x})=\left(y_{\min }-\mu_{\tilde{\mathcal{M}}}(\boldsymbol{x})\right) \Phi\left(\frac{y_{\min }-\mu_{\tilde{\mathcal{M}}}(\boldsymbol{x})}{\sigma_{\tilde{\mathcal{M}}}(\boldsymbol{x})}\right)+\sigma_{\tilde{\mathcal{M}}}(\boldsymbol{x}) \varphi\left(\frac{y_{\min }-\mu_{\tilde{\mathcal{M}}}(\boldsymbol{x})}{\sigma_{\tilde{\mathcal{M}}}(\boldsymbol{x})}\right),
$$

em que $\varphi$ e $\Phi$ são as PDF e CDF gaussianas, e $y_{\text {min }}$ é o ponto de mínimo conhecido atual (ou seja, o ponto em que se avaliou a função objetivo e obteve-se o menor resultado). Esta função é composta por duas partes complementares: A primeira parte está relacionada com a probabilidade de se encontrar um ponto de mínimo atual ainda menor, enquanto a segunda parte está associada à variância do metamodelo. A partir da combinação destas duas considerações, a função de melhoria esperada propicia uma exploração inteligente do espaço de projeto. Desse modo, o próximo ponto a ser adicionado ao DOE é escolhido como sendo o ponto que maximiza a EIF. No trabalho original em que esta abordagem foi proposta, os autores utilizavam um algoritmo de otimização para encontrar o ponto de máximo da função de melhoria esperada no espaço de projeto. Neste trabalho, como o custo de avaliação da EIF é pequeno, uma busca discreta é realizada. Um grande número de pontos é amostrado, e então o ponto que corresponde ao maior valor da função é selecionado. O procedimento da EGO pode então ser resumido nos seguintes passos:

1. Gerar um conjunto $\mathcal{S}$ com $N_{\mathrm{EGO}}$ pontos pertencentes ao espaço amostral, candidatos ao enriquecimento dos metamodelos $\mathcal{S}=\left\{\boldsymbol{s}^{(1)}, \ldots, \boldsymbol{s}^{\left(N_{\mathrm{EGO}}\right)}\right\}$

2. Gerar um projeto de experimento inicial $\mathcal{D}=\left\{\boldsymbol{d}^{(1)}, \ldots, \boldsymbol{d}^{(m)}\right\}$ e avaliar a função objetivo nestes pontos, definindo-se $\mathcal{C}=\left\{C_{T}\left(\boldsymbol{d}^{(1)}\right), \ldots, C_{T}\left(\boldsymbol{d}^{(m)}\right)\right\}$;

3. Treinar um metamodelo de Krigagem $\widetilde{C}_{T}$ a partir de $\{\mathcal{D}, \mathcal{C}\}$;

4. Avaliar a função de melhoria esperada em todos os pontos do conjunto de pontos candidatos $\mathcal{S}: \mathcal{E}=\left\{E I\left(\boldsymbol{s}^{(1)}\right), \ldots, E I\left(\boldsymbol{s}^{\left(N_{\mathrm{EGO}}\right)}\right)\right\}$

5. Selecionar o melhor ponto como sendo aquele que maximiza a EIF no conjunto $\mathcal{S}$ :

$$
\boldsymbol{s}^{*}=\arg \max _{s \in \mathcal{S}} \mathcal{E}
$$

6. Conferir o critério de convergência. Se ele estiver atendido, encerrar o algoritmo. Caso contrário, executar o passo 7;

7. Avaliar $C_{T}\left(\boldsymbol{s}^{*}\right)$ e adicionar $\left\{\boldsymbol{s}^{*}, C_{T}\left(\boldsymbol{s}^{*}\right)\right\}$ ao projeto de experimento $\{\mathcal{D}, \mathcal{C}\}$. Retornar para o passo 3;

Para os exemplos deste capítulo, adota-se $N_{\mathrm{EGO}}=10^{5}$, e os pontos em $\mathcal{S}$ são gerados a partir de uma amostragem por hipercubo latino sobre o espaço de projeto. O algoritmo é parado quando $\max _{\mathcal{E}} E I(s)$ é menor que um determinado valor, conforme recomendado em Bichon (2010). Adotou-se um limite de $10^{-3}$, que se mostrou adequado em todos os exemplos estudados. 


\subsection{Análise de confiabilidade global eficiente}

Ainda que a EGO seja eficiente, a solução de problemas de otimização de risco dependente do tempo pode continuar inviável mesmo com dessa abordagem. Isso se dá pelo fato de que a avaliação completa de um problema de confiabilidade dependente do tempo é necessária a cada vez que um custo total $C_{T}(\boldsymbol{d})$ é avaliado. Desse modo, modelos numéricos que podem ser complexos precisam ser avaliados um grande número de vezes em cada passo de tempo do problema de confiabilidade. Uma maneira direta de se lidar com este problema é a adoção de metamodelagem neste nível também. O caso mais geral possível deveria incluir a consideração de problemas dinâmicos, o que ainda é uma tarefa desafiadora de se abordar com metamodelagem (MAI et al., 2016; MAI; SUDRET, 2017)). Neste trabalho, limita-se o escopo da abordagem a problemas dependentes do tempo em que as cargas, apesar de variáveis, são aplicadas de forma lenta o suficiente para que os problemas mecânicos possam ser considerados estáticos. Para estes casos, um metamodelo de Krigagem $\widetilde{g}$ pode ser utilizado diretamente para aproximar o comportamento das funções de estado limite, diminuindo drasticamente o custo da solução via EGO.

Uma técnica para o estudo de problemas de confiabilidade inspirada na EGO foi proposta por Bichon et al. (2008), sendo chamada de análise de confiabilidade global eficiente (EGRA). Consiste na construção adaptativa de um metamodelo de maneira a se garantir sua precisão nas regiões próximas à superfície de falha do problema considerado. Assim como no caso da EGO, várias funções de mérito, neste contexto conhecidas como funções de aprendizado, foram propostas na literatura. Para o caso de metamodelos de Krigagem, isso inclui, em tradução livre, a função de melhoria esperada para a estimativa do contorno (RANJAN; BINGHAM; MICHAILIDIS, 2008), o número de desvio (ECHARD; GAYTON; LEMAIRE, 2011) e a função de probabilidade marginal (DUBOURG; SUDRET; BOURINET, 2012). Neste trabalho adota-se a função de viabilidade esperada (EFF), conforme proposta por Bichon et al. (2008):

$$
\begin{array}{r}
E F(\boldsymbol{x})=\mu_{\tilde{g}}(\boldsymbol{x})\left[2 \Phi\left(\frac{\mu_{\tilde{g}}(\boldsymbol{x})}{\sigma_{\tilde{g}}(\boldsymbol{x})}\right)-\Phi\left(\frac{-2 \sigma_{\tilde{g}}(\boldsymbol{x})-\mu_{\tilde{g}}(\boldsymbol{x})}{\sigma_{\tilde{g}}(\boldsymbol{x})}\right)-\Phi\left(\frac{2 \sigma_{\tilde{g}}(\boldsymbol{x})-\mu_{\tilde{g}}(\boldsymbol{x})}{\sigma_{\tilde{g}}(\boldsymbol{x})}\right)\right] \\
-\sigma_{\tilde{g}}(\boldsymbol{x})\left[2 \varphi\left(\frac{\mu_{\tilde{g}}(\boldsymbol{x})}{\sigma_{\tilde{g}}(\boldsymbol{x})}\right)-\varphi\left(\frac{-2 \sigma_{\tilde{g}}(\boldsymbol{x})-\mu_{\tilde{g}}(\boldsymbol{x})}{\sigma_{\tilde{g}}(\boldsymbol{x})}\right)-\varphi\left(\frac{2 \sigma_{\tilde{g}}(\boldsymbol{x})-\mu_{\tilde{g}}(\boldsymbol{x})}{\sigma_{\tilde{g}}(\boldsymbol{x})}\right)\right] \\
+2 \sigma_{\tilde{g}}(\boldsymbol{x})\left[\Phi\left(\frac{2 \sigma_{\tilde{g}}(\boldsymbol{x})-\mu_{\tilde{g}}(\boldsymbol{x})}{\sigma_{\tilde{g}}(\boldsymbol{x})}\right)-\Phi\left(\frac{-2 \sigma_{\tilde{g}}(\boldsymbol{x})-\mu_{\tilde{g}}(\boldsymbol{x})}{\sigma_{\tilde{g}}(\boldsymbol{x})}\right)\right] .
\end{array}
$$

Esta função se comporta de maneira similar à função de melhoria esperada, assumindo valores maiores quando o ponto avaliado está próximo à equação de estado limite, e também quando a variância da Krigagem é alta. O próximo ponto a ser adicionado ao projeto de experimento é aquele que maximiza a Equação. (8.4). Mais uma vez, ao invés de se buscar este ponto de máximo através de um algoritmo de otimização, realiza-se 
uma busca discreta em um conjunto grande de pontos, conforme proposto em Echard, Gayton e Lemaire (2011) no contexto do que foi chamado de active Kriging - Monte Carlo simulation (AK-MCS). O algoritmo então pode ser sintetizado da seguinte forma:

1. Gerar um conjunto amostral com $N_{\text {EGRA }}$ candidatos $\mathcal{U}=\left\{\boldsymbol{u}^{(1)}, \ldots, \boldsymbol{u}^{\left(N_{\mathrm{EGRA}}\right)}\right\}$. Os pontos são selecionados no espaço aumentado do problema. Desse modo, obtém-se um metamodelo global que pode ser utilizado para a análise de confiabilidade em qualquer configuração estrutural.

2. Gerar um projeto de experimento inicial $\mathcal{X}=\left\{\boldsymbol{x}^{(1)}, \ldots, \boldsymbol{x}^{\left(N_{0}\right)}\right\}$ e avaliar as equações de estado limite correspondentes $\mathcal{G}=\left\{g\left(\boldsymbol{x}^{(1)}\right), \ldots, g\left(\boldsymbol{x}^{\left(N_{0}\right)}\right)\right\}$;

3. Treinar um metamodelo de Krigagem $\widetilde{g}$ a partir do projeto de experimento adotado $\{\mathcal{X}, \mathcal{G}\}$

4. Avaliar a função de viabilidade esperada em todos os pontos candidatos $\mathcal{U}: \mathcal{H}=$ $\left\{E F\left(\boldsymbol{u}^{(1)}\right), \ldots, E F\left(\boldsymbol{u}^{\left(N_{\mathrm{EGRA}}\right)}\right)\right\}$;

5. Selecionar o ponto que maximiza $E F$ no conjunto $\mathcal{U}$ :

$$
\boldsymbol{u}^{*}=\arg \max _{\boldsymbol{u} \in \mathcal{U}} \mathcal{H}
$$

6. Conferir se o critério de convergência foi atendido. Se foi, encerrar o algoritmo. Caso contrário, ir para o passo 7 ;

7. Avaliar $g\left(\boldsymbol{u}^{*}\right)$ e adicionar $\left\{\boldsymbol{u}^{*}, g\left(\boldsymbol{u}^{*}\right)\right\}$ ao projeto de experimento $\{\mathcal{X}, \mathcal{G}\}$. Retornar para o passo 3 ;

Nos exemplos estudados neste capítulo, considera-se $N_{\text {EGRA }}=10^{5}$, com os pontos selecionados a partir de uma amostragem por hipercubo latino realizada no espaço aumentado do problema. Considera-se a convergência quando $\max _{\mathcal{F}} E F(\boldsymbol{u})$ é menor do que um limite, adotado nos exemplos como $10^{-3}$.

\subsection{Abordagem proposta}

Em síntese, a abordagem proposta se baseia na construção de dois níveis de metamodelagem. Para o nível "interno", constrói-se um metamodelo de Krigagem para as equações de estado limite do problema. Desse modo, pode-se estimar as probabilidades de falha acumuladas para as diferentes configurações estruturais que serão avaliadas de maneira eficiente, pela abordagem apresentada na Seção 8.3. O tempo de vida da estrutura é discretizado, de modo que os custos associados são trazidos para seus valores presentes por meio da aplicação das taxas de juros correspondentes, conforme a Equação 3.20. No nível "externo", o problema de otimização é resolvido por EGO (Seção 8.4). A computação 
dos termos do custo total $C_{T}(\boldsymbol{d})$ que exigem o cálculo de probabilidades de falha é realizada considerando o metamodelo do nível interior. Os dois níveis são interdependentes, e portanto uma boa precisão e um baixo custo de avaliação do metamodelo interno são cruciais para a eficiência desta metodologia. Buscando-se um projeto de experimento que garanta essas características, adota-se a abordagem da EGRA (Seção 8.5) na construção do metamodelo interno. As análises de confiabilidade executadas neste capítulo foram feitas a partir do software UQlab (MARELLI; SUDRET, 2013), cujo código foi adaptado para a construção da abordagem proposta.

\subsection{Estruturas sob processo de degradação}

\subsubsection{Exemplo - Viga sujeita a corrosão}

Seja uma viga metálica com seção transversal retangular $\left\{b_{0}, h_{0}\right\}^{T}$ e comprimento $L=5 \mathrm{~m}$, sujeita ao seu peso próprio $\rho_{s t} b_{0} h_{0}\left(\mathrm{Nm}^{-1}\right)$, sendo que $\rho_{s t}=78.5 \mathrm{kN} \mathrm{m} \mathrm{m}^{-3}$ é a densidade do aço, e sujeita também a uma carga concentrada aplicada no meio do vão.
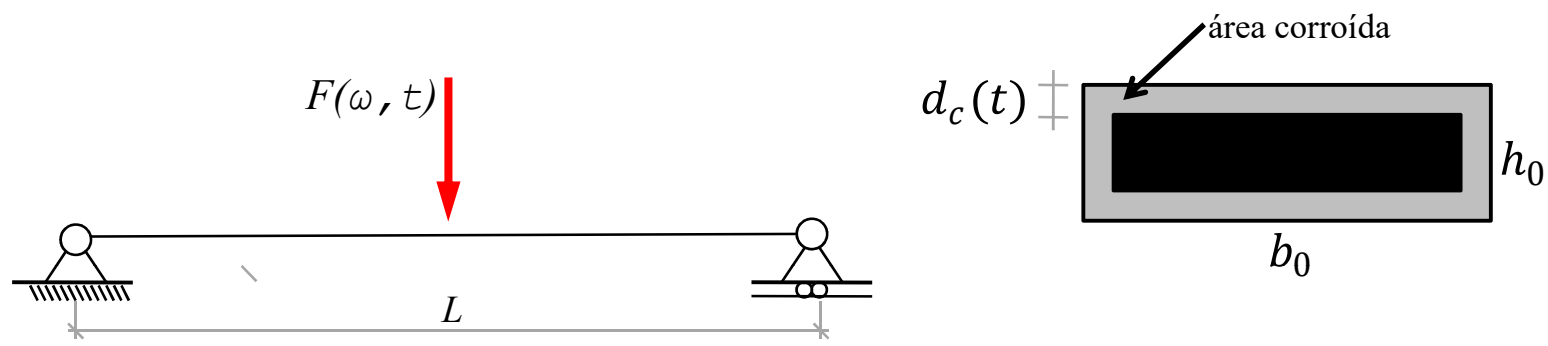

Figura 18: Viga submetida a corrosão, adaptado de Sudret (2008).

A viga é sujeita ainda a corrosão, de maneira que a profundidade corroída $d_{c} \mathrm{em}$ todas as faces da viga aumenta linearmente com o tempo, ou seja, $d_{c}=\kappa t$, em que $\kappa$ é a taxa de corrosão. Considera-se ainda que a área da seção transversal que foi corroída perdeu toda a sua resistência mecânica. A função de estado limite que descreve a formação de uma rótula plástica no meio do vão pode ser escrita como:

$$
g(\boldsymbol{d}, t, \mathbf{X})=\frac{\left(b_{0}-2 \kappa t\right)\left(h_{0}-2 \kappa t\right)^{2} f_{y}}{4}-\left(\frac{F L}{4}+\frac{\rho_{s t} b_{0} h_{0} L^{2}}{8}\right),
$$

em que a tensão de escoamento é denotada por $f_{y}$. A análise é realizada considerando-se o intervalo $[0,10]$ anos. Três cenários são considerados para a taxa de corrosão. No primeiro, a cinética da corrosão é controlada através de um parâmetro determinístico $\kappa=1 \mathrm{~mm}$ $a^{-1}$. No segundo cenário, a taxa de corrosão é uma variável aleatória, com média 1 $\mathrm{mm} \mathrm{ano}^{-1}$ e coeficiente de variação de $30 \%$. No terceiro cenário, a taxa de corrosão é considerada como um processo estocástico discreto, que assume um novo valor a cada ano, com intensidade média $1 \mathrm{~mm}^{\text {ano }}{ }^{-1}$ e coeficiente de variação de $30 \%$. Em todos so 
cenários, a carga $F$ é modelada como um processo estocástico gaussiano, com média 6000 N, CV 0.3 e uma função de autocorrelação gaussiana, com comprimento de correlação $\lambda=1$ mês. Os parâmetros aleatórios do problema são reunidos na Tabela 15. Define-se então o problema de otimização de risco a partir da Equação (8.7).

$$
\begin{gathered}
C_{T}=C_{I}+\sum_{i=1}^{10} C_{f} P_{f c_{i}} \\
\text { sujeito a } 0.1 \leq b_{0} \leq 0.5 \\
0.01 \leq h_{0} \leq 0.06 .
\end{gathered}
$$

Os custos iniciais são relacionados à seção transversal da viga $C_{I}=\nu b_{0} h_{0}$, com $\nu=1 / 125$, e os custos de falha são considerados 1000 vezes maiores, i.e. $C_{f}=1000 C_{I}$. Neste exemplo, um custo de falha alto é adotado propositalmente, penalizando as regiões inseguras do espaço de projeto, dando origem a uma função objetivo composta por duas regiões bastante distintas (uma região associada a valores altos de $C_{T}$, e outra, praticamente plana, associada a valores baixos), separadas por uma transição brusca, conforme ilustrado nas Figuras 19, 20 e 21. A representação deste tipo de comportamento com modelos de Krigagem é uma tarefa desafiadora. Por fim, uma taxa de juros mensal de $1 \%$ é considerada. O problema de otimização consiste na determinação do $\boldsymbol{d}=\left\{b_{0}, h_{0}\right\}^{T}$ que minimiza o custo total $C_{T}(\boldsymbol{d})$.

Tabela 15: Parâmetros aleatórios da viga sob corrosão

\begin{tabular}{llll}
\hline Parâmetro & Distribuição & Média & CV \\
\hline Tensão de escoamento (MPa) & Lognormal & 240 & $10 \%$ \\
Largura (m) & Lognormal & $b_{0}$ & $3 \%$ \\
Altura (m) & Lognormal & $h_{0}$ & $3 \%$ \\
\hline
\end{tabular}

As Figuras 19, 20 e 21 mostram as curvas de nível da função de custo em todo o espaço de projeto. Destacam-se as regiões planas, denotadas por poucas curvas de nível, em contraste com as demais regiões em que a concentração de curvas é muito alta. Os quadrados, triângulos e círculos vermelhos são os resultados de 30 aplicações da abordagem apresentada para cada cenário de corrosão. Além disso, uma avaliação custosa feita sobre o problema através de um algoritmo de enxame de partículas (PSO) (BANSAL et al., 2011) também é realizada sem a consideração de metamodelos, usando 30 partículas por iteração, de modo que os resultados possam ser comparados. O critério de parada para o PSO é uma tolerância de $10^{-4}$ na mudança do valor de todas as variáveis de projeto. $\mathrm{O}$ resultado de referência é representado nas figuras por um losango verde.

Utilizando-se a abordagem proposta, a função objetivo precisou ser avaliada, em média, para os cenários da taxa de corrosão determinística, definida por VA, e definida por PE, 23, 25 e 27 vezes, respectivamente. Já as soluções via EGO requereram 480, 510 e 510 avaliações, respectivamente. Os resultados para os custos totais em cada cenário 
são comparados na Figura 22. O "box-plot" mostra os resultados ótimos para as 30 soluções, para cada caso. Nota-se que resultados bastante precisos foram obtidos através da abordagem estudada, com apenas algumas avaliações da função de estado limite.

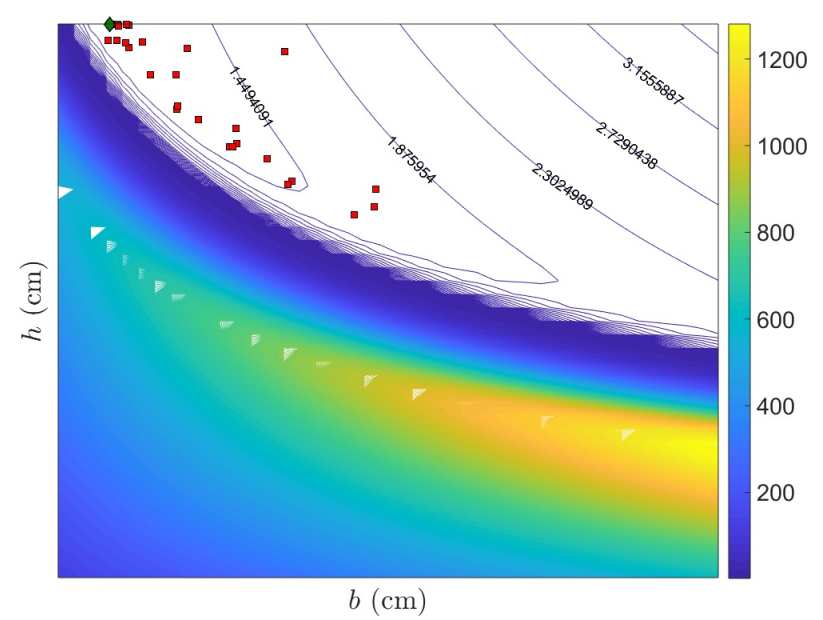

Figura 19: Resultados para $\kappa$ fixo.

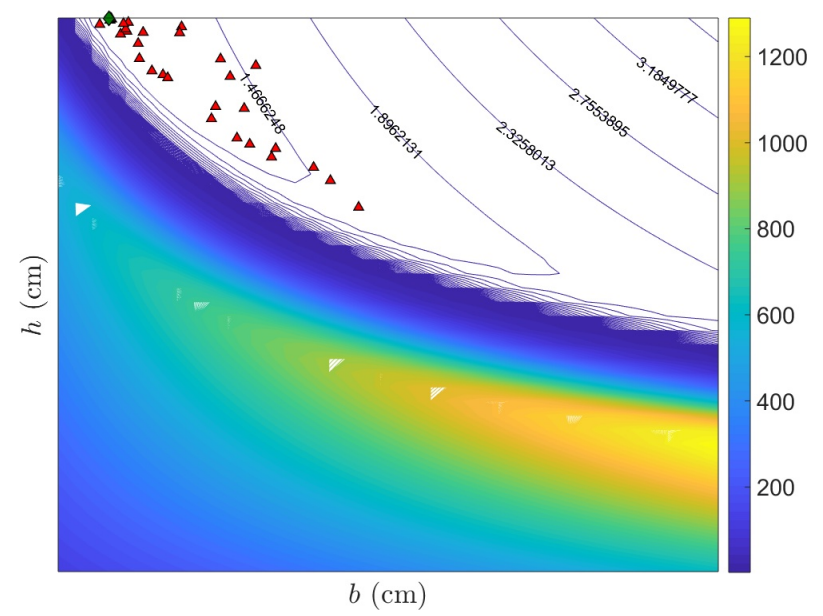

Figura 20: Resultados para $\kappa$ sendo uma VA. 


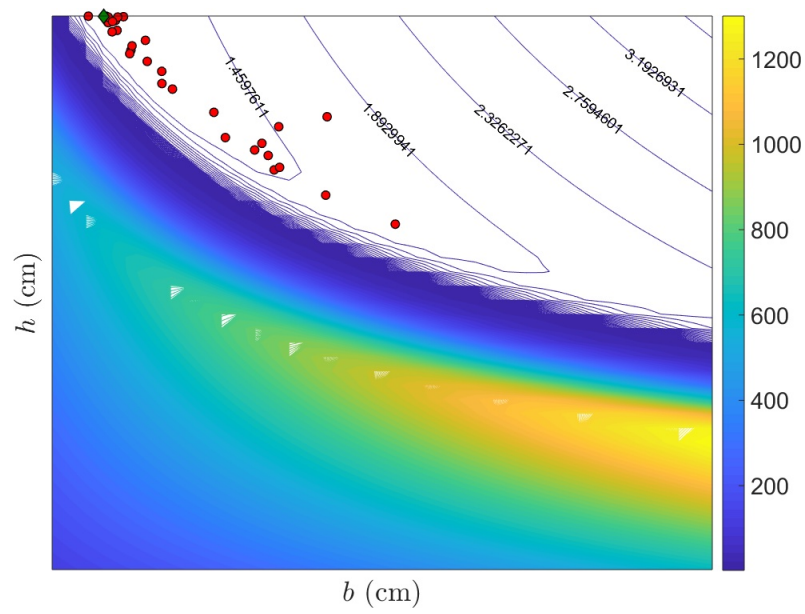

Figura 21: Resultados para $\kappa$ sendo um PE.

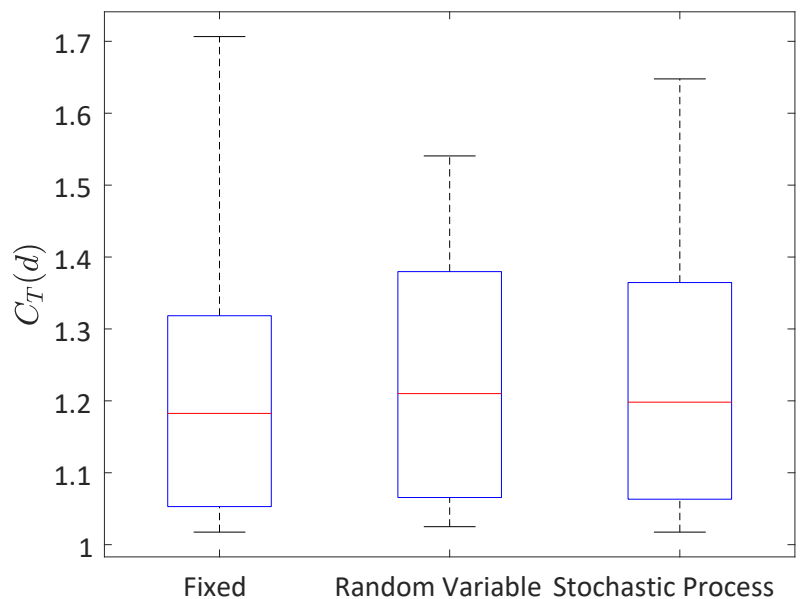

Figura 22: Box-plot para os custos totais considerando os três cenários de taxa de corrosão.

\subsubsection{Exemplo - Treliça com três tipos de barra}

Uma treliça bidimensional, adaptada a partir da treliça estudada na seção 4.5.1, é representada na Figura 23. A estrutura é composta por 23 barras e 13 nós, e sujeita a 6 cargas variantes no tempo, aplicadas aos seus nós superiores. Todos os carregamentos são descritos através de um único processo estocástico gaussiano com média $50 \mathrm{kN}$, desvio padrão 7.5 kN e função de de autocorrelação gaussiana com comprimento de correlação $\lambda=1$ ano. A treliça é construída com três tipos de barras, definidos por suas seções transversais e módulos de elasticidade, conforme indicado na figura. As variáveis de projeto do problema são os raios $d_{1}, d_{2}$ e $d_{3}$ das barras circulares de cada tipo. As barras estão sujeitas a corrosão, de maneira que o raio de suas seções transversais diminui ao longo do tempo, seguindo $r_{c}=\kappa t$. O raio no instante $t=0$ é $r_{i}$, e o raio atual em um tempo $t$ qualquer é $r(t)=r_{i}-r_{c}(t)$ conforme ilustrado na Figura 24.

Três cenários são considerados para a taxa de corrosão: no caso \#1, uma taxa determinística $\kappa=10 \mu \mathrm{m} \quad$ ano $^{-1}$ é considerada. No caso \#2, três taxas de corrosão 


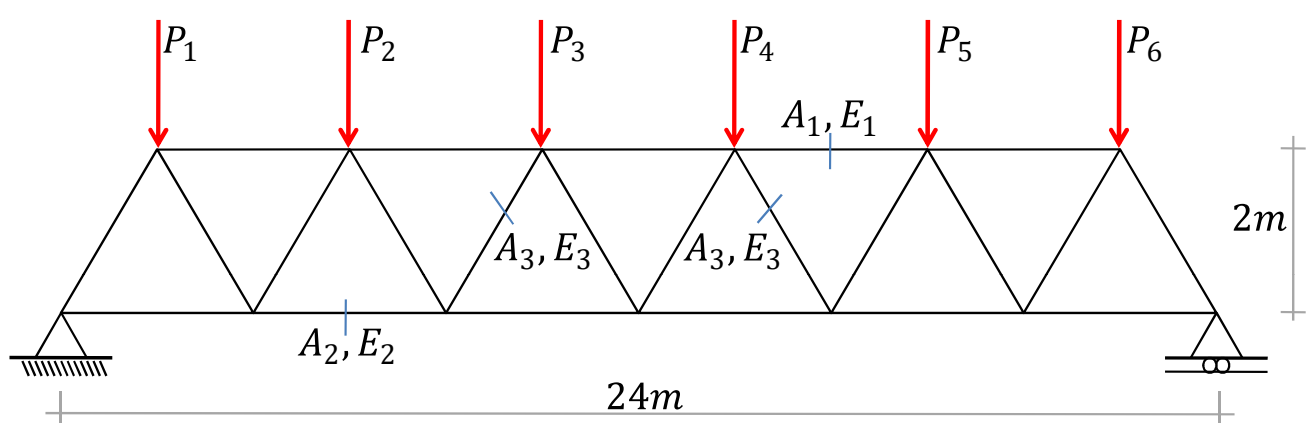

Figura 23: Treliça plana com três tipos de barra.

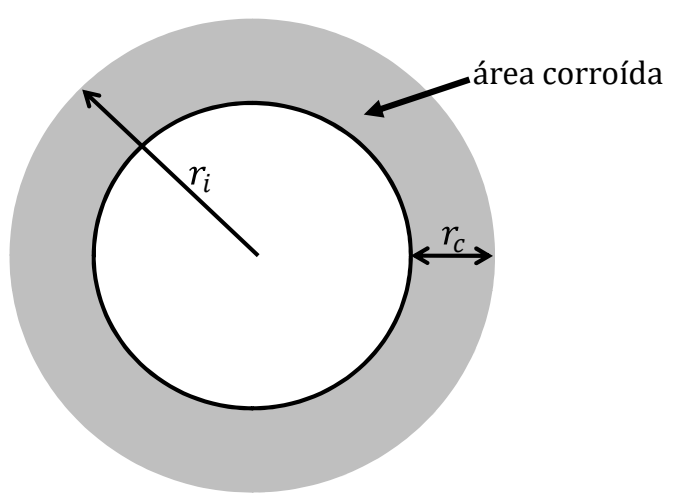

Figura 24: Perda de raio devido a corrosão.

diferentes são consideradas, uma para cada tipo de barra. $\kappa_{1}^{R V}, \kappa_{2}^{R V}$ e $\kappa_{3}^{R V}$ são variáveis aleatórias correlacionadas, com média $10 \mu \mathrm{m}$ ano ${ }^{-1}$ e CV 30\%. O coeficiente de correlação entre elas é de 0.8 . No caso \#3, três processos estocásticos discretos são utilizados para modelar a corrosão, um para cada tipo de barra. Os processos se renovam anualmente, e apresentam média $10 \mu \mathrm{m}$ ano ${ }^{-1}$, CV $30 \%$ e um coeficiente de correlação entre eles de 0.8. A Tabela 16 descreve as demais variáveis aleatórias consideradas neste problema. A equação de estado limite do problema de confiabilidade é definida implicitamente através de um modelo de elementos finitos, e é escrita em termos do deslocamento vertical do nó da treliça localizado no meio de seu vão, denotado por $V_{1}$. O deslocamento vertical máximo permitido é de $0.1 \mathrm{~m}$ :

$$
g(\boldsymbol{d}, t, \mathbf{X})=0.1-V_{1}(\boldsymbol{d}, t, \mathbf{X})
$$

O intervalo de tempo considerado na análise é $[0,30]$ anos, de maneira que a função 
objetivo do problema de otimização de risco é escrita como:

$$
\begin{gathered}
C_{T}=C_{I}+\sum_{i=1}^{30} C_{f} P_{f c_{i}}, \\
\text { sujeito a } 0.02 \mathrm{~m} \leq d_{1} \leq 0.04 \mathrm{~m} \\
\quad 0.02 \mathrm{~m} \leq d_{2} \leq 0.04 \mathrm{~m} \\
0.02 \mathrm{~m} \leq d_{3} \leq 0.04 \mathrm{~m}
\end{gathered}
$$

Os custos de construção são considerados proporcionais às áreas das barras, adotando-se $C_{I}=10^{4}\left(d_{1}^{2}+d_{2}^{2}+d_{3}^{2}\right)$, e os custos de falha são considerados como $C_{f}=10 C_{I}$. Uma taxa de juros anual de $1 \%$ também é considerada. Os resultados de 20 análises são resumidos pelas Figuras 25 a 28. As Figuras 25 a 27 mostram box-plots com os resultados para cada variável de projeto em cada cenário considerado. A Figura 28 reúne os custos totais ótimos correspondentes. Pode-se observar que a metodologia apresentada forneceu resultados consistentes. Em média, a função objetivo foi avaliada apenas 13, 13 e 14 vezes, em cada um dos cenários de corrosão considerados, respectivamente.

Tabela 16: Treliça sujeita a corrosão - variáveis aleatórias

\begin{tabular}{llll}
\hline Parâmetro & Distribuição & Média & CV \\
\hline$E_{1}(M P a)$ & Lognormal & 210000 & $10 \%$ \\
$E_{2}(M P a)$ & Lognormal & 210000 & $10 \%$ \\
$E_{3}(M P a)$ & Lognormal & 210000 & $10 \%$ \\
$A_{1}\left(\mathrm{~cm}^{2}\right)$ & Lognormal & $\pi r_{1}^{2}$ & $10 \%$ \\
$A_{2}\left(\mathrm{~cm}^{2}\right)$ & Lognormal & $\pi r_{2}^{2}$ & $10 \%$ \\
$A_{3}\left(\mathrm{~cm}^{2}\right)$ & Lognormal & $\pi r_{3}^{2}$ & $10 \%$ \\
\hline
\end{tabular}

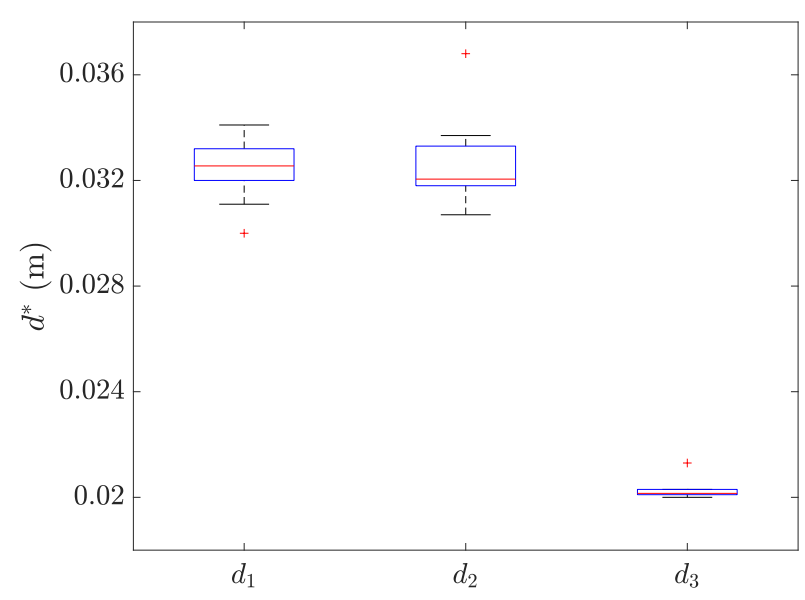

Figura 25: Valores ótimos dos raios para o caso \#1. 


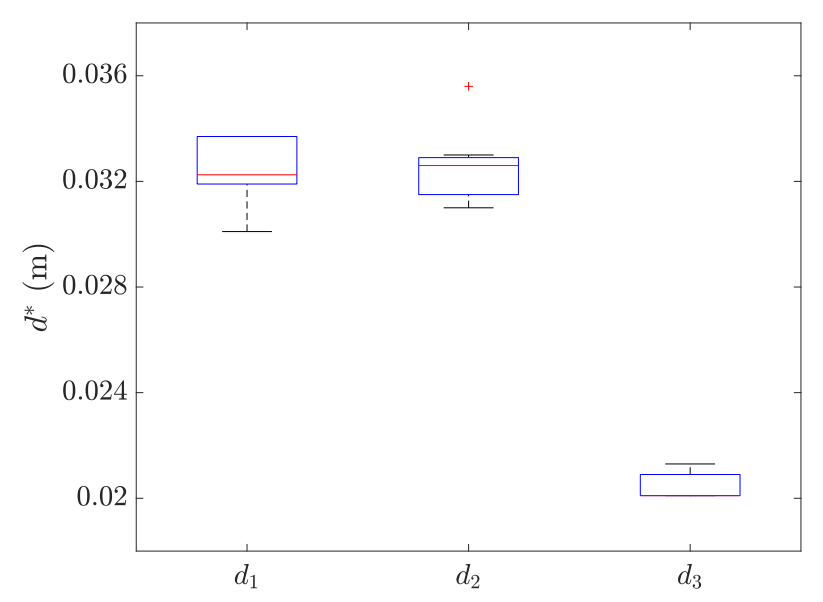

Figura 26: Valores ótimos dos raios para o caso \#2.

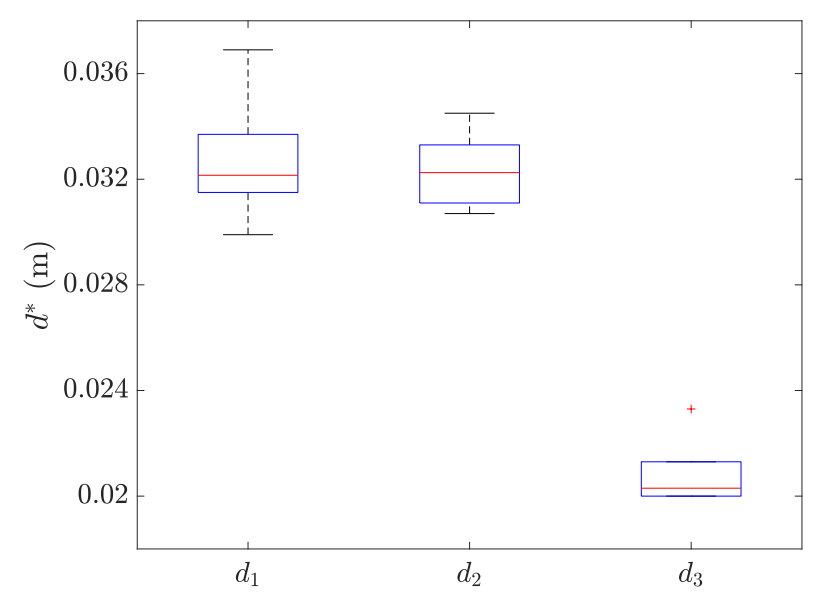

Figura 27: Valores ótimos dos raios para o caso \#3.

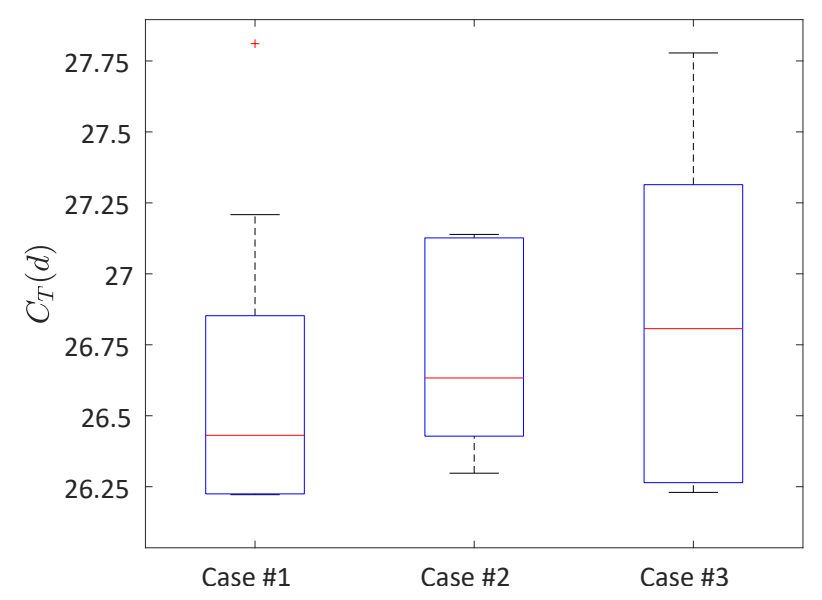

Figura 28: Custos totais ótimos obtidos.

\subsection{Dependência do caminho dos carregamentos}

Quando problemas de confiabilidade de sistemas dependem do tempo, as combinações das trajetórias seguidas pelos processos estocásticos podem definir qual modo 
de falha da estrutura será violado primeiro. Este comportamento dificulta a solução do problema. Para exemplificar, considere a treliça composta pelas barras circulares 1 e 2 , como mostrado na Figura 29. Duas cargas dependentes do tempo $H(t)$ e $V(t)$ são aplicadas no nó superior. Três modos de falha são considerados: ruptura por tração da barra $1\left(g_{t 1}\right)$, flambagem da barra $1\left(g_{b 1}\right)$, e flambagem da barra $2\left(g_{b 2}\right)$. Desse modo, um problema de confiabilidade de sistema dependente do tempo é definido, considerando as seguintes equações associadas a estes modo de falha:

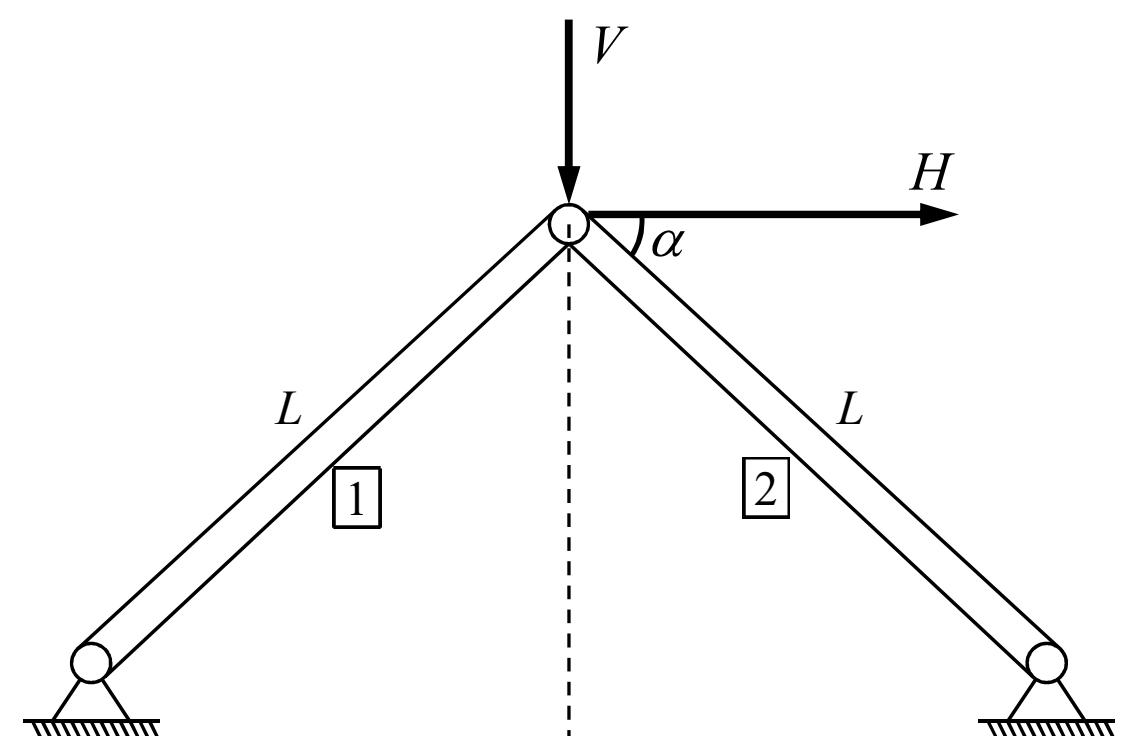

Figura 29: Treliça sujeita a cargas dependentes do tempo.

$$
\begin{aligned}
& g_{t 1}(\boldsymbol{X}, t)=A_{1} \sigma_{u}-\left[\frac{H(t)}{2 \cos \alpha}-\frac{V(t)}{2 \sin \alpha}\right] \\
& g_{b 1}(\boldsymbol{X}, t)=\frac{\pi^{2} E I_{1}}{L^{2}}-\left[-\frac{H(t)}{2 \cos \alpha}+\frac{V(t)}{2 \sin \alpha}\right] \\
& g_{b 2}(\boldsymbol{X}, t)=\frac{\pi^{2} E I_{2}}{L^{2}}-\left[\frac{H(t)}{2 \cos \alpha}+\frac{V(t)}{2 \sin \alpha}\right] \\
& g_{\text {sys }}(\boldsymbol{X}, t)=\min \left(g_{t 1}, g_{b 1}, g_{b 2}\right),
\end{aligned}
$$

sendo $A_{i}$ a área de iésima barra em $m^{2}$ e $L$ o comprimento de ambas as barras em $m$. A treliça é simétrica. As duas barras possuem o mesmo módulo de elasticidade $E$, definido como uma variável normal de média $\mu_{E}=70 \mathrm{GPa}$ e $C V_{E}=0.03$, e a mesma resistência última à tração, definida como uma variável normal $\sigma_{u}$, com $\mu_{\sigma_{u}}=24.5643 \mathrm{MPa}$ e $C V_{\sigma_{u}}=0.1$. O valor da resistência última à tração foi definido de modo que os três modos de falha tenham relevância semelhante no problema de confiabilidade de sistemas, ao menos na configuração inicial do problema. A probabilidade de que as variáveis aleatórias assumam valores negativos é muito pequena, e portanto pode ser desconsiderada neste exemplo. Este problema é dependente do caminho do carregamento. Isso significa que 
a estrutura pode falhar através de estados limites diferentes e em tempos diferentes a depender da trajetória desenvolvida pelos carregamentos ao longo do tempo. Para ilustrar este fenômeno, considere que o raio da seção transversal da primeira barra é $r_{1}=4$ mm e o raio da seção transversal da segunda barra é $r_{2}=5.2 \mathrm{~mm}$. A Figura 30 mostra três caminhos possíveis, bem como as três equações de estado limite quando avaliadas em suas médias $\mu_{\boldsymbol{X}}$. Suponha que no instante $t=t_{0}$ as cargas estão no ponto $A$, e em um instante $t=t_{f}>t_{0}$, o valor das cargas corresponde ao ponto $B$. Caso as cargas tenham seguido o caminho 1 , a estrutura falhou devido à flambagem da primeira barra. Caso as cargas tenham seguido o caminho 2, a carga horizontal cresceu antes da carga vertical, e a estrutura falha devido à ruptura por tração da primeira barra. Por fim, caso os carregamentos tenham seguido o caminho três, com as duas cargas sendo incrementadas ao mesmo tempo, o ponto B foi atingido com segurança.

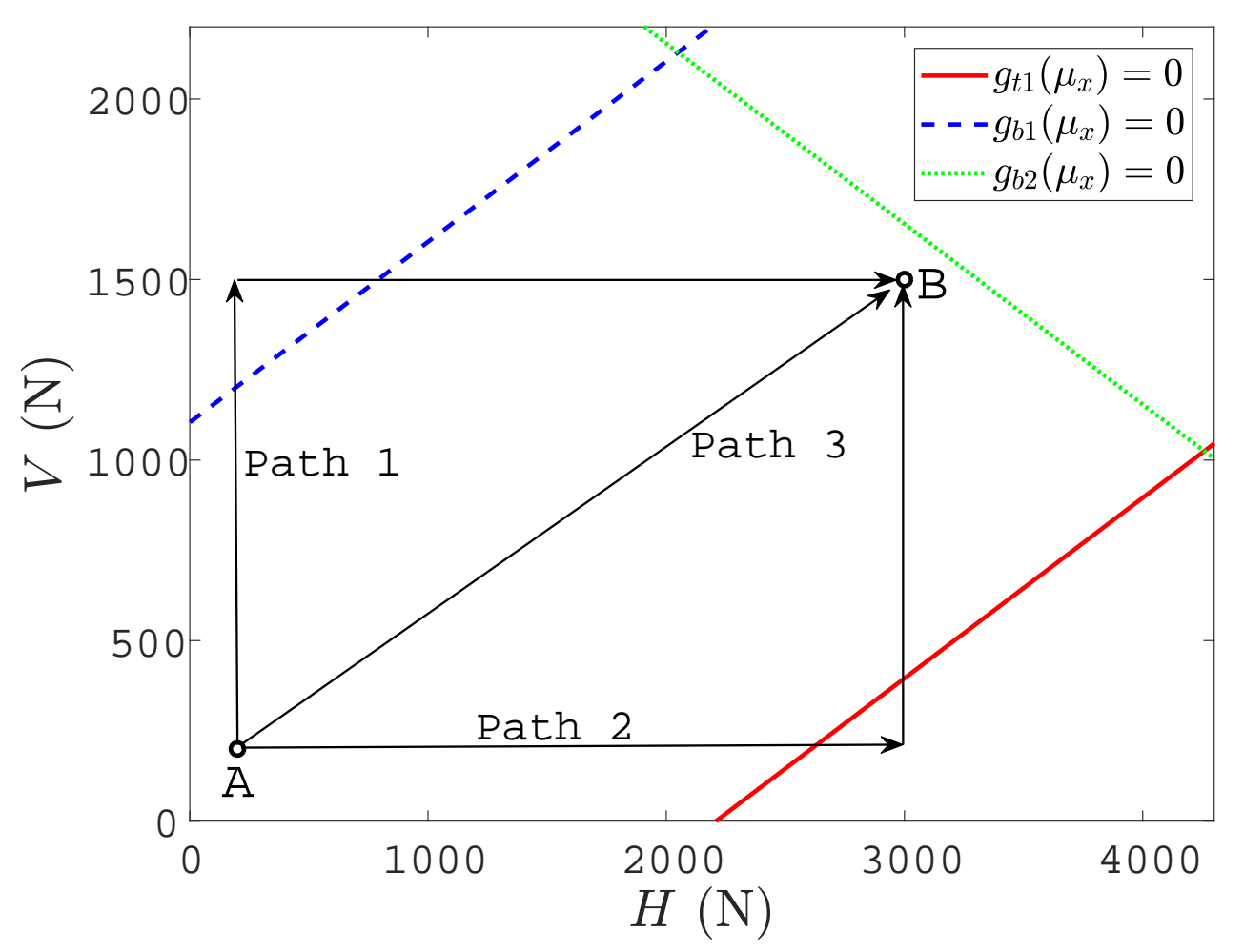

Figura 30: Caminhos de carregamento.

Quando as cargas são processos estocásticos contínuos, existe um número infinito de combinações de trajetórias que podem ser seguidas, e a avaliação da confiabilidade estrutural do sistema depende dessa consideração. Problemas dependentes do caminho dos carregamento não podem ser resolvidos por técnicas usuais, conforme discutido em Melchers e Beck (2018). Ainda assim, este tipo de problema pode ser resolvido por meio da consideração explícita de um grande número de trajetórias, da maneira proposta pela 
abordagem estudada neste capítulo.

\subsubsection{Exemplo - Treliça com três modos de falha}

Considere ainda a treliça representada na Figura 29, e que se tem interesse não apenas nas probabilidades de falha do sistema estudado, mas nas áreas ótimas das barras, de maneira a se minimizar o custo total da estrutura em um cenário de otimização de risco. As forças $V(t)$ e $H(t)$ são descritas como processos estocásticos gaussianos, com média $1 \mathrm{kN}$ e $2 \mathrm{kN}$, respectivamente. Ambas tem CV de 0.2 e comprimento de correlação $\lambda_{V}=\lambda_{H}=1$ mês. A função de autocorrelação dada por:

$$
R(x, \lambda)=\exp \left[-\left(\frac{x}{\lambda}\right)^{2}\right] .
$$

As cargas são independentes entre si. O problema é estudado ao longo de um intervalo de tempo de 10 anos. Sendo assim, a função objetivo é escrita como:

$$
\begin{aligned}
& C_{T}\left(r_{1}, r_{2}\right)=C_{I}\left(r_{1}, r_{2}\right)+\sum_{i=1}^{10} C_{f} P_{f c_{i}}\left(r_{1}, r_{2}\right) \\
& \text { sujeito a } 4 \mathrm{~mm} \leq r_{1} \leq 6 \mathrm{~mm} \\
& \qquad 4 \mathrm{~mm} \leq r_{2} \leq 6 \mathrm{~mm} .
\end{aligned}
$$

Os custos iniciais são proporcionais ao volume da estrutura: $C_{I}\left(r_{1}, r_{2}\right)=10^{5}\left(A_{1}\left(r_{1}\right)+\right.$ $\left.A_{2}\left(r_{2}\right)\right) L$, e o custo da falha do sistema é 10 vezes maior. Uma taxa de juros anual de $2 \%$ é considerada. Observe que custos de falha diferentes poderiam ser associados a cada estado limite, sem qualquer mudança no procedimento de solução do problema.

A Tabela 17 mostra as médias dos resultados de 10 soluções deste problema por meio da abordagem proposta neste capítulo, denotada por "EGO". A tabela ainda mostra os resultados obtidos pela solução direta com PSO sem a consideração de metamodelos. Os coeficientes de variação das 10 análises são mostrados entre parênteses.

Tabela 17: Média e COV dos resultados obtidos

\begin{tabular}{lllll}
\hline & $r_{1}(\mathrm{~mm})$ & $r_{2}(\mathrm{~mm})$ & $C_{T}$ & $N_{\text {calls }}$ \\
\hline EGO & $4.37(0.01)$ & $5.32(0.01)$ & $5.16(0.01)$ & $17(5.1)$ \\
PSO & 4.35 & 5.29 & 5.13 & 600 \\
\hline
\end{tabular}

A partir da Tabela 17, observa-se que os resultados obtidos com a metodologia proposta são muito próximos à referência, necessitando de apenas uma fração do número de avaliações do modelo.

\subsection{Conclusão}

Problemas de confiabilidade dependente do tempo envolvendo degradação da resistência da estrutura ou dependência do caminho do carregamento usualmente exigem 
uma solução baseada em simulação de Monte Carlo, com alto custo computacional, especialmente no contexto de um problema de otimização. Para uma solução precisa e eficiente deste tipo de problema, propõe-se uma abordagem de otimização baseada no acoplamento de dois metamodelos de Krigagem com aprendizado ativo. Um metamodelo é construído para substituir a função objetivo do problema a partir de um projeto de experimento inicial, definido a partir da amostragem de alguns pontos no espaço de projeto do problema, com o auxílio de LHS. O metamodelo é então enriquecido conforme o problema de otimização é resolvido por meio de EGO. Outro metamodelo é construído para as equações de estado limite, também a partir de um projeto de experimento inicial amostrado por LHS, porém no espaço aumentado das variáveis aleatórias e de projeto. Este metamodelo é então enriquecido por meio de EGRA.

Dois exemplos analíticos e um numérico foram estudados, com resultados satisfatórios de precisão e a necessidade de poucas chamadas da função objetivo para a solução dos problemas. Os custos das soluções se mostraram semelhantes para os três cenários de corrosão considerados nos problemas envolvendo degradação da resistência. A técnica se mostrou adequada para a solução de problemas envolvendo processos estocásticos nas equações de estado limite em ambas as parcelas de resistência e solicitação, bem como de problemas que apresentam dependência do caminho de carregamento. Por outro lado, a utilização de Monte Carlo bruto implica em um número excessivo de avaliações dos metamodelos internos, o que pode dificultar a solução de problemas envolvendo probabilidades de falha muito pequenas. Apesar da eficiência da técnica ter sido demonstrada para exemplos cujas características dificultam a solução do problema, em todos os casos os problemas de otimização envolveram poucas variáveis de projeto, o que favorece a solução via EGO. Uma continuação dos estudos é necessária para a inclusão de metamodelagem de sistemas dinâmicos no método, bem como para o estudo de problemas com muitas dimensões. 



\section{CONCLUSÃO}

\subsection{Comentários gerais}

Através desta tese, o cenário geral em que se encontra a otimização estrutural na presença de incertezas foi explorado, comentado, e algumas contribuições foram propostas. Após uma breve contextualização com comentários técnicos e também opinativos, dois capítulos foram dedicados à apresentação dos fundamentos teóricos e revisões da literatura sobre tópicos relevantes ao trabalho. A partir de então, os capítulos posteriores apresentaram estudos, aplicações e propostas de metodologias, buscando somar pequenas contribuições ao estado da arte da otimização de estruturas. No Capítulo 4, redes neurais artificiais, expansões em polinômios de caos e Krigagem são aplicadas como metamodelos para a solução de problemas de confiabilidade estrutural. Uma comparação do desempenho das três técnicas leva à conclusão de que a Krigagem deve ser a ferramenta empregada na mitigação do custo computacional das análises posteriores. O Capítulo 5 apresenta uma aplicação da RBDO à calibração de coeficientes parciais de segurança normativos. Os resultados mostram que os coeficientes adotados para um caso específico de uma norma brasileira vigente podem ser melhorados através da abordagem proposta neste trabalho. No sexto capítulo é proposto um método híbrido, que se vale da velocidade da solução de problemas de RBDO através de aproximações ao mesmo tempo que busca a precisão da solução através de simulações de Monte Carlo. Resultados melhores do que os contidos em referências clássicas são obtidos através da abordagem proposta. No capítulo 7 é apresentada uma metodologia para a solução de problemas de otimização de risco, para os quais não há muitas abordagens de solução na literatura. Os resultados demonstram a precisão e eficiência da proposta. O Capitulo 8 desenvolve um método para a solução de problemas de otimização de risco envolvendo confiabilidade dependente do tempo. Dois metamodelos são acoplados para reduzir o grande custo computacional natural a este tipo de problema. Os exemplos de aplicação da técnica apresentados incluem a otimização de estruturas sob degradação e com falhas dependentes do caminho dos carregamentos. A técnica proposta se revela adequada mesmo para a solução de tais problemas, em geral de difícil solução.

Quase todo o código programado para a obtenção dos resultados apresentados foi desenvolvido com a intenção de compor programas que podem vir a ser utilizados por outros pesquisadores, de modo a gerar benefícios para a ciência e a tecnologia além dos estudos realizados em si. Desse modo, resultados paralelos deste trabalho incluem uma primeira versão do módulo de otimização do software StRAnD, programado juntamente com um colega, o módulo de calibração de normas do mesmo software, programado apenas pelo autor e contribuições pontuais sobre simulação de Monte Carlo e tratamento de 
processos estocásticos para o software UQlab (MARELLI; SUDRET, 2013), da chair of risk, safety and uncertainty quantification do Instituto Federal de Tecnologia da Suíça (ETH - Eidgenössische Technische Hochschule Zürich). Em ambos os casos, versões incluindo as contribuições ainda não foram disponibilizadas para o público.

Apesar do esforço empregado na obtenção de resultados de excelência, a revisão da literatura realizada, bem como uma avaliação das limitações observadas nas metodologias propostas, tornam claro que ainda há muito em que se avançar. O tema da otimização estrutural sob incertezas é não apenas recente, mas também bastante amplo, havendo ainda muito espaço para o seu desenvolvimento. Alguns tópicos abordados nesta tese podem ser aprofundados, bem como aplicações diferentes podem ser exploradas através das metodologias propostas. Sendo assim, a próxima seção apresenta algumas sugestões para trabalhos futuros.

\subsection{Sugestões para trabalhos futuros}

Os resultados apresentados no Capítulo 5 foram selecionados para exemplificar o procedimento de calibração de normas adotado e programado no software StRAnD. A ferramenta foi utilizada em outra tese ainda não publicada do grupo de pesquisa do autor na obtenção de resultados mais abrangentes, obtendo-se a calibração de coeficientes parciais de segurança para outros tipos de elementos estruturais de concreto e também estruturas metálicas. Ainda assim, um estudo sobre os códigos normativos abordados e a relevância da referida tese ilustram uma importante carência em diversas normas técnicas brasileiras. Certamente, existem diversos outros exemplos de códigos em que os coeficientes não foram otimizados. Sugere-se o estudo de normas técnicas que versam sobre outros tipos de estruturas, como de alvenaria estrutural, madeira e estruturas de fundações, e a aplicação da calibração através do StRAnD, caso a mesma carência seja identificada.

Com relação ao método híbrido apresentado no Capítulo 6, a otimização das variáveis do tipo "Z" é realizada com base na exploração de técnicas bastante recentes, de modo aparentemente bastante apropriado. Já na etapa de otimização das variáveis do tipo "D", apesar dos resultados consistentes, a necessidade do cálculo repetido de probabilidades de falha e a adoção de um método que supõe a qualidade da aproximação linear poderiam ser aprimoradas, de modo a se iterar a partir de uma aproximação mais sofisticada.

No Capítulo 7 é apresentada uma abordagem para a solução de problemas de otimização de risco através da combinação de várias técnicas que visam redução de custo computacional. O método dos vagalumes foi escolhido devido a sua eficiência em problemas estruturais, quando comparado a alguns outros métodos. Ainda assim, os resultados obtidos neste trabalho não evidenciam a vantagem de sua utilização, sendo interessante sua substituição por outros algoritmos heurísticos, para fins de comparação. Além disso, o metamodelo global utilizado é construído a partir de uma amostragem esparsa no espaço 
aumentado do problema de otimização. O estudo de técnicas mais eficientes, para que o metamodelo seja construído a partir de menos pontos sem sacrificar sua precisão, pode ser de grande utilidade.

Por fim, o Capítulo 8 introduz uma metodologia abrangente para a solução de problemas de otimização de risco dependentes do tempo. O principal aprimoramento para a obtenção de um método ainda mais geral é a consideração de metamodelos capazes da representação de problemas dinâmicos. Além disso, um estudo que permita a substituição das simulações de Monte Carlo brutas por uma técnica mais eficiente seria uma grande contribuição, uma vez que não é possível fazer isso de forma direta devido à natureza dos problemas considerados. 



\section{REFERÊNCIAS}

ABCP. Vocabulário de Teoria das Estruturas. [S.l.]: Associação Brasileira de Cimento Portland, 1967.

ABNT. NBR 8681- Projeto e execução de estruturas de concreto armado e protendido. [S.1.]: ABNT - Associação Brasileira de Normas Técnicas, 2003.

NBR 6118 - Ação e segurança nas estruturas - procedimento. [S.l.]:

ABNT - Associação Brasileira de Normas Técnicas, 2014.

AGARWAL, H. et al. An inverse-measure-based unilevel architecture for reliability-based design optimization. Structural and Multidisciplinary Optimization, v. 33, n. 3, p. 217-227, Mar 2007.

AISSANI, A.; CHATEAUNEUF, A.; SAAD, L. Life cycle optimization of corroded RC structures considering nonlinear failure cost. In: Safety, Reliability, Risk and Life-Cycle Performance of Structures and Infrastructures. [S.l.]: CRC Press, 2014. p. 4717-4724. ISBN 978-1-138-00086-5.

ANDRIEU-RENAUD, C.; SUDRET, B.; LEMAIRE, M. The PHI2 method: a way to compute time-variant reliability. Reliab. Eng. Sys. Safety, v. 84, p. 75-86, 2004.

AOUES, Y.; CHATEAUNEUF, A. Benchmark study of numerical methods for reliability-based design optimization. Struct. Multidisc. Optim., v. 41, n. 2, p. 277-294, 2010 .

ARORA, J. Introduction to Optimum Design. [S.l.]: Academic Press, 2016.

ATAíDE, C.; CORRêA, M. Estudo comparativo entre o método das tensões admissíveis e o método dos estados limites para alvenaria estrutural. Cadernos de Engenharia de Estruturas, v. 8, p. 105-134, 2006.

BABAEI, M.; PAN, I. Performance comparison of several response surface surrogate models and ensemble methods for water injection optimization under uncertainty. Computers and Geosciences, v. 91, p. 19 - 32, 2016. ISSN 0098-3004.

BACHOC, F. Cross validation and maximum likelihood estimations of hyper-parameters of Gaussian processes with model misspecifications. Comput. Stat. Data Anal., v. 66, p. 55-69, 2013.

BANSAL, J. C. et al. Inertia weight strategies in particle swarm optimization. In: 2011 Third World Congress on Nature and Biologically Inspired Computing. [S.l.: s.n.], 2011. p. 633-640.

BECK, A. Reliability Analysis of Degrading Uncertain Structures - with Applications to Fatigue and Fracture under Random Loading. 2003. Tese (Doutorado) - University of Newcastle, Australia, 2003.

BECK, A. Curso de Confiabilidade Estrutural: Notas de Aula. [S.l.]: Escola de Engenharia de São Carlos, 2014. 
BECK, A.; JUNIOR, A. S. A first attempt towards reliability based calibration of brazilian structural design codes. Journal of the Brazilian Society of Mechanical Sciences and Engineering.

BECK, A. T.; GOMES, W. A comparison of deterministic, reliability-based and risk-based structural optimization under uncertainty. Probabilistic Engineering Mechanics, v. 28 , p. $18-29,2012$.

BECK, A. T.; TESSARI, R. K.; KROETZ, H. M. System reliability-based design optimization and risk-based optimization: a benchmark example considering progressive collapse. Engineering Optimization, Taylor \& Francis, v. 0, n. 0, p. 1-13, 2018. Disponível em: <https://doi.org/10.1080/0305215X.2018.1502760>.

BEnJAMin, J.; CORNELL, C. Probability, Statistics, and Decision for Civil Engineers. Dover Publications, 2014. (Dover books on engineering). ISBN 9781523106752. Disponível em: < https://books.google.com.br/books?id=VHNPswEACAAJ > .

BENTO, J. Modelling mechanical behaviour without mechanics. In: TASSO, C.; OLIVEIRA, E. R. de Arantes e (Ed.). Development of Knowledge-Based Systems for Engineering. [S.l.]: Springer Vienna, 1998.

BERKE, L.; HAJELA, P. Applications of artificial neural nets in structural mechanics. Structural optimization, v. 4, n. 2, p. 90-98, Jun 1992.

BEYER, H.; SENDHOFF, B. Robust optimization - a comprehensive survey. Comp. Meth. in App. Mech. and Eng., v. 196, n. 33, p. 3190 - 3218, 2007.

BICHON, B. Efficient surrogate modeling for reliability analysis and design. 2010. Tese (Doutorado) — Vanderbilt University, Nashville, TE, 2010.

BICHON, B. et al. Efficient global reliability analysis for nonlinear implicit performance functions. AIAA Journal, v. 46, n. 10, p. 2459-2468, 2008.

BICHON, B. J. et al. Efficient global surrogate modeling for reliability-based design optimization. Journal of Mechanical Design, v. 135, 2013.

BIONDINI, F.; FRANGOPOL, D. Lifetime reliability-based optimization of reinforced concrete cross-sections under corrosion. Structural Safety, v. 31, p. 483-489, 2009.

BLATMAN, G.; SUDRET, B. Adaptive sparse polynomial chaos expansions using a regression approach. [S.l.], 2008.

BLATMAN, G.; SUDRET, B.; BERVEILLER, M. Quasi-random numbers in stochastic finite element analysis. Mécanique \& Industries, v. 8, p. 289-297, 2007.

BRODING W. C., F. W. D. P. B. P. Structural optimization and design based on a reliability design criterion. J. of Spacecraft, v. 1, p. 56-61, 1964.

CARDOSO, J. B. et al. Structural reliability analysis using monte carlo simulation and neural networks. Advances in Engineering Software, v. 39, n. 6, p. 505 - 513, 2008. ISSN 0965-9978.

CARRERAS, J. et al. Systematic approach for the life cycle multi-objective optimization of buildings combining objective reduction and surrogate modeling. Energy and

Buildings, v. 130, n. Supplement C, p. 506 - 518, 2016. 
CHOJACZYK, A. et al. Review and application of artificial neural networks models in reliability analysis of steel structures. Structural Safety, v. 52, p. 78 - 89, 2015. ISSN 0167-4730.

CRESSIE, N. The origins of kriging. Mathematical Geology, v. 22, n. 3, p. 239-252, Apr 1990.

DITLEVSEN, O.; MADSEN, H. Structural reliability methods. [S.l.]: J. Wiley and Sons, Chichester, 1996.

DUBOURG, V. Adaptive surrogate models for reliability analysis and reliability-based design optimization. 2011. Tese (Doutorado) - Université Blaise Pascal, Clermont-Ferrand, France, 2011.

DUBOURG, V.; SUDRET, B.; BOURINET, J.-M. Reliability-based design optimization using Kriging and subset simulation. Struct. Multidisc. Optim., v. 44, n. 5, p. 673-690, 2011.

Reliability-based design optimization using Kriging surrogates and subset simulation. Struct. Multidisc. Optim., v. 44, n. 5, p. 673-690, 2011.

Meta-model-based importance sampling for reliability sensitivity analysis. In:

Proc. 11th ASCE Specialty Conference on Probabilistic Mechanics and Structural Reliability, Notre Dame, USA. [S.l.: s.n.], 2012.

EBERHART, R.; KENNEDY, J. A new optimizer using particle swarm theory. In: MHS'95. Proceedings of the Sixth International Symposium on Micro Machine and Human Science. [S.l.: s.n.], 1995. p. 39-43.

ECHARD, B.; GAYTON, N.; LEMAIRE, M. AK-MCS: an active learning reliability method combining Kriging and Monte Carlo simulation. Struct. Saf., v. 33, n. 2, p. $145-154,2011$.

ECHARD, B. et al. A combined importance sampling and Kriging reliability method for small failure probabilities with time-demanding numerical models. Reliab. Eng. Syst. Safety, v. 111, p. 232-240, 2013.

EISENHOWER, B. et al. A methodology for meta-model based optimization in building energy models. Energy and Buildings, v. 47, n. Supplement C, p. 292 - 301, 2012. ISSN 0378-7788.

ENEVOLDSEN, I.; SORENSEN, J. Reliability-based optimization in structural engineering. Structural Safety, v. 15, p. 169-196, 1994.

FARAVELLI, L. Response surface approach for reliability analysis. J. Eng. Mech., v. 115, n. 12 , p. 2763-2781, 1989.

FAUSETT, L. Fundamentals of Neural Networks: Architectures, Algorithms, and Applications. [S.l.]: Prentice-Hall, 1994. (Prentice-Hall international editions). ISBN 9780133341867.

FIROUZI, A.; RAHAI, A. An integrated ann-ga for reliability based inspection of concrete bridge decks considering extent of corrosion-induced cracks and life cycle costs. Scientia Iranica, v. 19, n. 4, p. $974-981,2012$. ISSN 1026-3098. 
FORSELL, C. Ekonomioch byggnadsvasen. Sunt Fornoft, p. 74-77, 1924.

FRANGOPOL, D. Structural optimization using reliability concepts. J. Struct. Eng., v. 111, n. 11, p. 2288-2301, 1985.

FRANGOPOL, D. M. Probabilistic structural optimization. Progress in Structural Engineering and Materials, John Wiley \& Sons, Ltd., v. 1, n. 2, p. 223-230, 1998.

FRANGOPOL D.M., K. M. Life-cycle reliability-based optimization of civil and aerospace structures. Computers and Structures, v. 81, p. 397-410, 2003.

GANDOMI, A. H.; YANG, X.-S.; ALAVI, A. H. Mixed variable structural optimization using firefly algorithm. Computers \& Structures, v. 89, n. 23, p. 2325 - 2336, 2011.

GANO, S.; KIM, H.; BROWN, D. Comparison of three surrogate modeling techniques: Datascape, kriging, and second order regression. In: 11th AIAA/ISSMO Multidisciplinary Analysis and Optimization Conference. [S.l.: s.n.], 2006. p. 7048 .

GASPAR, B.; TEIXEIRA, A.; Guedes Soares, C. Assessment of the efficiency of Kriging surrogate models for structural reliability analysis. Prob. Eng. Mech, v. 37, p. 24-34, 2014.

Genova Today. La storia del ponte morandi: un tempo avverniristico, ma non mancavano cricità. Genova Today, Agosto 2018. Disponível em: <www.genovatoday.it/cronaca/ storia-ponte-morandi-a10.html>.

GHANEM, R.; SPANOS, P.-D. Polynomial chaos in stochastic finite elements. J. Applied Mech., v. 57, p. 197-202, 1990.

GHISTA, D. Structural Optimization with Probability of Failure Constraints. [S.l.], 1966. 1-15 p.

GOLDBERG, D. Genetic Algorithms in Search, Optimization, and Machine Learning. [S.l.]: Addison-Wesley Publishing Company, 1989. (Artificial Intelligence). ISBN 9780201157673.

GOMES, H. M.; AWRUCH, A. M. Comparison of response surface and neural network with other methods for structural reliability analysis. Structural Safety, v. 26, n. 1, p. 49 - 67, 2004. ISSN 0167-4730.

GOMES, W.; BECK, A. Global structural optimization considering expected consequences of failure and using ANN surrogates. Comput. Struct., v. 126, p. 56-68, 2013.

GOMES, W. J.; BECK, A. T.; HAUKAAS, T. Optimal inspection planning for onshore pipelines subject to external corrosion. Reliab. Eng. Syst. Saf., v. 118, p. 18 - 27, 2013. ISSN 0951-8320.

HASOFER, A.; LIND, N. Exact and invariant second moment code format. J. Eng. Mech., v. 100, n. 1, p. 111-121, 1974.

HAYKIN, S. S. et al. Neural networks and learning machines. [S.l.]: Pearson Upper Saddle River, 2009. v. 3. 
HILTON, H. H.; FEIGEN, M. Minimum weight analysis based on structural reliability. J. Aero. Sci., v. 27, p. 641-653, 1960.

HOLICKY, M. Probabilistic risk optimization of road tunnels. Structural Safety, v. 31, p. 260-266, 2009.

HORNIK, K.; STINCHCOMBE, M.; WHITE, H. Multilayer feedforward networks are universal approximators. Neural Networks, v. 2, n. 5, p. 359 - 366, 1989. ISSN 0893-6080.

Universal approximation of an unknown mapping and its derivatives using multilayer feedforward networks. Neural Networks, v. 3, n. 5, p. $551-560,1990$. ISSN 0893-6080.

HURTADO, J. E.; ALVAREZ, D. A. Neural-network-based reliability analysis: a comparative study. Comput. Method. Appl. M., v. 191, n. 1-2, p. 113-132, 2001.

J., L.; MOURELATOS, Z.; TU, J. A single-loop method for reliability-based design optimization. In: International Design Engineering Technical Conferences and Computers and Information in Engineering Conference. [S.l.: s.n.], 2004.

JIA, G.; TAFLANIDIS, A. A. Kriging metamodeling for approximation of high-dimensional wave and surge responses in real-time storm/hurricane risk assessment. Computer Methods in Applied Mechanics and Engineering, v. 261-262, p. 24 - 38, 2013. ISSN 0045-7825.

JOANNI, A.; RACKWITZ, R. Cost benefit optimization for maintained structures by a renewal model. Reliability Engineering and System Safety, v. 93, p. 489-499, 2008.

Joint Committee on Structural Safety. JCSS probabilistic model code. [S.l.], 2002. http://www.jcss.byg.dtu.dk.

JONES, D.; SCHONLAU, M.; WELCH, W. Efficient global optimization of expensive black-box functions. J. Global Optim., v. 13, n. 4, p. 455-492, 1998.

JUNIOR, A. S. Aplicação de confiabilidade na calibração de coeficientes parciais de segurança de normas brasileiras de projeto estrutural. 2009. Dissertação (Mestrado) — Universidade de Sâo Paulo, Brasil, 2009.

KABALA, R. E. Design of minimal- weight structures given reliability and cost. J. Aerospace Sciences, v. 29, p. 355-356, 1962.

KAKADE, S. M.; SHALEV-SHWARTZ, S.; TEWARI, A. Regularization techniques for learning with matrices. J. Mach. Learn. Res., JMLR.org, v. 13, jun. 2012. ISSN $1532-4435$.

KAPUR, J.; KESAVAN, H. Entropy optimization principles with application. [S.l.]: Academic Press, New York, 1992.

KAYMAZ, I. Application of Kriging method to structural reliability problems. Structural Safety, v. 27, n. 2, p. 133-151, 2005.

KINER, D. E. Elastic Minimum Weight Design with a Probability of Failure Constraint. 1966. Tese (Doutorado) - Case Inst. of Technology, 1966. 
KIRKPATRICK, S.; GELATT, C. D.; VECCHI, M. P. Optimization by simulated annealing. Science, v. 220 4598, p. 671-80, 1983.

KROETZ, H. Metamodelagem em Confiabilidade Estrutural. 2015. Dissertação (MSc Thesis) - University of São Paulo, USP, 2015. Disponível em: < http: //www.teses.usp.br/teses/disponiveis/18/18134/tde-08042015-162956/pt-br.php>.

KROETZ, H.; TESSARI, R.; BECK, A. Performance of global metamodeling techniques in solution of structural reliability problems. Adv. Eng. Soft., v. 114, p. 394-404, 2017.

KUSCHEL, N.; RACKWITZ, R. Optimal design under time-variant reliability constraints. Structural Safety, v. 22, p. 113-127, 2000.

LENI, P.-E.; FOUGEROLLE, Y. D.; TRUCHETET, F. Kolmogorov superposition theorem and wavelets for image compression. In: INTERNATIONAL SOCIETY FOR OPTICS AND PHOTONICS. Wavelet Applications in Industrial Processing VII. [S.1.], 2010. v. 7535 , p. 753502.

LEONEL, E. D.; BECK, A. T.; VENTURINI, W. S. On the performance of response surface and direct coupling approaches in solution of random crack propagation problems. Structural Safety, v. 33, n. 4, p. $261-274$, 2011. ISSN 0167-4730.

LI, C.; KIUREGHIAN, A. D. Optimal discretization of random fields. J. Eng. Mech., v. 119, n. 6, p. 1136-1154, 1993.

LI, G.; HU, H. Risk design optimization using many-objective evolutionary algorithm with application to performance-based wind engineering of tall buildings. Structural Safety, v. 48, p. 1-14, 2014.

LI, M.; BAI, G.; WANG, Z. Time-variant reliability-based design optimization using sequential kriging modeling. Structural and Multidisciplinary Optimization, v. 58, n. 3, p. 1051-1065, Sep 2018.

Time-variant reliability-based design optimization using sequential Kriging modeling. Struct. Multidisc. Optim., v. 58, p. 1051-1065, 2018.

MAI, C.; SUDRET, B. Surrogate models for oscillatory systems using sparse polynomial chaos expansions and stochastic time warping. SIAM/ASA J. Unc. Quant., v. 5, p. 540-571, 2017.

MAI, C.-V. et al. Surrogate modeling for stochastic dynamical systems by combining nonlinear autoregressive with exogeneous input models and polynomial chaos expansions. Int. J. Uncer. Quant., v. 6, n. 4, p. 313-339, 2016.

MAlthuS, T. An Essay on the Principle of Population: Or, A View of Its Past and Present Effects on Human Happiness; with an Inquiry Into Our Prospects Respecting the Future Removal Or Mitigation of the Evils which it Occasions. Reeves and Turner, 1872. (Essay on the principle of population). Disponível em: < https://books.google.com.br/books?id=kY0VAAAAYAAJ>.

MARELLI, S.; SUDRET, B. UQLab: a framework for uncertainty quantification in MATLAB. In: Swiss Numerics Colloquium 2013, Lausanne. [S.l.: s.n.], 2013. 
Compressive polynomial chaos expansion for multi-dimensional model maps. In: HAUKAAS, T. (Ed.). Proc. 12th Int. Conf. on Applications of Stat. and Prob. in Civil Engineering (ICASP12), Vancouver, Canada. [S.l.: s.n.], 2015. Paper \#209.

MARQUARDT, D. An algorithm for least-squares estimation of nonlinear parameters. J. Soc. Indus. Appl. Math., v. 11, n. 2, p. 431-441, 1963.

MAXWELL, J. C. The scientific papers of James Clerk Maxwell. [S.1.]: Dover Publications, INC. New York, 1952.

MCKAY, M. D.; BECKMAN, R. J.; CONOVER, W. J. A comparison of three methods for selecting values of input variables in the analysis of output from a computer code. Technometrics, v. 2, p. 239-245, 1979.

MELCHERS, R.-E. Structural reliability analysis and prediction. [S.l.]: John Wiley \& Sons, 1999.

MELCHERS, R.-E.; BECK, A. Structural reliability analysis and prediction. [S.l.]: John Wiley \& Sons, 2018.

MICHELL, A. G. M. The limits of economy of material in frame structures. Philosophical Magazine, v. 81, p. 1087-1092, 1904.

MLODINOV, L. O Andar do Bêbado. [S.l.]: Editora Zahar, 2008.

MOCKUS, J. On Bayesian methods for seeking the extremum. In: Proceedings of the IFIP Technical Conference. London, UK: Springer-Verlag, 1974. p. 400-404.

MOSES, F. Structural system reliability and optimization. Comput. Struct., v. 7, p. 283-290, 1977.

MOUSTAPHA, M. et al. Quantile-based optimization under uncertainties using adaptive Kriging surrogate models. Struct. Multidisc. Optim., v. 54, n. 6, p. 1403-1421, 2016.

NATAF, A. Détermination des distributions dont les marges sont données. C. R. Acad. Sci. Paris, v. 225, p. 42-43, 1962.

NGAH, M.; YOUNG, A. Application of the spectral stochastic finite element method for performance prediction of composite structures. Composite Structures, v. 78, n. 3, p. $447-456,2007$.

NGUYEN, D.; WIDROW, B. Improving the learning speed of 2-layer neural networks by choosing initial values of the adaptive weights. In: IJCNN. [S.l.: s.n.], 1990.

NIELSEN J.S.; SORENSEN, J. Methods for risk-based planning of o\&m of wind turbines. Energies, v. 7, p. 6645-6664, 2014.

NOWAK, A.; NOWAK, A.; SZERSZEN, M. Calibration of design code for buildings (aci 318): Part 1 - statistical models for resistance. ACI Structural Journal, v. 100, p. 377-382, 052003.

NOWAK, A.; RAKOCZY, A.; SZELIGA, E. Revised statistical resistance models for r/c structural components. American Concrete Institute, ACI Special Publication, v. 284 , p. $61-76,012011$. 
OKASHA, N. Improved weighted average simulation approach for solving reliability-based analysis and design optimization problems. Struct. Saf., v. 60, p. 47-55, 2016.

OKASHA, N.; FRANGOPOL, D. Lifetime-oriented multi-objective optimization of structural maintenance considering system reliability, redundancy and life-cycle cost using ga. Struct. Saf., v. 31, p. 460-474, 2009.

OLSSON, A.; SANDBERG, G.; DAHLBLOM, O. On Latin Hypercube sampling for structural reliability analysis. Structural Safety, v. 25, p. 47-68, 2003.

PANAYIRCI, H. M.; SCHUËLLER, G. I. On the capabilities of the polynomial chaos expansion method within sfe analysis - an overview. Archives of Computational Methods in Engineering, v. 18, n. 1, p. 43-55, Mar 2011.

PAPADRAKAKIS, M.; LAGAROS, N. Reliability-based structural optimization using neural networks and Monte Carlo simulation. Comput. Methods Appl. Mech. Engrg., v. 191, n. 32, p. 3491-3507, 2002.

PAPADRAKAKIS, M.; LAGAROS, N.; PLEVRIS, V. Design optimization of steel structures considering uncertainties. Engineering Structures, v. 27, n. 9, p. 1408 1418, 2005. ISSN 0141-0296.

PAPADRAKAKIS, M.; PAPADOPOULOS, V.; LAGAROS, N. D. Structural reliability analyis of elastic-plastic structures using neural networks and monte carlo simulation.

Computer Methods in Applied Mechanics and Engineering, v. 136, n. 1, p. 145 163, 1996. ISSN 0045-7825.

RACKWITZ, R. Reliability analysis - A review and some perspectives. Structural Safety, v. 23, p. 365-395, 2001.

RACKWITZ, R.; FIESSLER, B. Structural reliability under combined load sequences. Computers \& Structures, v. 9, p. 489-494, 1978.

RACKWITZ, R.; JOANNI, A. Risk acceptance and maintenance optimization of aging civil engineering infrastructures. Structural Safety, v. 31, p. 251-259, 2009.

RANJAN, P.; BINGHAM, D.; MICHAILIDIS, G. Sequential experiment design for contour estimation from complex computer codes. Technometrics, v. 50, n. 4, p. 527-541, 2008.

RAO, S. Engineering Optimization: Theory and Practice. [S.1.]: John Wiley \& Sons, 1996.

RASHKI, M.; MIRI, M.; MOGHADDAM, M. A new efficient simulation method to approximate the probability of failure and most probable point. Struct. Saf., v. 39, p. $22-29,2012$.

A simulation-based method for reliability-based design optimization problems with highly nonlinear constraints. Aut. Const., v. 47, p. 24-36, 2014.

RASMUSSEN, C.; WILLIAMS, C. Gaussian processes for machine learning. Internet. Cambridge, Massachusetts: MIT Press, 2006. 266 p. (Adaptive computation and machine learning). 
RIBEIRO, M. História Do Direito. Montecristo Publishing LLC, 2011. ISBN 9781619650121. Disponível em: <https://books.google.com.br/books?id= cf1DDwAAQBAJ>.

ROMERO, V.; SWILER, L.; GIUNTA, A. Construction of response surfaces based on progressive lattice-sampling experimental designs with application to uncertainty propagation. Structural Safety, v. 26, n. 2, p. 201-219, 2004.

ROSEnBLATT, M. Remarks on a multivariate transformation. Ann. Math. Stat., v. 23, p. 470-472, 1952.

SAAD, L. et al. Reliability-based optimization of direct and indirect LCC of RC bridge elements under coupled fatigue-corrosion deterioration processes. Eng. Fail. Anal., v. 59, p. 570-587, 2016.

SACHDEVA, S.; NAIR, P.; KEANE, A. Comparative study of projection schemes for stochastic finite element analysis. Comput. Methods Appl. Mech. Engrg., v. 195, n. 19-22, p. 2371-2392, 2006.

SANTIAGO, W.; BECK, A. A new study of brazilian concrete strength conformance. Revista IBRACON de Estruturas e Materiais, v. 10, n. 4, p. 906-923, 2017. ISSN 0141-0296.

SANTIAGO, W.; KROETZ, H.; BECK, A. Uma primeira tentativa de calibração baseada em confiabilidade das normas brasileiras usadas em projetos de estruturas de concretos. In: Anais do 60 Congresso Brasileiro do Concreto. São Paulo, SP. [S.l.: s.n.], 2018.

SANTNER, T.; WILLIAMS, B.; NOTZ, W. The Design and Analysis of Computer Experiments. [S.l.]: Springer, New York, 2003.

SANTOS, K. d.; BECK, A. A benchmark study on intelligent sampling techniques in Monte Carlo simulation. Latin American Journal of Solids and Structures, scielo, v. 12, p. 624 - 648, 08 2015. ISSN 1679-7825. Disponível em: <http://www.scielo.br/ scielo.php?script=sci_arttext\&pid=S1679-78252015000400624\&nrm=iso >.

SCHÖBI, R.; SUDRET, B.; MARELLI, S. Rare event estimation using Polynomial-ChaosKriging. ASCE-ASME J. Risk Uncertainty Eng. Syst., Part A: Civ. Eng, v. 3, n. 2, 2017. D4016002.

SCHUËLLER, G. A state-of-the-art report on computational stochastic mechanics. Prob. Eng. Mech., v. 12, n. 4, 1997. IASSAR report.

SCHUËLLER, G.; JENSEN, H. Computational methods in optimization considering uncertainties - An overview. Comp. Meth. App. Mech. Eng., v. 198, p. 2-13, 2009.

SHERMER, M. Doomsday catch. Scientific American, Maio 2016.

SOIZE, C.; GHANEM, R. Physical systems with random uncertainties: chaos representations with arbitrary probability measure. SIAM J. Sci. Comput., v. 26, n. 2, p. 395-410, 2004.

SPIRIDONAKOS, M. D.; CHATZI, E. N. Metamodeling of dynamic nonlinear structural systems through polynomial chaos NARX models. Comput. Struct., v. 157, p. 99-113, 2015 . 
STEFANOU, G. The stochastic finite element method: Past, present and future. Comput. Methods Appl. Mech. Engrg., v. 198, p. 1031-1051, 2009.

STREICHER, H.; JOANNI, A.; R., R. Cost-benefit optimization and risk acceptability for existing, aging but maintained structures. Structural Safety, v. 30, p. 375-393, 2008.

SUDRET, B. Uncertainty propagation and sensitivity analysis in mechanical models - Contributions to structural reliability and stochastic spectral methods. [S.l.], 2007. Habilitation à diriger des recherches, 173 pages.

Analytical derivation of the outcrossing rate in time-variant reliability problems. Struct. Infrastruct. Eng, v. 4, n. 5, p. 353-362, 2008.

Lecture Notes on Structural Reliability and Risk Analysis. [S.l.], 2015.

. Polynomial chaos expansions and stochastic finite element methods. In:

[S.l.]: Taylor and Francis, 2015. (Risk and Reliability in Geotechnical Engineering, Phoon, K.-K. and Ching, J. (Eds)), cap. 6, p. 265-300.

Sudret, B.; Berveiller, M.; Lemaire, M. A stochastic finite element procedure for moment and reliability analysis. Eur. J. Comput. Mech., v. 15, n. 7-8, p. 825-866, 2006.

SUDRET, B.; KIUREGHIAN, A. D. Stochastic finite elements and reliability: a state-of-the-art report. [S.l.], 2000.

SWITSKY, H. Minimum weight with structural reliability. J. of Aircraft, v. 2, p. 228-232, 1965.

SWITZKY, H. Minimum weight design with structural reliability. In: AERONAUTICS, A. I. of; ASTRONAUTICS PALM SPRINGS, C. (Ed.). Proc. 5 Annual Structures and Materials Conf. [S.l.: s.n.], 1964.

SZERSZEN, M.; NOWAK, A. Calibration of design code for buildings (aci 318): Part 2 reliability analysis and resistance factors. ACI Structural Journal, v. 100, p. 383-391, 052003.

TAFLANIDIS, A. A.; BECK, J. L. Life-cycle cost optimal design of passive dissipative devices. Structural Safety, v. 23, p. 508-522, 2009.

TESSARI, R.; KROETZ, H.; BECK, A. Performance-based design of steel towers subject to wind action. Engineering Structures, v. 143, n. Supplement C, p. 549 - 557, 2017.

TORII, A.; LOPEZ, R. H.; MIGUEL, L. F. A general rbdo decoupling approach for different reliability analysis methods. Structural and Multidisciplinary Optimization, v. 54, n. 2, p. 317-332, Aug 2016.

TORII, A. J.; LOPEZ, R. H.; MIGUEL, L. F. F. A gradient-based polynomial chaos approach for risk and reliability-based design optimization. Journal of the Brazilian Society of Mechanical Sciences and Engineering, v. 39, n. 7, p. 2905-2915, Jul 2017.

TURKSTRA, C. J.; MADSEN, H. O. Load combinations in codified structural design. J. STRUCT. DIV. PROC. ASCE., v. 106, p. 2527-2543, 121980. 
TVERSKY, A.; KAHNEMAN, D. Belief in the law of small numbers. Psychological Bulletin, p. 105-110, 1971.

VALDEBENITO, M. A.; SCHUËLLER, G. I. A survey on approaches for reliability-based optimization. Structural and Multidisciplinary Optimization, v. 42, n. 5, p. 645-663, 2010.

VANDERPLAATS, G. Structural optimization-past, present, and future. AIAA, v. 20, n. 7, p. $992-1000,1982$.

WANG, Z.; CHEN, W. Time-variant reliability assessment through equivalent stochastic process transformation. Eng. Syst. Saf., v. 152, p. 166-175, 2016.

WüBBENHORST, K. Life cycle costing for construction projects. Long Range Planning, v. 19, n. 4, p. 87-97, 1986.

WEN, Y.; KANG, Y. Minimum building life-cycle cost design criteria i: Methodology. Journal of Structural Engineering, p. 330-337, 2001.

Minimum building life-cycle cost design criteria ii: Applications. Journal of Structural Engineering, p. 338-346, 2001.

YANG, X.-S. Firefly algorithms for multimodal optimization. In: WATANABE, O.; ZEUGMANN, T. (Ed.). Stochastic Algorithms: Foundations and Applications. Berlin, Heidelberg: Springer Berlin Heidelberg, 2009. p. 169-178. ISBN 978-3-642-04944-6. . Nature-Inspired Metaheuristic Algorithms. [S.l.: s.n.], 2010.

ZHANG, J.; FOSCHI, R. O. Performance-based design and seismic reliability analysis using designed experiments and neural networks. Probabilistic Engineering Mechanics, v. 19, n. 3, p. 259 - 267, 2004. ISSN 0266-8920. Fifth International Conference on Stochastic Structural Dynamics.

ZHANG, J.; TAFLANIDIS, A. Multi-objective optimization under uncertainty utilizing kriging modeling in augmented input space. In: BUCHER, C.; ELLINGWOOD, B.; D.M., F. (Ed.). Proceedings of the 12th International Conference on Structural Safety and Reliability. [S.l.: s.n.], 2017.

ZHANG, J.; TAFLANIDIS, A.; MEDINA, J. Sequential approximate optimization for design under uncertainty problems utilizing kriging metamodeling in augmented input space. Computer Methods in Applied Mechanics and Engineering, v. 315, n. Supplement C, p. 369 - 395, 2017. 